LI'Gikex.h

HAVAL, POWH DUATE SCHOCK

... I IF. 93940 

$\frac{\text { Ronald Charles Tipper }}{\text { (Name of student) }}$

in Biological Oceanography presented on

in Biological Oceanography presented on

for the

(1) Ph. D.

(Degree)

(Date)

Title: ECOLOGICAL ASPECTS OF TWO WOOD-BORING MOLLUSCS

FROM THE CONTINENTAL TERRACE OFF OREGON

Abstract approved:

Dr. James E. McCauley

A mooring system was designed and constructed to make possible the installation and the recovery of racks of sample panels for a study of deep-ocean wood-boring molluscs. Racks containing pine, fir, oak, and cedar boards were exposed to borer attack at six stations with depths of 50, 100, 150, 200, 500 and 1000 meters, all west of Depoe Bay', Oregon.

Two wood-boring molluscs, a pholad, Xylophaga washingtona Bartsch, and a teredinid, Bankia setacea (Tyron), were recovered from exposed wood materials. Xylophaga washingtona was the dominant form and was found at all three deep stations. Bankia setacea was found only at the 200 -meter site and in very low numbers. This reports the deepest known teredinid actively settling and boring into a test board.

Borer attack increased in intensity with time, and in general, decreased with increasing depth. Initial attack appeared to 
commence right above the line where sample panels were in contact with the sediment. Attack was heaviest in this zone and decreased with increasing distance upward from the sea-sediment interface, approaching zero in about 20 centimeters.

In general cedar was the most heavily attacked wood type followed in turn by pine, fir, and then oak, which proved the most resistant to xylophagan borers. The degree of maximum borer penetration into any wood type correlated nicely with the density of the wood, higher density wood being correspondingly most resistant to borer attack. Degree of maximum borer penetration increased with time and decreased with increasing depth.

The mooring system is fully described along with a summary of field installation and recovery methods. Future research problems are suggested. 


\title{
Ecological Aspects of Two Wood-Boring Molluscs From the Continental Terrace Off Oregon \\ by
}

Ronald Charles Tipper

\author{
A THESIS \\ submitted to \\ Oregon State University
}

in partial fulfillment of

the requirements for the

degree of

Doctor of Philosophy

June 1968 

APPROVED:

Associate Professor of Oceanography
in charge of major

Chairman of Department of Oceanography

Dean of Graduate School

Date thesis is presented

Typed by Opal Grossnicklaus for 


\section{ACKNOW LEDGMENTS}

I wish to express my gratitude to Dr. James E. McCauley for the opportunity to undertake this research and for his role as adviser, teacher, defender, and friend during these past four years.

Special thanks also go to Mr. Ronald Dale Pillsbury for his guidance in the development of a workable mooring system and for his many hours of labor at sea and ashore which made this research possible.

I also wish to thank my student associates and the ship's complement of the R/V YAQUINA for the moral support and the willing help which overcame so many difficulties.

I am also grateful for the expert advice of Dr. R. D. Turner concerning the taxonomy and habits of deep-water boring molluscs and to Dr. Lyle Calvin for guidance in setting up methods of data analysis.

Special thanks also go to Mr. Robert Fries, Mr. Jeffrey Stander and Mr. Dale Pillsbury for the photographic record of this work, to Mr. Ronald Hill, Mr. William Gilbert and Mr. Roger Paul for assistance with graphics, to Dr. Robert Smith who journeyed to sea many times in my behalf, to Dr. Andrew G. Carey, Jr., Dr. June G. Pattullo, Mrs. Diane Merten, and Dr. Lyle Calvin for suggestions regarding this manuscript and lastly to my wife Maryellen 
for years of patience, trust, and help in completion of this research.

This research was made possible through the financial support of the United States Navy and the Office of Naval Research (ONR Contract No. Nonr 1286-10). 

General Remarks 1

Deep-water Boring Molluscs 4

Taxonomy and Distribution 4

Biology of the Xylophagan Borers 8

The Teredinid Bankia setacea 13

Statement of the Problem 15

$\begin{array}{ll}\text { METHODS AND MATERIALS } & 18\end{array}$

Mooring System Design 18

Mooring Line 20

Surface Float 20

Ground Tackle 22

Critical Connection Areas 23

Sample Array Design 25

Installation and Recovery Technique $\quad 27$

Installation $\quad 29$

Recovery 30

Field Sampling Programs 32

Sample Materials $\quad 32$

Exposure Sites 33

Exposure Intervals 36

Oceanographic Environmental Data 37

Hydrographic Data 37

Geological Data 38

Special Data 38

Critical Analysis of Field Methods 39

Orientation 39

Disturbance $\quad 42$

Laboratory Analysis $\quad 43$

Preservation of Sample Materials 43

Taxonomic Identification 43

Enumeration of Surface Attack 44

Sectioning 46

$\begin{array}{ll}\text { TAXONOMY AND BATHYMETRIC DISTRIBUTION } & 47\end{array}$

Taxonomy 47

Bathymetric Distribution 51 
Attack on Pine Sample Panels

Variation of Surface Attack with Length of

Exposure

Variation of Surface Attack with Depth of Exposure

Distribution of Surface Attack with Increasing

Distance From the Sediment

Degree of Borer Penetration

Attack on Fir Sample Panels

Attack on Oak Sample Panels

Attack on Cedar Sample Panels

Integration and Summary of Wood Destruction Caused

by the Pholad Borer Xylophaga

Variation of Surface Attack with Exposure Time

Variation of Surface Attack with Exposure Depth

Distribution of Attack with Increasing Distance

From the Sea-Sediment Interface

Density of Substrate Versus Average Depth of Maximum Borer Penetration

ATTACK BY THE TEREDINID BORER BANKIA

Location and Intensity

Orientation of Màximum Attack

Competition

EXPERIMENTAL ERRORS AND PROBLEMS TO BE SOLVED

IN FUTURE RESEARCH

Experimental Error Encountered

Future Research Needed 


\section{LIST OF FIGURES}

$\underline{\text { Figure }}$

$\underline{\text { Page }}$

1. Mooring system design.

2. Toroid surface float.

3. Critical connection area.

4. Sample panels with rods and spacer.

5. Loaded sample panel rack.

6. Connection of sample array to steel ground line.

7. Connection of main anchor to nylon mooring line.

8. Launching the surface float.

9. Recovery of enough ground line to permit attachment to winch.

10. Station locations off Depoe Bay, Oregon.

11. "Pisa meter," 1/2 actual size.

12. "Pisa meter" housing, 0.4 actual size.

13. Basic cross-grain grid overlay ( $/ / 2 \mathrm{X})$.

14. Modified grid overlays, cross -grain $\mathrm{cm}$ interval, (left); with-grain cm interval (right), ( $/ 2 \mathrm{X}$ ).

15. Xylophaga washingtona removed from a pine panel exposed 72 days at 200 m (70 times actual size).

16a. Xylophaga washingtona, from Turner, 1955.

16b. Bankia setacea, from Turner, 1966.

17. Settling of Bankia setacea in relation to water temperature. 
LIST OF FIGURES (CONTINUED)

Figure

Page

18. Settling of Bankia setacea in relation to water temperature.

19. Model of proposed settlement of Bankia setacea in relation to temperatures observed off Newport, Oregon, and within the reproductive limits of Miller, 1951 .

20. Borer attack on pine test panels exposed in time series at $200 \mathrm{~m}$.

21. Temporal variation in surface attack of Xylophaga washingtona at $200 \mathrm{~m}$.

22. Temporal variation in surface attack of Xylophaga washingtona at $500 \mathrm{~m}$.

23. Temporal variation in surface attack of Xylophaga washingtona at $1000 \mathrm{~m}$.

24. Variation in Xylophaga washingtona surface attack with depth of exposure at 30 days.

25. Variation in Xylophaga washingtona surface attack with depth of exposure at 60 days.

26. Relationship of Xylophaga washingtona attack to distance from the sediment; panels exposed 30 days at $500 \mathrm{~m}$.

27. Relationship of Xylophaga washingtona attack to distance from the sediment; panels exposed 30 days at $1000 \mathrm{~m}$.

28. Pine panel exposed 30 days at 1000 meters (.66X).

29. Relationship of Xylophaga washingtona attack to distance from the sediment; panels exposed 60 days at $500 \mathrm{~m}$. 



\section{LIST OF FIGURES (CONTINUED)}

Figure

Page

30. Pine panels exposed 60 days at $500 \mathrm{~m}$. (1/2X).

31. Relationship of Xylophaga washingtona attack to distance from the sediment; panels exposed 60 days at $1000 \mathrm{~m}$.

32. Pine panels exposed 60 days at $1000 \mathrm{~m} .(1 / 2 \mathrm{X})$.

33. Uniform gradient of Xylophaga washingtona attack across adjacent pine panels exposed 72 days at $200 \mathrm{~m}$.

34. Split gradient of Xylophaga wa shingtona attack across adjacent pine panels exposed 72 days at $200 \mathrm{~m}$.

35. Sample panel position diagrammed in relationship to sediment data for Sample III, exposed 72 days at $200 \mathrm{~m}$.

36. Temperature profiles near the water-sediment interface measured on the continental slope.

37. Comparative sections of pine and cedar panels exposed 50 days (on left) and 72 days (on right) at $200 \mathrm{~m}$; all magnifications equal (2.4X).

38. Average depth of maximum borer penetration versus time of exposure at $200 \mathrm{~m}$.

39. Average depth of maximum penetration versus depth of exposure for 30 days.

40. Average depth of maximum penetration versus depth of exposure for 60 days.

41. Xylophaga washingtona gradient across pine and fir panels exposed 38 days at $200 \mathrm{~m}$. 


\section{LIST OF FIGURES (CONTINUED)}

Figure

$\underline{\text { Page }}$

42. Uniform gradient of Xylophaga washingtona attack across adjacent fir panels exposed 72 days at $200 \mathrm{~m}$.

43. Split gradient of Xylophaga washingtona attack across 99 adjacent fir panels exposed 72 days at $200 \mathrm{~m}$.

44. Xylophaga washingtona gradient on oak panels exposed 60 days at $1000 \mathrm{~m}$.

45. Margin of a cedar test panel exposed 72 days at $200 \mathrm{~m}$; section of this panel shown in Figure 36b $(1.3 X)$.

46. Gradient on cedar 72 days at $200 \mathrm{~m}$.

47. Gradient on cedar 60 days at $500 \mathrm{~m}$.

48. Gradient on cedar 60 days at $1000 \mathrm{~m}$.

49. Comparison of wood density with average maximum depth of penetration on wood exposed 50 days at $200 \mathrm{~m}$. Range of wood density from U.S. D.A. (1955).

50. Temporal variation of Bankia setacea surface attack at $200 \mathrm{~m}$. 
TABLE

Table

$\underline{\text { Page }}$

1. Sample sites, depths, and intervals. 


\section{ECOLOGICAL ASPECTS OF TWO WOOD-BORING MOLLUSCS FROM THE CONTINENTAL TERRACE OFF OREGON}

\section{INTR ODUCTION}

\section{General Remarks}

Wood-boring molluscs, commonly called shipworms, most likely have been a problem for man ever since he placed the first wooden structure or boat in the sea. This battle is well documented as far back as Theophrastus in 350 B.C. Shipworms were a serious problem to early explorers such as Cooke and Drake. Even Columbus lost all his vessels to borer attack on his fourth voyage, and had to be rescued from Jamaica (Turner, 1959).

One of the first detailed monographs on teredinid wood borers was written by Sellius (1733) at a time when the dikes of The Netherlands were in danger of destruction by shipworms. Sellius was the first to recognize that shipworms were molluscs.

An extensive annotated bibliography on marine borers by Clapp and Kenk (1963) provides a comprehensive survey of the numerous studies on wood-boring molluscs that were published from the time of the invention of the printing press through the year 1954. Among the more important works are: a survey of wood borers by Tyron (1862), who recognized the Teredinidae as a distinct family, and 
the long term study of borers along the eastern coast of the United States initiated by William F. Clapp in 1922. His study blossomed into the W. F. Clapp Foundation and Laboratories at Duxbury, Massachusetts where research on marine borers is still underway. On the Pacific coast the most significant early work was conducted by Kofoid, Hill, Miller and others (Hill and Kofoid, 1927) who carried out a detailed study of the marine borer problem in San Francisco Bay.

In general, all these studies were concerned with borer attack in shallow water. Usually research in a given geographic a rea was spurred forward only after an outbreak of shipworm attack on economically important structures. These early investigative studies have given way to more refined experiments involving test panel exposures designed to study the biology of common surface-water borers (Miller, 1926; Fraser, 1923; Johnson and Miller, 1935; Graham and Miller, 1959). Turner (1959) reported that a worldwide shallow-water testing program was initiated during the Symposium on Marine Wood Borers held at the Friday Harbor Laboratories of the University of Washington in 1959.

There has been much emphasis placed on wood borer research in shallow water, but little attention has been given to wood-boring molluscs in the deep sea. The earliest reports of deep-ocean borers came from wood dredged up from the sea floor. Bartsch (1921, 1927) 
described several new species of wood borers, including members of the pholad genus Xylophaga, from dredged wood from the ALBATROSS collections. Knudson (1961) described 17 new species of this genus from wood dredged up on the GALATHEA Expedition. Turnex (1966a) found teredinid specimens in wood dredged from below 1000 meters on this same expedition. Many of these species were described on the basis of a few whole specimens or even dry shell fragments.

Although Turner (1966a) reported many teredinid specimens which appeared to have been alive at depths below 1000 meters, she stated that there was no proof that they entered the wood after it reached the bottom. She felt that larvae could have penetrated drifting wood in surface waters and survived at the greater depths as the wood sank.

More recently, planned sampling of deep-ocean borer populations using test panels has been undertaken. DePalma (1962, 1963) has conducted a series of tests on the ocean bottom off Fort Lauderdale, Florida, at depths ranging from 30 to 150 meters, and in the Tongue of the Ocean, Bahamas, at depths of 969 and 1737 meters. Muraoka (1964, 1965, 1966a, 1966b, 1966c, 1967) has placed test-panel arrays at depths of 2340 to 6800 feet $(714$ to 2074 meters) off southern California. Dr. R. D. Turner, Museum of Comparative Zoology, Harvard University, identified the borers 
recovered in both these studies. She is subsequently correlating the information gained in these diverse exposure trials and is spearheading the quest for biological understanding of deep-water borer populations.

In my study of boring molluscs from the continental shelf and upper continental slope off Oregon, two boring molluscs were found: Xylophaga washingtona Bartsch, 1921, and Bankia setacea (Tyron, 1863). A review of the literature on these two organisms seems in order.

\section{Deep-water Boring Molluscs}

Previous deep-water testing by DePalma (1962) and by Muraoka (1964, 1965, 1966a, 1966b, 1966c, 1967) has shown that pholad borers of the genus Xylophaga àre the primary destructive agents to wood test panels exposed at depths below 700 meters. Little is revealed in the literature about the distribution and the biology of this genus.

Taxonomy and Distribution

Species in the genus Xylophaga have been included in the family Pholadidae and the subfamily Xylophaginae by Turner (1955). Purchon (1941) had previously removed the genus from the pholads and created a new family, the Xylophaginidae. However, the shell characteristics of the Xylophaga with a distinct mesoplax and lack 
of apophyses, and the agglutination of fecal pellets to form a "chimney" lining the burrow wall, are typical of other pholad genera.

Members of the genus also lack the calcareous lining of the burrow wall seen in the Teredinidae. Purchon (1941) also felt that the woodboring habit and the possible alternation of sexes seen in Xylophaga related them more closely with the Teredinidae. Turner (1955) pointed out, however, that these characteristics are also found in other typical pholad genera such as Martesia.

The genus Xylophaga has a world-wide distribution. As late as 1955 most of the known members of this genus had been collected from floating and waterlogged wood, and the group was thought to be largely pelagic (Turner, 1955). Additional sampling since that time has prompted a different point of view. Knudson (1961) described 17 new species from plant materials dredged from depths greater than 400 meters on the GALATHEA Expedition. Many species in his collection were based on small numbers of specimens, and some were based only on shell fragments. The feeling was engendered, however, that the Xylophaga were essentially a deep-water population. Further testing by DePalma (1962) and by Muraoka (1964, 1965, 1966a, 1966b, 1966c, 1967) has provided support to this line of reasoning, and Turner (1966b) now refers to Xylophaga as a basically deep-water genus.

After the GALATHEA specimens were described (Knudson, 
1961), 28 species were known in the genus Xylophaga. Of these 28, six forms occurred commonly in the western Atlantic or the eastern Pacific and were discussed in a comprehensive paper by Turner (1955).

Xylophaga dorsalis (Turton, 1819), Turton, 1822, a common littoral species of the northeast Atlantic, may occasionally be abundant in restricted localities in floating or submerged waterlogged wood. It is one of the few xylophagan borers whose basic biology has been studied (Purchon, 1941). This biology will be discussed later.

Xylophaga globosa Sowerby, 1835, was described from specimen collected at 60 fathoms (110 meters) off Valparaiso, Chile. It is known to exist at depths of from 6 to 135 fathoms ( 11 to $247 \mathrm{~m}$ ) with a range from Panama to Chile (Turner, 1955).

Xylophaga abyssorum (Dall, 1886), was described from shells only, and occurs along the western Atlantic coast. Turner (1955) reported that $\underline{X}$. abyssorum, in addition to boring into wood, is recorded to bore into mud, sand, and soft stone, but since all available specimens were dead upon recovery and were from considerable depths (in excess of 138 fathoms [252 meters]), little can be said as to their true habitat.

Xylophaga mexicana Dall, 1908, was described from a single valve of a dead specimen taken at 141 fathoms (258 meters) off 
Acapulco, Mexico. Other specimens are known only from areas near the type locality (Turner, 1955).

Xylophaga atlantica Richards, 1942, is a species taken in floating or waterlogged wood from Quebec, Canada, south to Virginia. Specimens have been recovered from wood dredged from 100 to 1000 fathoms (183 to 1829 meters), but no record was made if the specimens were living or dead (Turner, 1955).

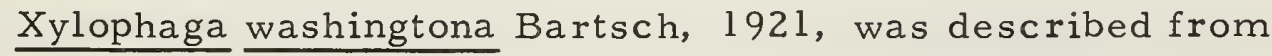
specimens taken at Friday Harbor, Washington. Additional specimens obtained at depths of 37 to 136 fathoms (67 to 250 meters) from dredge hauls of the ALBATROSS extended the range southward along the Pacific coast to southern California. Deep-water testing of materials by Muraoka (1964, 1965, 1966a, 1966b, 1966c, 1967) has provided specimens known to be actively settling on and penetrating wood from depths of 2340 to 6800 feet ( 714 to 2074 meters) off southern California.

Work now in progress by Dr. R. D. Turner of the Museum of Comparative Zoology, Harvard University, utilizing materials from the sampling programs of DePalma and Muraoka (Dr. R. D. Turner, personal communication) should provide added insights into the taxonomy and the relationships of deep-water borers. 
Biology of the Xylophagan Borers

Probably the most definitive statement which can be made with regard to the biology of the xylophagan borers is that we know almost nothing. Purchon (1941) dealt with the biology of $\underline{X}$. dorsalis. This . form is more typically an inhabitant of the surface waters, while the majority of xylophagan species have deeper distributions.

Knudson (1961) postulated that the genus Xylophaga originated in shallow tropical waters where abundant plant debris was available from rivers or mangrove swamps. In the se particular areas, however, present shallow-water borer populations are dominated by teredinids and other pholads, primarily Martesia. Knudson goes on to speculate that due to competition from the aforementioned forms, the xylophagan borers may have been unable to survive in shallow waters. Turner (1954) reported that Martesia, with species from the Carboniferous, seems to be the most ancient pholad genus. The oldest Xylophaga comes from the lower Cretaceous, and with the exception of the genus Barnea which appeared about the same time, the remaining pholad genera are more recent, mostly of Tertiary origin. Purchon (1955) speculated that the Xylophaga may have buanched off at an early stage in the development of the Pholadidae. Knudson (1961) stated that the restricted distributions of the present species of Xylophaga living in deep water, may be 
due to a patchy occurrence of plant debris on the sea bottom.

The first and only detailed study of reproduction in Xylophaga was made on $\underline{X}$. dorsalis by Purchon (1941), who found the species to be a protandric hermaphrodite. A gradual change to female began when the borer reached a length of about $3 \mathrm{~mm}$. He also stated that individuals could undergo more than one sexual change so that large specimens ( 8 to $10 \mathrm{~mm}$ ) might consist of individuals which were females for a second time. This pattern of sexual alternation was seen in the teredinid borer Teredo navalis by Coe (1933).

Purchon (1941) also demonstrated the presence of a vesicula

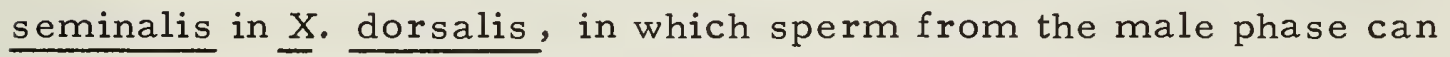
be stored, thus allowing for later self-fertilization. This capability is of great survival value to an animal such as $\underline{X}$. dorsalis which lives in driftwood where the chance of fertilization may be slight if eggs and sperm were to be discharged freely into the sea (Purchon, 1941; Turner, 1954). Purchon (1941) did not observe larval incubation in $X$. dorsalis but postulated this to be highly likely. Turner (1954) reported internal fertilization in $X$. atlantica coupled with brooding until the late veliger stage. Knudson (1961) found brood protection quite obvious 9 of the 17 new species he described from the deep ocean. In most cases, a small number of embryos were found attached to the shell of the parent borer. The juveniles 
resembled the adults in their sof $t$ parts and were lacking a velum. Knudson felt this indicated a lack of pelagic life and also a poor ability for larval dispersal, hence patchy, isolated distributions in the deep sea, localized near sources of plant debris.

The literature offers even less information regarding the food sources of the xylophagan borers. Yonge (1937) concluded that xylophagans were unable to digest wood. However, Purchon (1941) felt $\underline{X}$. dorsalis was, in part, able to digest wood, but might be independent of it at some times since specimens had been found boring in the guttapercha sheaths of submarine cables. Purchon (1941) found indication of a cellulase in $X$. dorsalis, and Knudson (1961) noted that plant materials seem to be the normal habitat for xylophagan borers. The only known exceptions are $\underline{X}$. abyssorum, which possibly bores in sand, mud, or soft rock (Turner, 1955), and X. dorsalis, which bores into submarine cables as mentioned above. Fecal pellets of some xylophagan specimens contained fine particles of wood with no trace of other items such as plankton or suspended matter (Knudson, 1961). Muraoka (1967) reported that X. washingtona bored into several types of plastics, an unlikely substrate for an organism thought to consume wood for nutrition. Dr. R. D. Turner (personal communication) feels that the xylophagans feed on microorganisms in the water, although she thinks the possession of a large caecum typical of many herbivores indicates that they may 
use wood for food. Modern experimental proof of an endogenous cellulase within these borers is lacking. The possibility of a symbiotic association with a bacterial or ciliate cellulase-producing intestinal commensal should be considered.

Although it was not known how juvenile xylophagan borers began their attack, Knudson (1961) stated that boring was always begun from the wood surface and not from within the burrow of the parent. Turner (1954) observed that young Zirfaea crispata Linné, another pholad, attached themselves to the substrate by means of a single byssal thread in the protection of minute crevices. Here, metamorphosis took place, and the shell changed into a boring tool. Knudson (1961) observed a byssal attachment of xylophagan juveniles to the shell of the parent.

Muraoka (1964, 1965, 1966a, 1966b, 1966c, 1967) determined that the settlement of the larva of $X$. washingtona in deep water was heaviest near the sea-sediment interface. In such situations he found the number of entrance holes to reach as high as 50 per square centimeter. In both Atlantic and Pacific deep-water tests, boards a meter off the bottom were only slightly attacked and those over ten meters off the bottom were usually free of borers (Turner, 1966b). Settlement was also more intense in protected areas such as irregularities in the boards or between boards and their attachment to test panel racks (Turner, 1966b). 
The excavations of Xylophaga are oblong-pearshaped and most often at right angles to the wood grain, in contrast to the burrowing habits of most teredinids which usually turn and bore parallel with the grain (Knudson, 1961).

Rate of growth in the xylophagan borers is not well understood. Turner (1956), reporting on X. washingtona recovered from a wooden anchor housing, observed that growth up to four millimeters in length had occurred over a four month (September to January) exposure interval in 109 meters of water off southern California. The golden brown protodissoconch was still prominent on many specimens. From this sample, Turner (1956) learned that settling and possibly breeding occurred in $X$. washingtona at least during the fall.

Many species of Xylophaga are known to line the burrow wall with a cemented tube of fecal pellets called a "chimney" (Turner, 1956). Some xylophagans occasionally bore into the burrow of a neighbor, a trait seldom seen in teredinid borers (Knudson, 1961).

The manner in which boxing occurs in the pholads has been treated several times in the literature. Early theories that the rock boring pholads excavated by means of an acid were given by Johnston (1850). Buonanni (1681) was the first to believe that the shell was the instrument of boring. Dubois (1889) felt that water pressure from the siphons spun the animal in the burrow much like an auger, while Smith (1894), felt that action of the foot with sand 
grains was the boring mechanism. MacGinitie (1935) presented an excellent account of the boring of Zirfaea gabbi Tyron, in which he stressed the interaction of the shell parts, the adductor muscles, the foot, and water action, in total boring activity. Through careful examination he deduced that the real boring movements were mainly the up and down motions of the valves. Turner (1954) reviewed his work and found it to agree with her observations on other pholad borers including the wood borer Martesia striata Linné. Ansell and Nair (1967) repeated these observations for $X$. dorsalis, ar riving at the same conclusions as MacGinitie. The only new feature of their study was to attach a recording pen to one valve of the borer to obtain a graphical output of boring movements.

Specimens of $X$. dorsalis which bore into coverings of cables or hard wood are often malformed and stenomorphic (Turner, 1955). Knudson (1961) also observed some cases of variation in his study of 17 new deep-ocean species. A paper now in preparation by $\mathrm{Dr}$. R. D. Turner (personal communication) will deal with the variation in shell morphology due to differences in boring substrate for X. washingtona.

The Teredinid Borer Bankia setacea

Bankia setacea (Tyron, 1863) was one of the two marine woodboring molluscs recovered during my sampling. The paragraphs 
below briefly discuss the taxonomy and the biology of this species; additional details are included later (pp. 57-63).

Turner (1966a) has provided an excellent comprehensive survey and classification of the family Teredinidae, including $B$. setacea. Members of the genus Bankia, first described by Gray,(1838), are readily recognized by their "cone-in-cone" type pallets (Turner, 1966a). Like other teredinids their burrow wall is lined with a calcareous layer. Bankia setacea is a common surface-water borer all along the eastern Pacific coastline of North America, and bores only into wood (Quayle, 1960).

The sexual products of male and female $\underline{B}$. setacea are extruded into the water separately; fertilization is external (Coe, 1941). The duration of the free swimming larval stages, studied in detail by Quayle (1953), is measured in weeks. The seasonal spawning and settling patterns of this species have been studied by placing test boards in surface waters at various locations along the Pacific coast of North America (Fraser, 1923; Miller, 1926; Johnson and Miller, 1935; and Neave, 1943).

Although $\underline{B}$. setacea usually attacks pilings and other wooden marine structures in fairly low numbers, the extreme size attainable in the adult (up to three feet) provides quite significant destructive potential (Johnson and Miller, 1935).

Kofoid and Miller (1927) compared B. setacea with another 
common teredinid borer Teredo navalis Linné in their report of the San Francisco Bay Marine Piling Survey. Bankia setacea was better adapted to lower temperature waters of open ocean salinity while T. navalis tolerated waters of periodically very low salinity and higher temperatures. Bankia setacea, occurring near the mud line of pilings, was capable of speedily destroying the bearing power of untreated piles even though sparsely set (Kofoid and Miller, 1927). Miller (1951) regards $B$. setacea as a species of northern temperate waters, flourishing best in regions where the temperature during a year does not go much below six nor much above fourteen degrees centigrade.

\section{Statement of the Problem}

Very little controlled sampling of the deep-ocean borer population has ever been carried out. DePalma (1962) has sampled depths near $1000 \mathrm{~m}$ in the Tongue of the Ocean, Bahamas, while on the west coast of the United States the only sampling undertaken has been by Muraoka (1964, 1965, 1966a, 1966b, 1966c, 1967) at depths of about 700 to 2000 meters. Muraoka's studies have been oriented mainly towards materials testing rather than borer ecology. Turner (1965) has called for additional sampling at other geographic locations and especially at depths between 300 and 2000 feet ( 90 and 600 meters). No experimental work on deep-ocean borers had ever been conducted 
off the coast of Oregon, although dredge hauls had pointed towards a xylophagan borer population in these waters.

Methods for obtaining organisms from test panels exposed for long periods from deep water under open ocean conditions were not well developed. Successful mooring and recovery systems such as the one developed at the United States Naval Civil Engineering Laboratory, Port Hueneme, California (Jones, 1965), were extremely costly and had been used under surface environmental conditions somewhat less rigorous than those found off Oregon.

In general, a four-fold research problem on deep-water boring molluscs off Oregon then evolved. (1) A reasonably-priced, simplydesigned system for placing and recovering test panels in the deepocean environment off Oregon had to be developed. (2) The presence of an active population of boring molluscs at depths below 200 meters had to be confirmed and such borers identified. (3) The distribution of such borers with depth, especially in the interval between 200 and 1000 meters required study. (4) The general ecology of the borer population needed to be studied and major problems for continued research identified.

Current trends in science and technology pointing towards increased utilization of the continental ter race areas by man provide additional rationale. The current Man-in-the-Sea effort on the part of the federal government demonstrates this point. If we are 
to enter this region of the sea floor successfully, it behooves us to first understand all the factors operative there, both biological and physical. A thorough knowledge of the behavior and the function of "normal" organisms in relation to their environment is a requisite in the development of materials and methods for controlling their activities. 
METHODS AND MATERIALS

\section{Mooring System Design}

The methods for this study were centered around a reliable deep-ocean mooring system which would permit installing and recovering sample materials placed on the ocean floor.

In a series of trial mooring projects it was found that taut-line mooring systems, designed by Isaacs et al. (1965), were unsatisfactory for recovering sample panel arrays. Recovery of the large dead-weight anchor, required in such systems due to the absence of scope in the mooring line, caused the three strand nylon line in use to unlay and fail. Again, the taut nylon line required a large surface float which was awkward to launch and to recover, and which presented a substantial area to wind and wave stress. This combination also contributed to mooring system failure. "Fishbite" damage seen in warmer waters (H.J. Turner, 1965) was not found to be a contributing factor in these mooring system failures. Consequently the taut-line system was abandoned in favor of a design providing scope in the mooring line. The final mooring system (Figure 1) will be discussed in detail below. All descriptions of mooring sytem hardware will be given in English units to simplify duplication of the equipment by future users. 


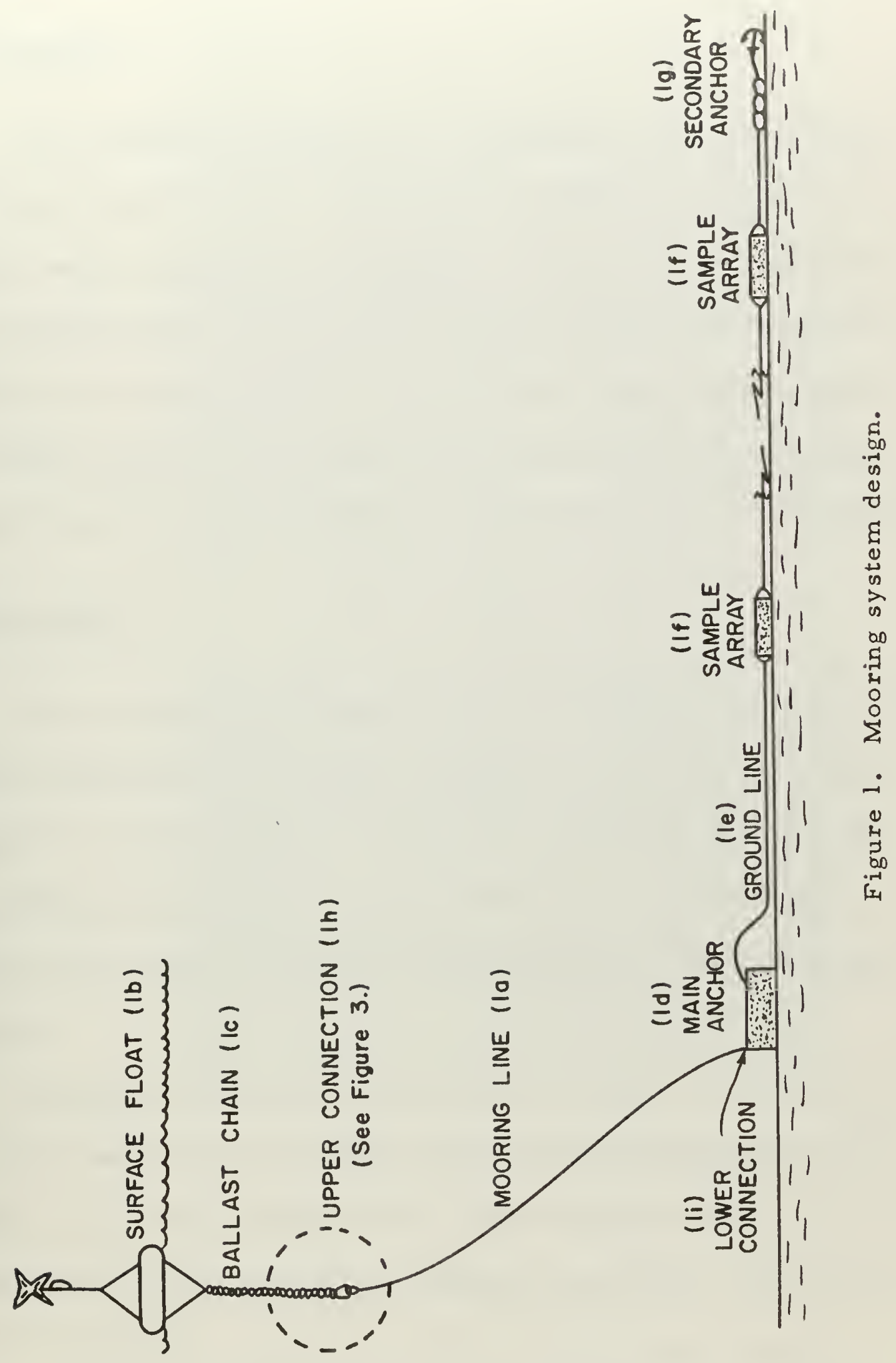



Mooring Line

The mooring line (Figure la) consisted of a continuous length of Samson 2-in-1 Braided Nylon Rope, ${ }^{1}$ 9/16 inch in diameter, cut with a scope of twice the water depth. This line, of a torque free, non-rotating design, eliminated the tendency of the mooring line to unlay under recovery tension. The all-nylon construction provided for high resistance to biological deterioration, nearly neutral buoyancy in seawater, and a breaking strength in excess of 10,000 pounds.

\section{Surface Float}

The surface float designed by Mr. R. D. Pillsbury (Figures lb and 2) consisted of a foam-filled, fiberglass toroid (four foot outside diameter, one foot circle of rotation) which provided approximately 400 pounds net buoyancy. A rada $r$ reflector and a flashing light aided in the recovery of the float and eliminated any hazard to navigation.

Stability with respect to wind and wave action was achieved by some 20 feet of $3 / 4$-inch ballast chain suspended beneath the toroid (Figure lc). The combination of a scope mooring system and a neutrally buoyant line permitted the effective use of such a small, easy

\footnotetext{
${ }^{l}$ Registered Trademark, Samson Cordage Works, Boston,
} Mass. 


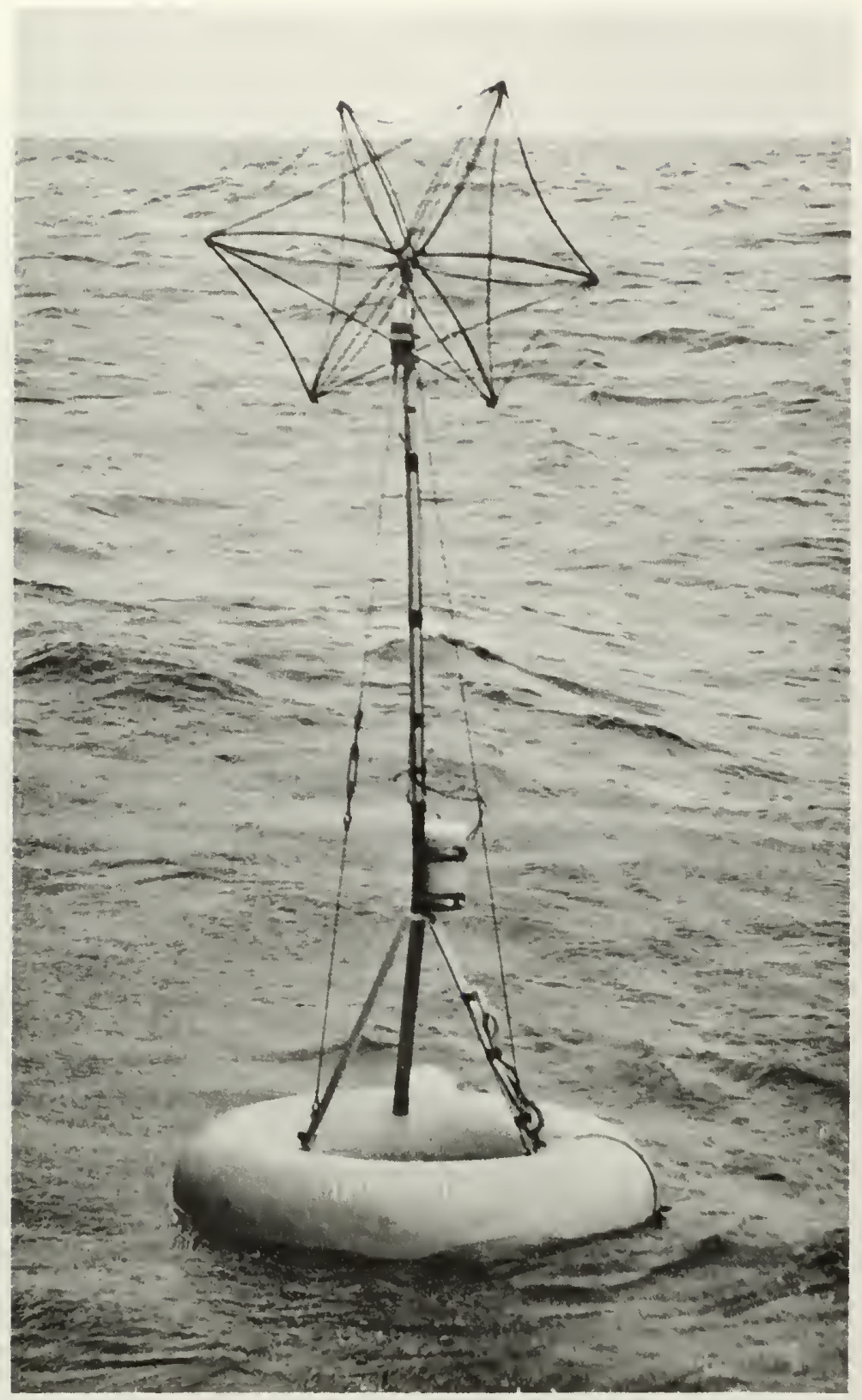

photo by Pillsbury

Figure 2. Toroid surface float. 
to handle float.

\section{Ground Tackle}

Design of the ground tackle was bent on accomplishing three goals, a lighter weight anchor which could be easily recovered, a safety backup system which would allow for recovery if the surface float was lost, and a means of securing a time-series sample while using only one mooring system.

The small main anchor (Figure ld), a rectangular steelreinforced concrete slab weighing only about 400 pounds in air, was effective even in deep, open-ocean conditions because of the low drag of the small surface float and the use of a scope mooring system.

The ground line (Figure le) was a length of $1 / 4$-inch seven by nineteen, non-rotating, galvanized, preformed wire rope approximately three times the water depth. This length provided a large target for recovery by grappling methods should the surface float fail, It also provided for the exposure and the separate recovery of more than one sample panel array (Figure lf). Details of the recovery operation will be fully discussed later.

The terminal end of the ground tackle consisted of a secondary anchor (Figure $\mathrm{lg}$ ), composed of seven 35 -pound anchor-chain shackles and one 25-pound Danforth anchor. The ground line was 
connected to both anchors by means of Nicopress ${ }^{2}$ fittings.

\section{Critical Connection Areas}

The areas of attachment of the mooring line to the float-ballastchain system and the main anchor-ground tackle system were most critical with respect to the survival of the moorage at sea. Connection had to provide protection against vibration, chafing, rotation, and electrolytic corrosion of dissimilar metals. Figure 3 illustrates the basic series of 1/2-inch chain safety shackles, 1/2-inch swivel, four-inch internal diameter steel ring, and 9/16-inch wire rope thimble employed at both critical connection sites (points $h$ and $i$ in Figure 1).

All metallic components were hot-dip galvanized to prevent electrolytic corrosion of dissimilar metals. The mooring line was eye-spliced about the 9/16-inch thimble and then triple dipped in a quick drying liquid nylon (Gental 101$)^{3}$ to provide a barrier against chafing. The swivel prevented hockling of the mooring line while the large metal ring prevented any pounding contact between the connecting shackles and the mooring line.

${ }^{2}$ Registered Trademark, The National Telephone Supply Co., Cleveland, Ohio.

${ }^{3}$ Registered Trademark, General Dispersions, Inc., Bloom. field, N. J. 


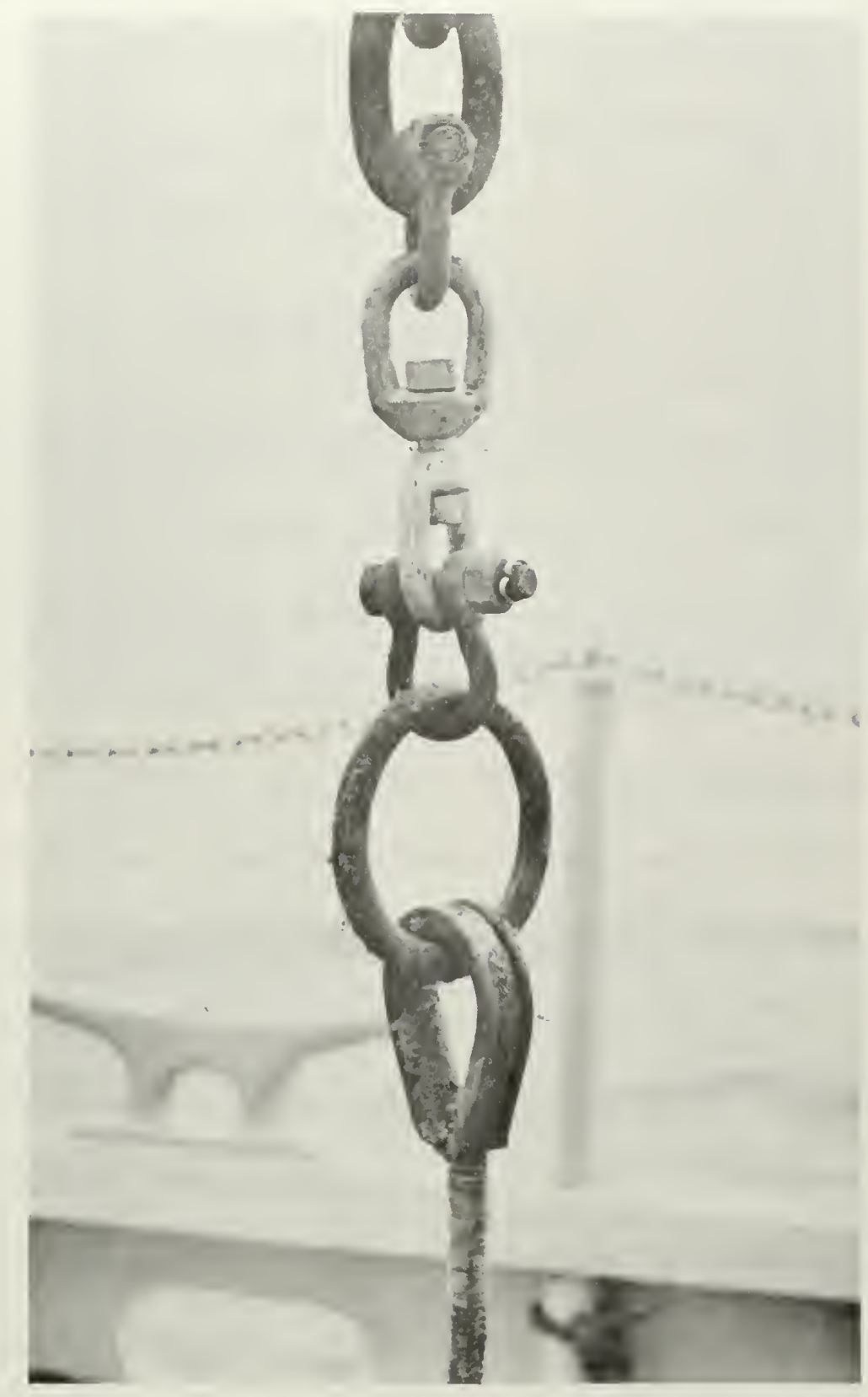

photo by Pillsbury

Figure 3. Critical connection area. From the top: anchor chain ballast, safety shackle, swivel, safety shackle, steel ring, thimble and eye-splice, main mooring line. 
Although normal operations called for the entire ground tackle system not to exceed 2,000-pound loads, all components of the mooring system were designed to handle a 10,000-pound load, thus providing a five to one safety factor.

\section{Sample Array Design}

Sample materials which were to be exposed to borer attack were cut into panels of approximately 9 by 4 by $3 / 4$ inches (Figure 4 ). These dimensions were chosen so that an exposed panel, with specimens, could be preserved in a standard, widemouth, one gallon jar and also be easily handled during microscopic examination in the laboratory. Allowance, however, had not been made for the swelling of panels after exposure in water and, after Sample $I_{\text {, subsequent }}$ panels were cut 9 by $3 \frac{1}{2}$ by $3 / 4$ inches.

To secure and protect the sample panels, racks six feet long and one foot square were constructed of $\frac{1}{4}$-inch steel (Eigure 5). The sample racks were hot-dip galvanized following assembly to insure protection against corrosion. Each sample panel was supported on two 3/4-inch acrylic rods (also seen in Figure 5) and separated at 2 -inch intervals from adjacent panels by spacers made from acryl. ic tubing. Use of this dielectric acrylic material for support and separation allowed the insertion of test panels made of dissimilar metals without serious electrolytic corrosion. 


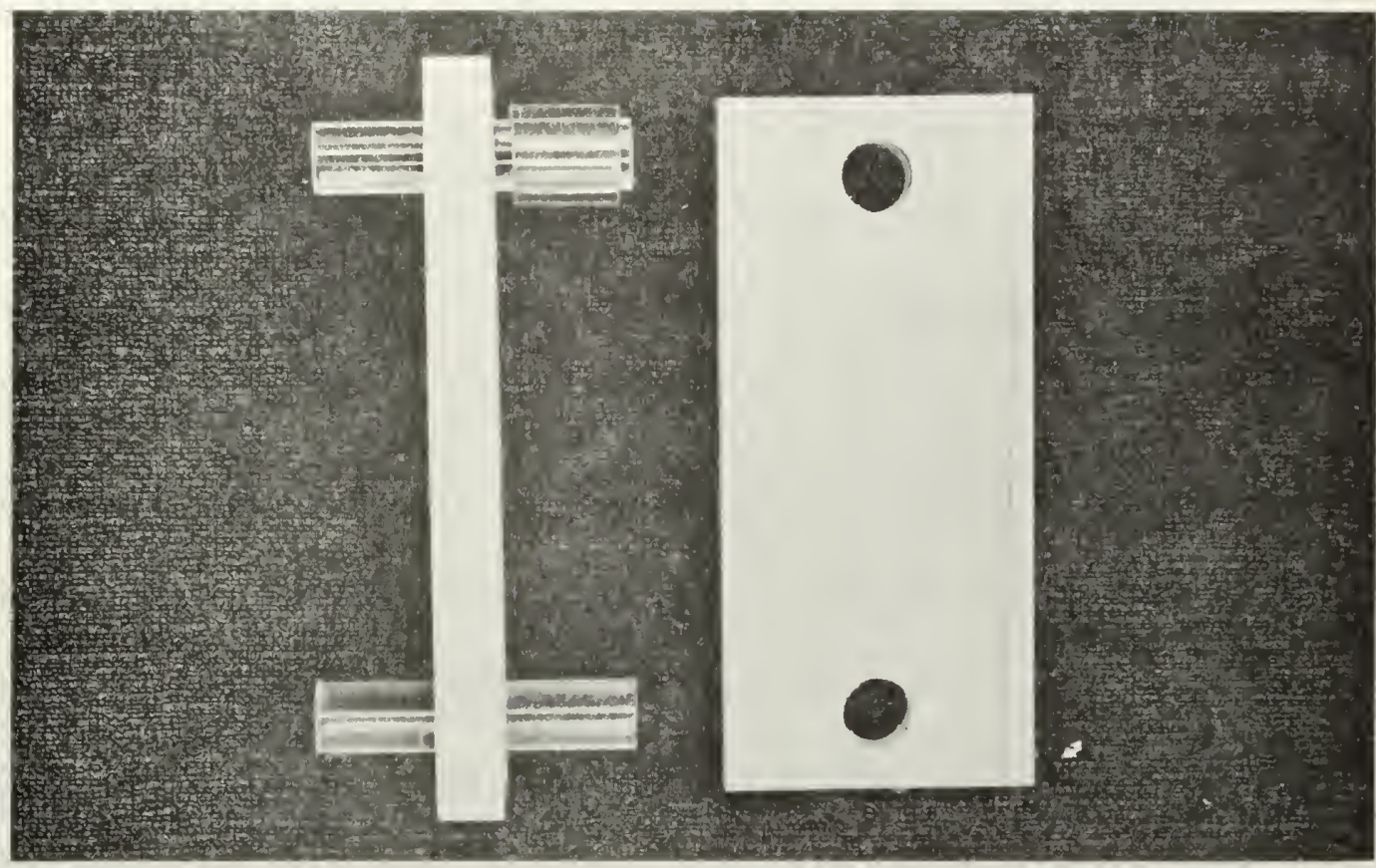

photo by Stander $(0.33 \mathrm{X})$

Figure 4. Sample panels with rods and spacer.

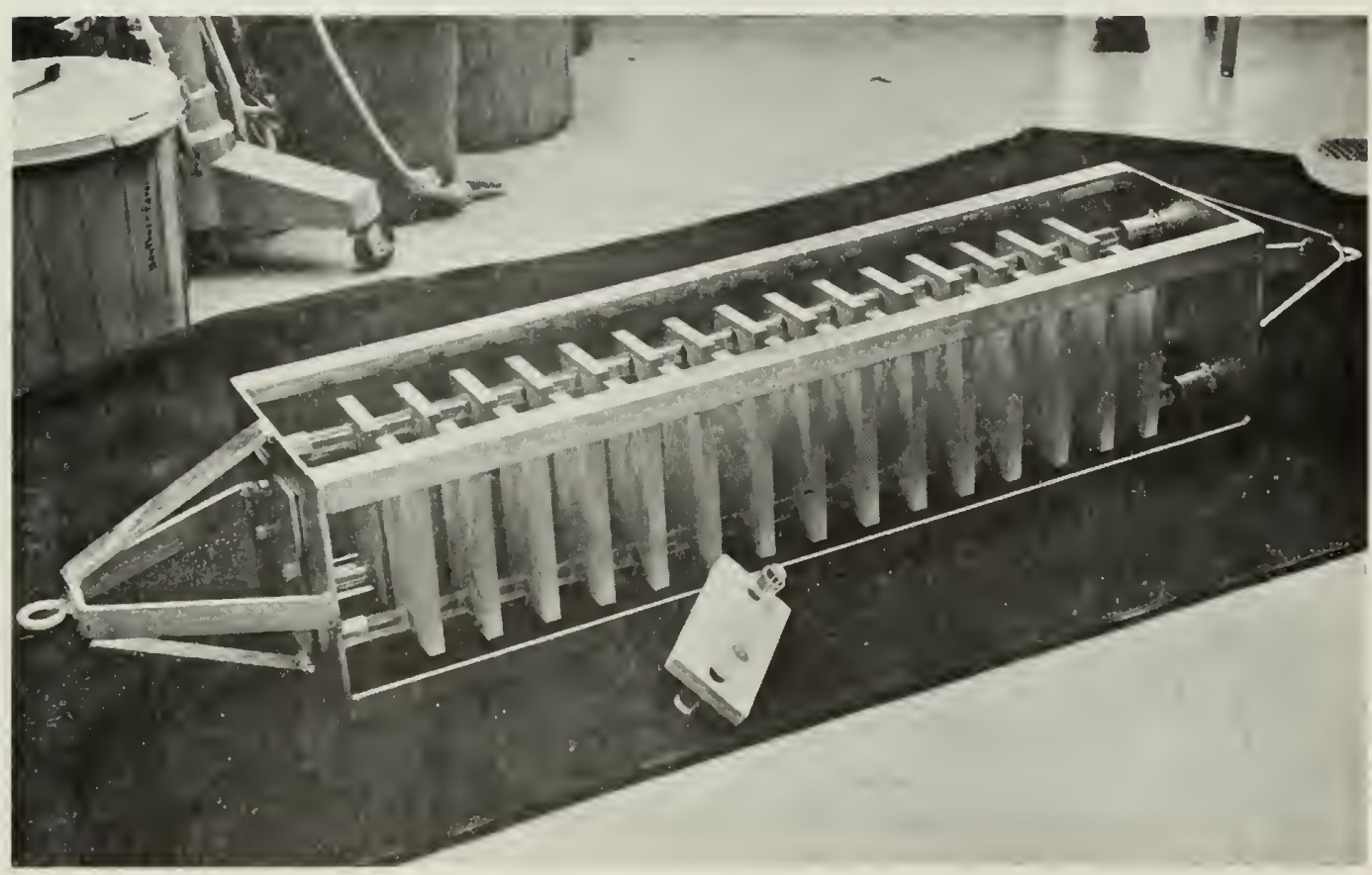

photo by Stander

Figure 5. Loaded sample panel rack. 
Test racks were loaded by sliding the acrylic rods through holes in the two end plates of the rack, and then slipping the spacers and panels over the rods. A cover plate (easily seen in Figure 5) which bolted over the rods held them in place. The heavy construction of the sample rack, which weighed about 80 pounds in air, provided adequate protection for the sample panels during normal installation and recovery operations, and anticipated the possible damage which might result if a grappling method of recovery were required.

Sample arrays were attached to the ground line (Figure le) by means of pennants of $\frac{1}{4}$-inch galvanized wire rope and cable clamps (as shown in Figure 6). This arrangement provided for easy attachment and removal of the sample arrays without cutting the ground line.

\section{Installation and Recovery Technique}

Hardware and technique are inter related in any ocean engineering situation. Mr. R. D. Pillsbury and many other individuals-oespecially members of the ship's company of the R/V YAQUINA--have greatly contributed to the refinement of these methods. Let us break the installation process into the following simple steps. 


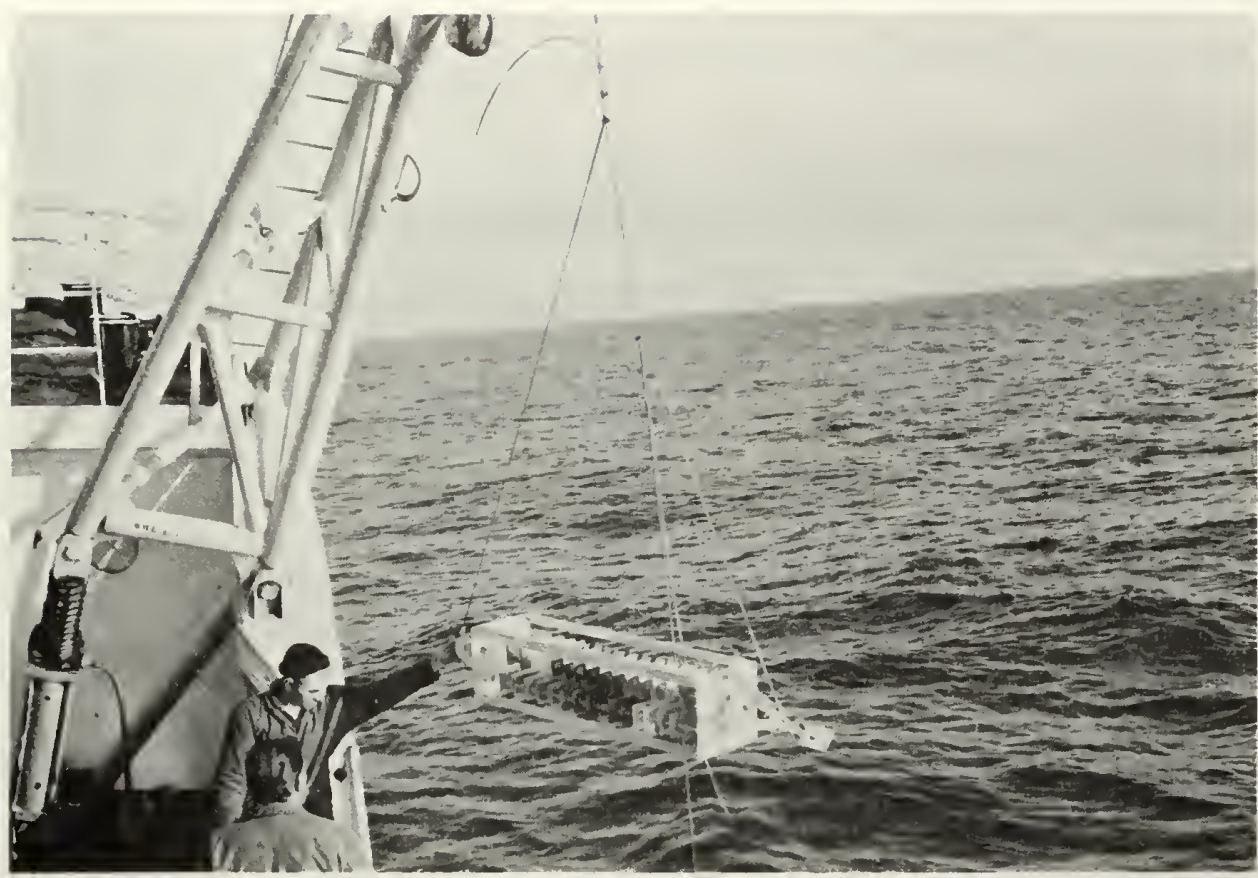

photo by Fries

Figure 6. Connection of sample array to steel ground line.

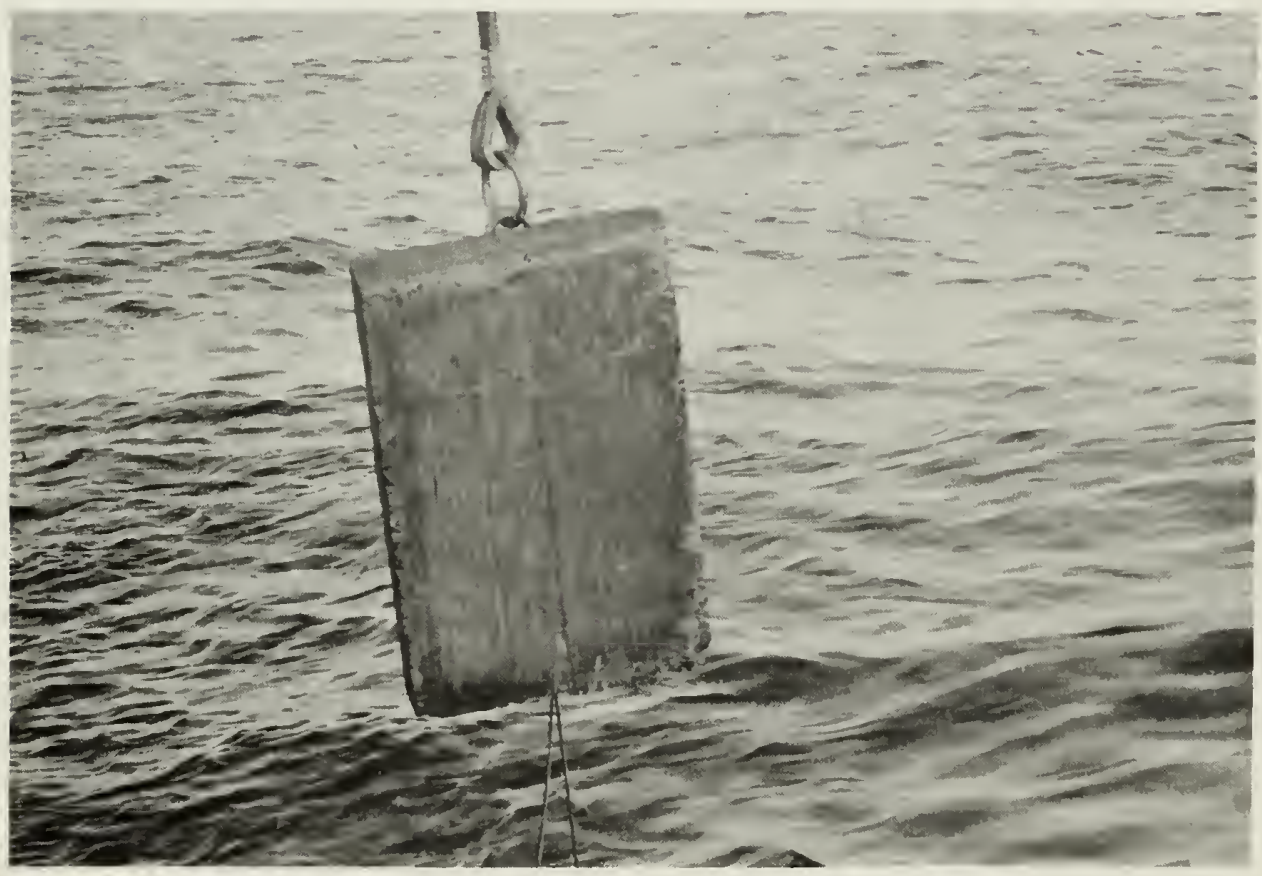

photo by Fries

Figure 7. Connection of main anchor to nylon mooring line. 
Installation (refer to Figure 1)

(1) With the desired amount of ground line (somewhat more than three times the water depth) wound on a winch, the secondary anchor attached to the ground line was lowered over the side to a depth of about ten meters.

(2) The first sample array was then attached to the ground line with cable clamps.

(3) The wire rope ground line was then paid out until the secondary anchor was on the bottom. At this time an accurate navigational fix was taken to record the position of the secondary anchor. Near shore, we have found a combination fix by using radar ranges and Loran A to be adequate.

(4) The installing vessel then moved slowly ahead to keep the ground line stretched straight while additional wire rope was being paid out.

(5) When an amount of wire rope equal to three times the water depth had been paid out, the second sample array was then attached and lowered over the side about ten meters.

(6) At this point the ground line was stoppered off, cut above the cable stoppers, and attached to the main anchor.

(7) The mooring line (Figure 7) was then attached to the main anchor and the strain of the entire ground tackle system was taken 
by the mooring line before the cable stoppers on the ground line were let go.

(8) With the mooring line about a capstan or gypsy head, the entire ground tackle system was lowered until the main anchor touched bottom. A second navigational fix was then taken.

(9) Slack mooring line still on board the installing vessel was then paid out by hand while the float as sembly was being attached to the upper end.

(10) The float was launched with a small block and tackle, as seen in Figure 8, and a final navigational fix taken.

\section{$\underline{\text { Recovery }}$}

The recovery procedure was essentially the reverse of the installation method, with the float brought aboard the recovery vessel first. Two points are worth mentioning in more detail. First, when the main anchor is brought aboard, a few meters of the ground line must be hauled up on the deck of the recovery vessel by brute force (Figure 9), stoppered off, and re-attached to the cable on the winch. This maneuver allows the weight of the ground tackle system to be recovered by the winch. Second, only the sample array nearest the main anchor need be removed. If this is done with care, the mooring system can be immediately reinstalled without disturbing the sample array still on the sea floor next to the secondary anchor. This second array can then be left for additional exposure as part of a time-series exposure at the sampling site. This 


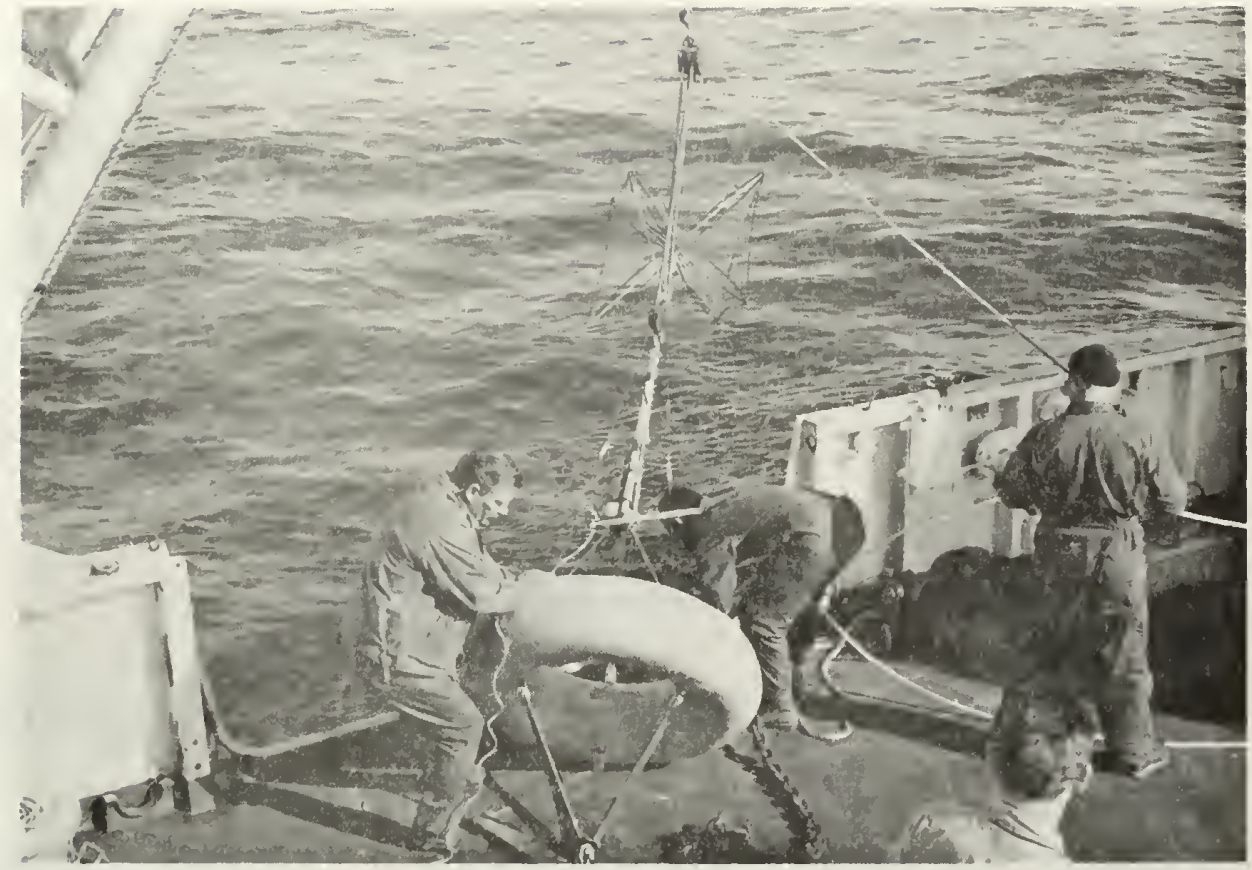

photo by Fries

Figure 8. Launching the surface float.

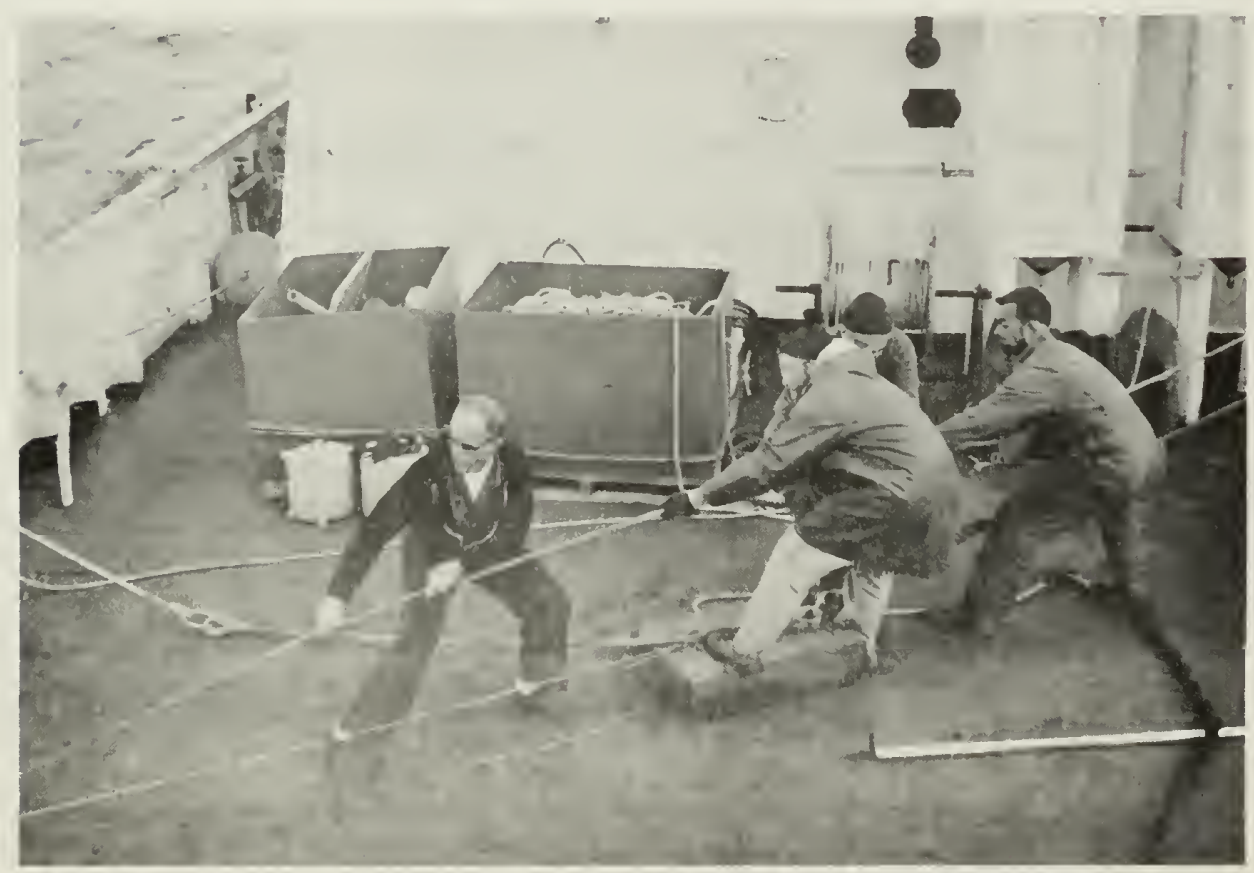

photo by Fries

Figure 9. Recovery of enough ground line to permit attachment to winch. 
method was used to obtain time-series exposures in this study.

If the float should be lost during the exposure interval, which happened on two occasions in my experiment, the navigational fixes on either end of the ground tackle system provide a backup means of recovery by grappling.

\section{Field Sampling Program}

Sample Materials

Fourteen materials were initially selected for exposure in the test-panel arrays: five plastics (nylon, teflon, polyvinylchloride, polyethylene, and acrylic), eight wood types (Ponderosa pine, Douglas -fir, Oreg on oak, Port Orford cedar, Oregon ash, red alder, redwood, and Philippine mahogany), and one metal (aluminum). The plastics and the metal, under deep-ocean marine biodeterioration and corrosion study at the United States Naval Civil Engineering Laboratory (USNCEL), Port Hueneme, California (Muraoka, 1964), were selected due to their increasing role in man-made marine structures and sampling apparatus. These sample specimens were forwarded to USNCEL for cooperative engineering analysis, which is beyond the scope of this thesis. The woods were selected as substrates for exposure to possible marine borer populations. Of the eight woods, four (pine, fir, oak, and cedar) are frequently 
mentioned in literature on marine borers. These four wood types also form a graded series of substrate densities (U.S.D.A., 1955) and are readily available in uniform lots. For these reasons they were selected as the primary test materials to be examined in this study. Test boards were picked for uniformity of characters and freedom from anomalous areas such as knots. When possible, all sample panels of each wood were cut from a single piece of lumber. All wood was kiln-dried, finished lumber, untreated by preservative. A pair of panels of each of the four wood types was included in every sample array. The only exception to this occurred in a trial exposure, Sample I, when only pine and fir were exposed.

\section{Exposure Sites}

Sample panel arrays were exposed at six stations along a line running across the continental shelf and upper continental slope, west of Depoe Bay, Oregon. Stations were located at depths of 50, 100, 150, 200, 500, and 1000 meters (Figure 10 and Table 1).

Previous sampling schemes had often placed test materials at fairly scattered points; for example, DePalma (1962, 1963) conducted shallow-water exposures off Fort Lauderdale, Florida, while deeper test sites were located more than $260 \mathrm{~km}$ away in the Tongue of the Ocean, Bahamas. At other times researchers have been forced to place long-term test materials in areas cut off from an open ocean environment (DePalma, 1966). 



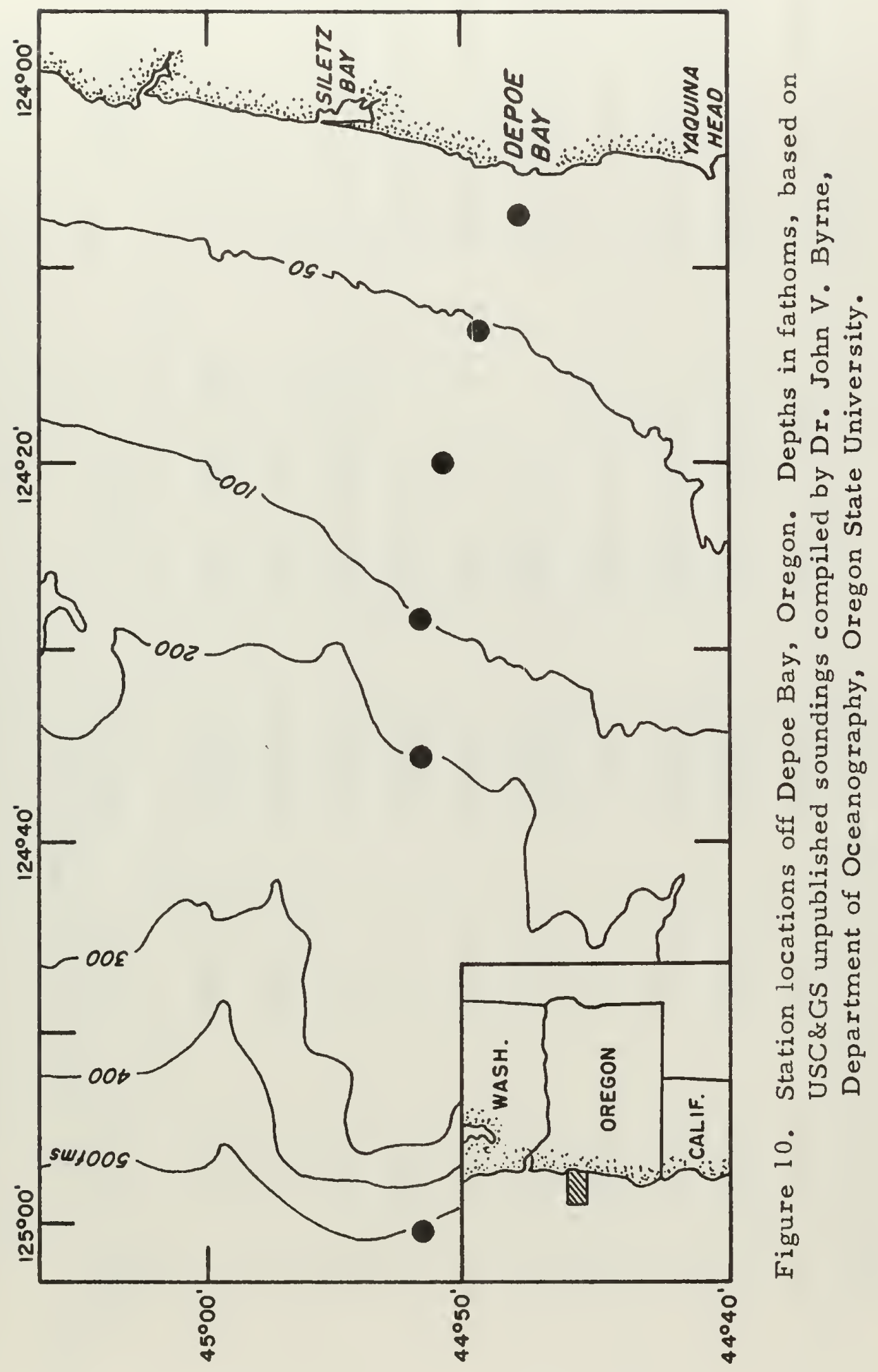




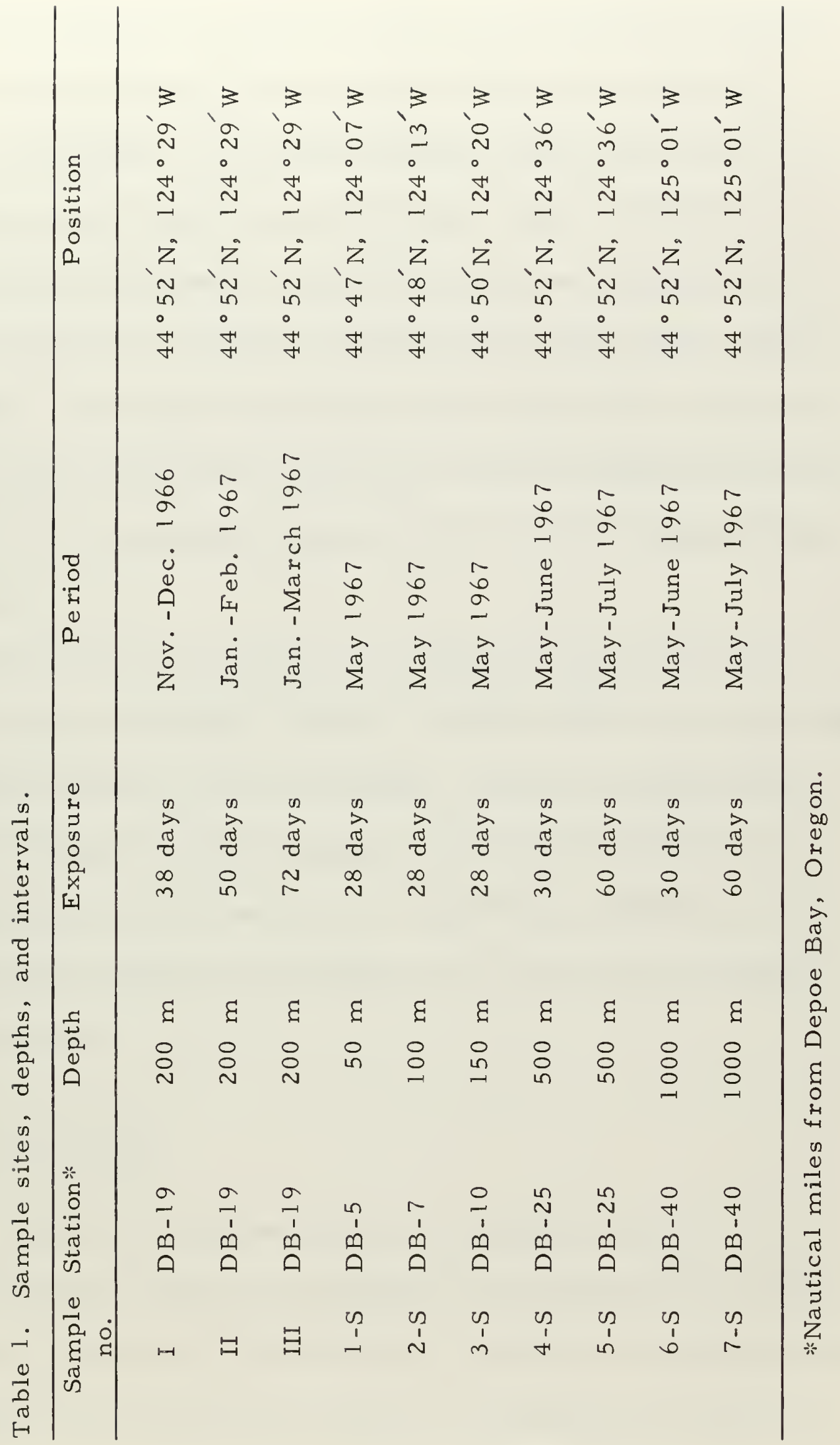


Sites chosen off Oregon for this study crossed the continental shelf and upper slope in an open ocean environment and along a nearly straight line. The station closest inshore (DB-5) was 9.3 kilometers from land, the station farthest offshore (DB-40) being 74 kilometers from land. The area selected has a fairly smooth bottom profile, and sediment characteristics grade, in an offshore direction, from sand through silty-sand to sandy-silt. Such positioning of the sample sites allowed for more meaningful inferences to be drawn from the data on ranges and habits of the boring molluscs present.

The sample area chosen was within two and one-half hours steaming time of Newport, Oregon, the home port of the Oregon State University Research Vessel YAQUINA, and was currently under study by the physical oceanography group of the Department of Oceanography. These factors were important in reducing the cost of operations and increasing efficient use of ship time by doublingup on cruises.

\section{Exposure Intervals}

A trial one month installation, designed primarily to test the mooring system design, was conducted at the 200-meter station in November-December of 1966 (Table l). Based on the positive attack of marine borers seen in this sample, a 30-day time interval was 

chosen as the shortest practical sampling exposure.

An initial plan was devised with a time series sample of 30 , 60, and 90 days at the 200-meter station, and 30- and 90-day samples at 500 and 1000 meters.

Only 30-day samples were planned at the three inshore sites (50, 100, and 150 meters) where a high rate of deterioration was expected. Difficulties in obtaining ship time and the local vagaries in climatic conditions influencing time when the ship was available, caused actual sampling periods to vary from the desired intervals ( Table 1).

\section{Oceanographic Environmental Data}

Ideally, one would measure all possible environmental conditions concurrently with the biological sampling. In this study, due to monetary limitations, ship-scheduling priority, and physical equipment limitations, environmental data were not simultaneously gathered. Data were obtained, however, from on-going research projects by other groups within the Department of Oceanography.

\section{Hydrographic Data}

Several on-site deep hydrographic casts taken during the sampling period were made through the kindness of Dr. Robert L. Smith of the physical oceanography group. Such sampling was carried out 

as near to the ocean floor as sea conditions and standard hydrographic techniques permitted. Data from the very near-bottom environment, taken at comparable depths but at different locations (about $18.5 \mathrm{~km}$ south), was provided by Dr. Andrew G. Carey, Jr. A wide selection of data for depths less than 1000 meters were available from hydrographic data reports (Barstow et al., 1968a, 1968b). Most of these data were taken off Newport, Oregon, also some 18.5 $\mathrm{km}$ south of Depoe Bay.

\section{Geological Data}

The sediment composition found at the test sites was described in the doctoral dissertations of Maloney (1965) and Runge (1966).

\section{Special Data}

Temperature profiles across the sea-sediment interface in the region being studied were obtained from the doctoral dissertation of Mesecar (1968b). Concomitant sampling with moored current meter arrays of the type reported by Collins, Creech, and Pattullo (1966). provided data on circulation and temperature patterns some distance above the ocean floor at the 50-, 100-, $150_{-}$, and $200-$ meter exposure sites. 



\section{Critical Analysis of Field Methods}

\section{Orientation}

One of the major problems encountered was controlling and understanding the orientation of the sample panels with respect to the sea-sediment interface. The sample array often settled on the bottom at an angle such that sediment covered varying areas of the sample panels; this made enumeration of borer attack quite difficult.

To get some indication of the orientation of the sample array with respect to the sea floor, a leaning-tube bottom current meter, Carruthers, (1963), nicknamed the "Pisa Meter" by its originator, was modified into an inexpensive attitude sensing device (Figure 11). The meter, when kept hot, maintains a fluid interface between an upper (low density) oil layer and a lower (higher density) immiscible pectin-glycerin layer. When cooled to room temperature or below, the pectin-glycerin layer hardens, locking the position of the interface layer as a permanent record of meter attitude. In the sample array, a polyvinylchloride housing, filled with hot water (Figure 12) served to keep the meter warm during installation. As the meter cooled at depth, it recorded the final position of the sample array. 

Plastic Cap

Rubber

Diaphram

Aluminum Spacer

with Rod

Standard $80 z$.

Baby Bottle

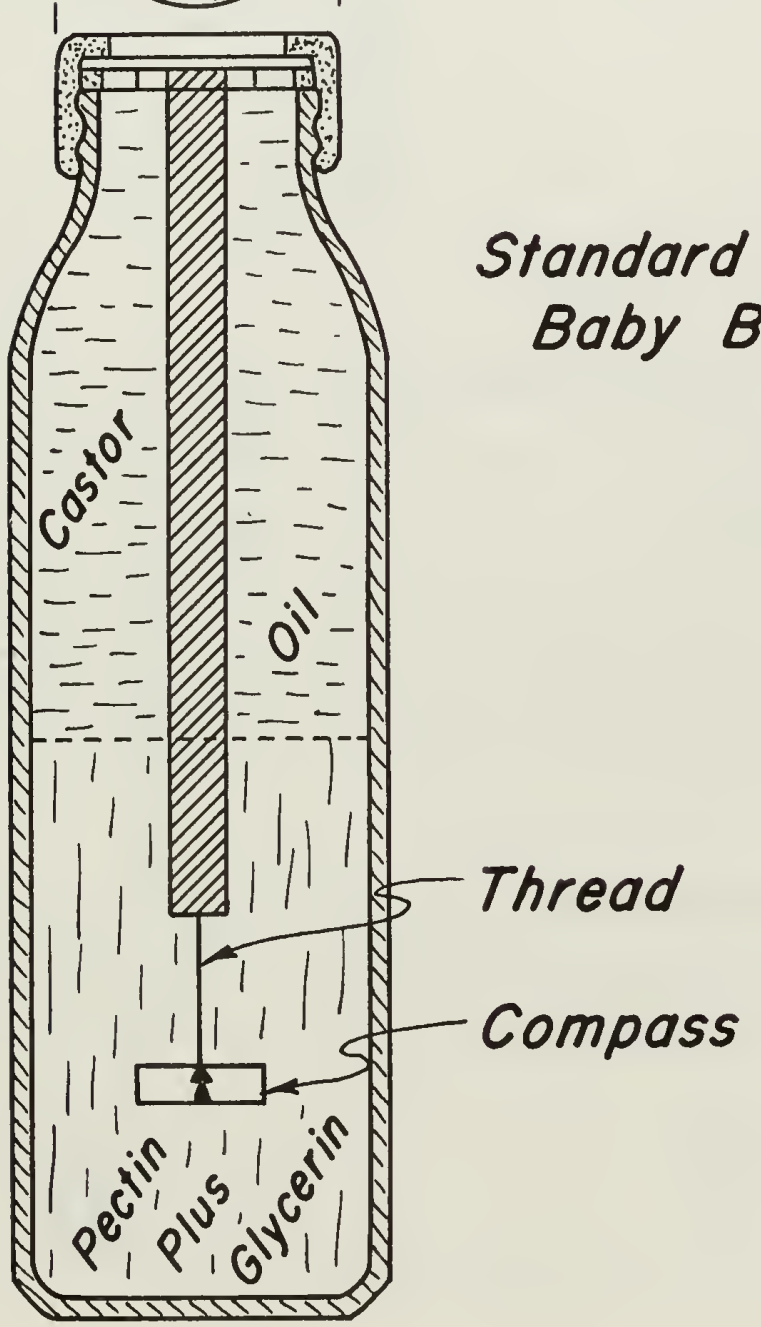

Figure 11. "Pisa meter," $1 / 2$ actual size. 

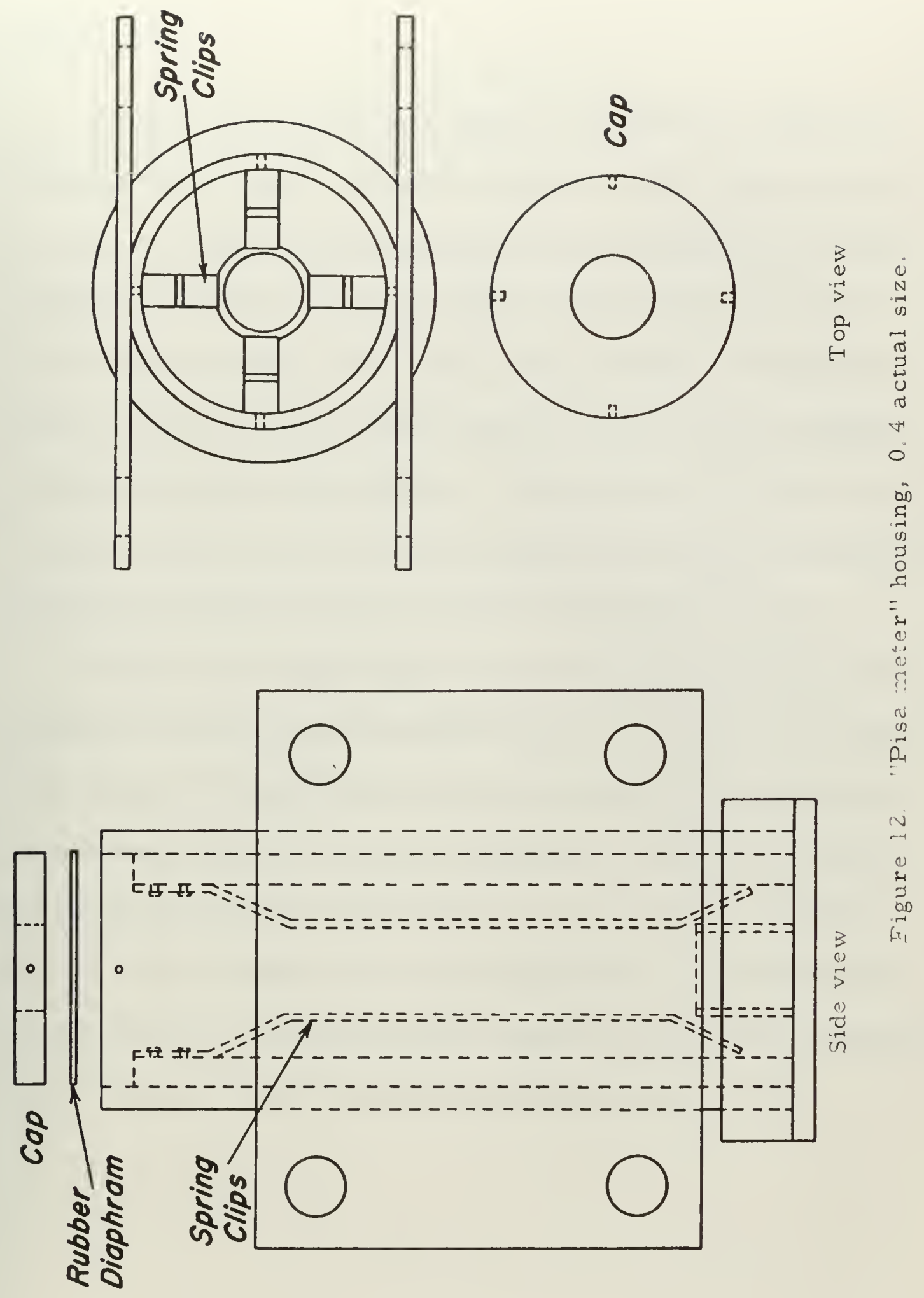


\section{Disturbance}

A second group of factors which were extremely difficult to control or detect were possible disturbances at the unmanned mooring sites. During the sampling period, Soviet fishermen observed working in the test area employed large trawling nets capable of disturbing any sample array. Also, large numbers of American fishing vessels and considerable coastal steamer traffic regularly passed through the sampling area. Although no such incidents were reported, there is no real way of knowing if any sample arrays were disturbed by fishing activity or possible ship-float collision.

Another type of disturbance can occur when the ground line is pulled up to remove the first sample array in a time-series exposure, presumably leaving the other array unaltered in position f see the previous section on recovery techniques). If this operation is not carried out quickly and carefully, chances become quite high that the second sample array will be disturbed. One sample rack recovered in our sampling program appeared to have been disturbed in this manner and will be fully discussed later (see p. 82). 


\section{Laboratory Analysis}

\section{Preservation of Sample Materials}

Immediately after recovery of the sample array at sea, test panels were removed from the rack and placed in preserving solution of buffered $10 \%$ formalin in seawater. Panels remained in this killing solution only 48 hours, after which they were rinsed with $\mathrm{fresh}$ water and transferred to a $40 \%$ is opropyl alcohol- $10 \%$ glycerin solution.

Many wood types, especially redwood and cedar, lose extrac. tants such as tannins into the preserving medium. Extreme discoloration of all sample materials, and occasionally the destruction of the borer specimens, resulted within about three months. It is suggested that specimens required for taxonomic, anatomical, or physiological study be removed from test panels as quickly as possible after recovery at sea.

Dr. R. D. Turner of Harvard University (personal communication) has suggested that prompt freezing of test panels after recovery may be a highly successful method of preservation.

\section{Taxonomic Identification}

My tentative identifications of boring mollusc specimens were kindly verified by Dr. R. D. Turner, Museum of Comparative 

Zoology, Harvard University, Cambridge, Massachusetts.

Methods of Enumeration of Surface Attack

The number of individual borer penetrations on the surface of a single sample panel was often quite large. Counts were made through an overlying acrylic grid to determine the number of penetrations per unit surface area. The earliest grids employed were cut to match the size of the sample panels and inscribed with five pairs of parallel lines (Figure 13). The number of borer penetrations within the lines were then counted. The areas counted were a form of systematic sample which was oriented to cut across the wood grain. This eliminated the effect of differential settling on spring versus summer woods (which will be illustrated and discussed later). On panels with extremely low numbers of borers, grid row widths were spread up to $1 \mathrm{~cm}$ to increase the sample area. Conversely, on boards which were quite heavily infested, grid lines were moved closer together to provide rows as narrow as $1 \mathrm{~mm}$.

As additional sample arrays were recovered, other gradients, within the sample panels themselves, became apparent. The basic grid plan was then modified in order to enumerate the new gradients (Figure 14) and to measure gradients across panels which had been exposed with grain running perpendicular to the sediment surface. 



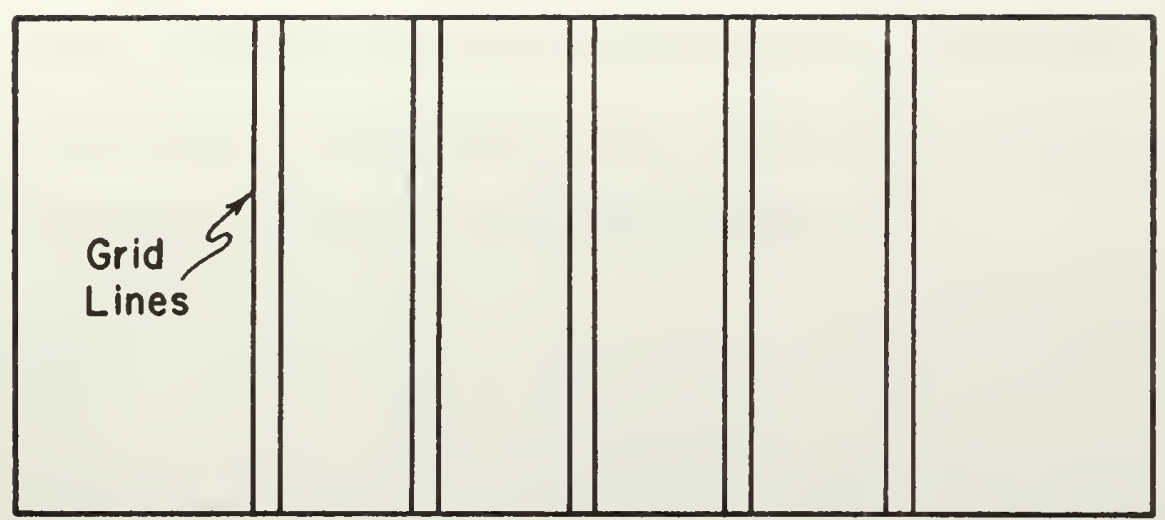

Figure 13. Basic cross-grain grid overlay (1/2 X.)

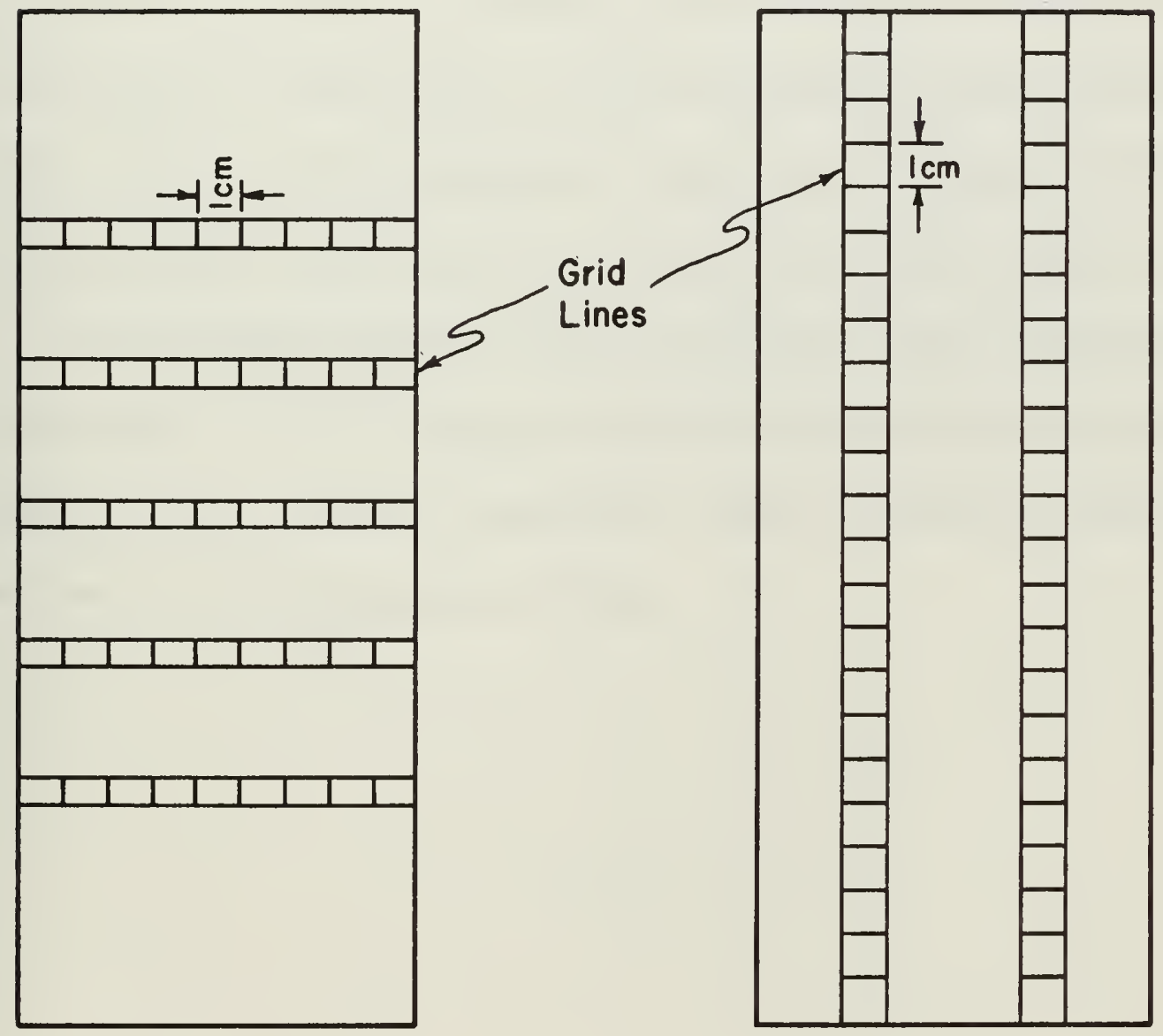

Figure 14. Modified grid overlays, cross-grain cm interval, (left); with-grain cm interval (right), (1/2 X.) 

I wish to express my appreciation to Dr. Lyle Calvin, Department of Statistics, Oregon State University, for his many hours of patient guidance on data enumeration techniques.

\section{$\underline{\text { Sectioning }}$}

Sample panels from each exposure series were sectioned by the horribly crude but effective method of "single-edged razor blade plus hammer." Borer residue was then washed from the burrows by agitating the section in a dilute bleach solution, followed by rinsing thoroughly in $f$ resh water. Dried sections were then inspected under a Wild M-5 Sterioscopic Microscope, and the depths of 100 burrows in each type of wood were measured for each exposure series. Measurement was made with a calibrated occular micrometer. The average of the 10 deepest burrows in the particular wood type was arbitrarily chosen as the average depth of maximum penetration for that type in that exposure series. 



\section{TAXONOMY AND BATHYMETRIC DISTRIBUTION}

\section{$\underline{\text { Taxonomy }}$}

Two species of wood-boring molluscs, identified as Xylophaga washingtona Bartsch, 1921, and Bankia setacea (Tyron, 1863), were recovered from sample panels exposed during this study. Identifications of these boring mollusc specimens were verified through the kindness of Dr. Ruth D. Turner, Museum of Comparative Zoology, Harvard University.

Xylophaga washingtona (Figures 15 and $16 a$ ) belongs in the family Pholadidae because it has accessory plates, a trait unique in this family among all other pelecypod molluscs (Turner, 1954).

Bankia setacea (Figure 16b), a member of the Teredinidae, lacks accessory plates, but has a calcified burrow wall and a set of distinctive pallets (Turner, 1966a).

It is interesting to note the complete absence of other species of boring and fouling organisms on all of the panels exposed. Some special "absentees" are worthy of further comment.

The wood-boring isopod Limnoria lignorum (Rathke, 1799) was not found, even though the area studied was within the geographic range of this species (Menzies, 1959; Graham and Miller, 1959). These reports, however, were based on observations in shallow 



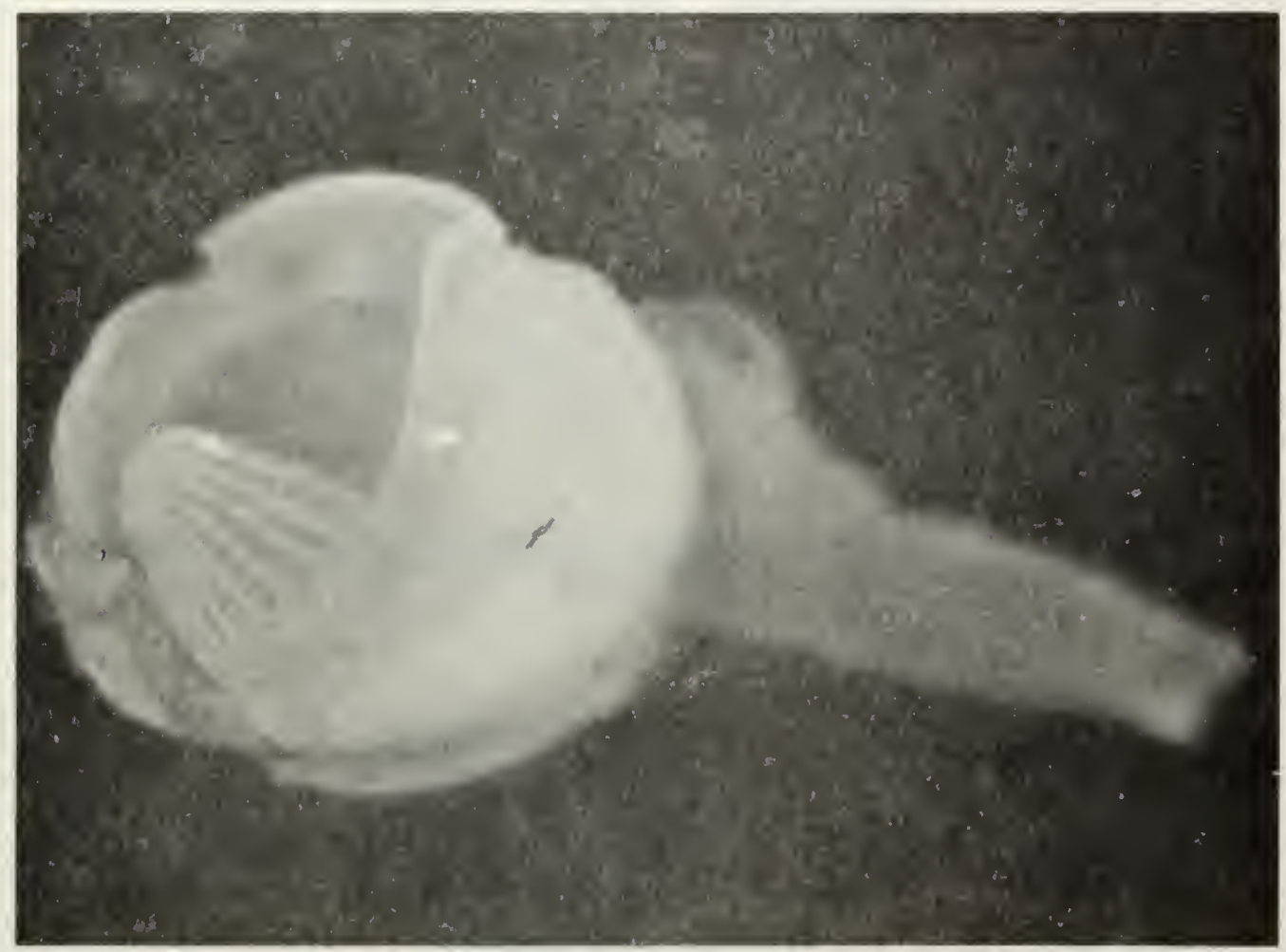

photo by Stander

Figure 15. Xylophaga washingtona removed from a pine panel exposed 72 days at $200 \mathrm{~m}$ ( 70 times actual size). 


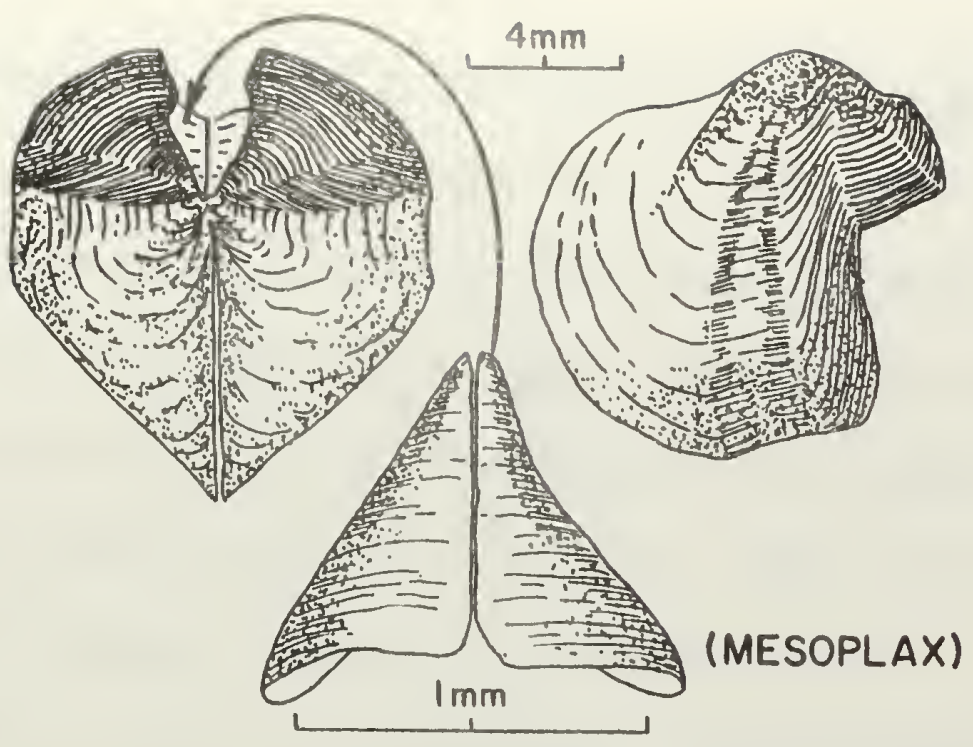

Figure 16a. Xylophaga washingtona, from Turner, 1955.
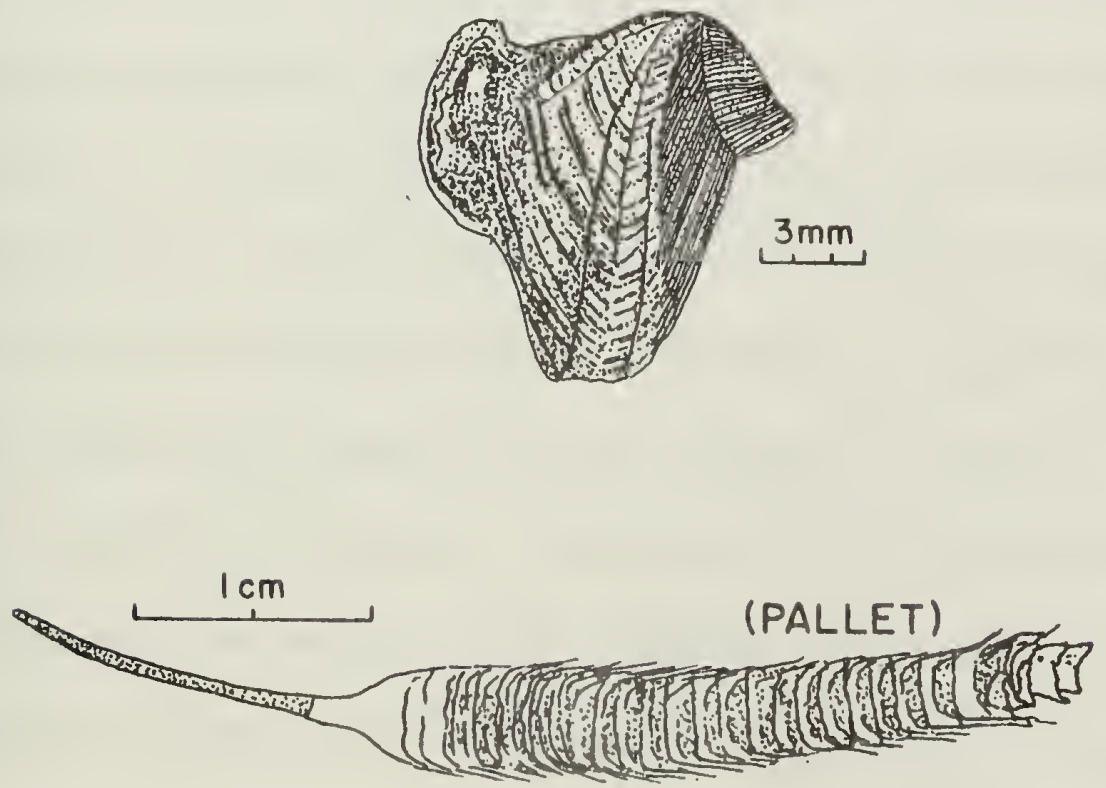

Figure 16b. Bankia setacea, from Turner, 1966. 
water. Menzies (1959) stated that only four species of Limnoria have been found in water below the "littoral" zone, and these records are based only on scattered reports from Japan, the Indian Ocean, the Banda Sea, and Australia. Limnoria infestation has also failed to be reported in recent deep-water materials test programs off California, by Muraoka (1964, 1965, 1966a, 1966b), and in the Tongue of the Ocean, Bahamas, by DePalma (1962).

DePalma (1966, p. 11) stated that a restricted offshore distribution in L. lignorum probably results "because the larvae are poor swimmers and tend to remain near brood sites close to shore." Other forms, notably bryozoans, hydroids, barnacles, and serpulids, reported as active foulers in local coastal waters /Graham and Miller, 1959; and W.H.O.I., 1952), also were absent from our sample panels. One may speculate that the period of sampling may have been of such short duration, especially at the shallower test depths, that a more typical fouling community (W.H.O.I., 1952) had no opportunity to develop. DePalma (1966) found that wooden test panels, while being excellent collectors of marine borers, were unsuitable substrates for the collection of barnacles, tubeworms, and bryozoans. He concluded, as did Pomerat and Weiss (1946), that asbestos board was the most promising material for maximum attachment of fouling organisms.

As for my wooden sample panels exposed off Oregon, the season 

of the year, the depth and the durations of exposure, and the distance of exposure sites from shore, may all contribute to the lack of a true fouling community on the panels. Clearly, if our goal in this study had been to sample the fouling community at these depths, exposures of much longer duration and employing better substrates for foulers would have been advisable.

DePalma (1968), in summarizing studies made in clear tropical waters off Fort Lauderdale, Florida, and in the Tongue of the Ocean, Bahamas, stated that fouling tends to be continuous in the upper 150 to 200 meters of the water column, decreasing in intensity with increasing depth and distance from shore. For depths greater than 200 meters and distances over 5 miles $(9.3 \mathrm{~km})$ from shore, fouling was es sentially negligible.

\section{Bathymetric Distribution}

Xylophaga washingtona, the pholad borer, was present in all wooden sample panels exposed at the 200-, 500-, and 1000-meter depths, but was absent from panels recovered from the three shallower exposure sites at 20, 100 , and 150 meters.

Most specimens of $X$. washingtona collected prior to testing of materials in deep-water were known only from dredge hauls and fortuitous collections by naturalists (Turner, 1955). Larvae of X. washingtona were reported from depths of 25 fathoms (46 meters) in British Columbia waters by Fraser (1923) and Quayle (1953). Miller (1951) also reported X. washingtona in test blocks exposed 

in Puget Sound, but he stated that it was rarely found and was of no economic importance.

The holotype of X. washingtona, Bartsch, 1921, was collected by Dr. C. Engberg at San Juan Island, Washington. It is in the United States National Museum, Cat. No. 334479; the depth of collection, however, is not given. Turner (1955) noted that specimens were collected via dredge hauls taken in Puget Sound, Washington, at a depth of 10 fathoms (18 meters), at ALBATROSS station 2867 off Washington (Lat. $48^{\circ} 07^{\prime} \mathrm{N}$.; Long. $124^{\circ} 55^{\prime} \mathrm{W}$. ) in 37 fathoms (68 meters), at ALBATROSS station 5432 off Cape Meares Light, Oregon, in 97 fathoms ( 177 meters), and at ALBATROSS station 4523 off Point Pinos Light, California, in 108 fathoms (198 meters). One has no way of knowing whether or not the specimens were alive at the recorded depths.

Turner (1956) reported the occurrence of $X$. washingtona at 109 meters off Oceanside, California, in a sample derived from the wooden housing of a sand filled anchor which had been exposed for four months. These specimens most likely were alive.

Muraoka (1964, 1965, 1966a, 1966b), in a large scale study of deep-ocean biodeterioration conducted off the coast of southern California, reported heavy infestation of wood and manila rope by several species of xylophagan borers including $\mathrm{X}$. washingtona, X. duplicata, and some new species now being described by 

Dr. R. D. Turner, Harvard University (Dr. R. D. Turner, personal communications). Sampling depths in Muraoka's study ranged from 2340 feet (714 meters) to 6800 feet (2074 meters), with exposure times from four months to three years.

DePalma (1962) reported infestation of test boards exposed at 1737 meters in the Tongue of the Ocean, Bahamas, by Xylophaga spp. Turner (1966b) reported that this attack was attributed to two new species which are now in the process of being described (Dr. R. D. Turner, personal communication).

It appears that $\underline{X}$. washingtona has basically a deep-water distribution, restricted to the northeastern Pacific. The upper bathymetric limits seem to lie in the surface waters in the northerly latitudes near Puget Sound, Washington, where the larvae are reported to be common in the near-surface waters and specimens occasionally occur in shallow-water test panels. Adequate field studies on this northern part of the distribution have not yet been made. Southward from these Puget Sound waters, the upper limits of bathymetric distribution for $\mathrm{X}$. washingtona are even more in question, for it has never been reported in test panels exposed in surface waters south of that area.

The data from dredge hauls taken by the ALBATROSS and the occurrence reported at 109 meters off southern California by Turner (1956), lead to speculation that the upper limit of distribution 

increases in depth at lower latitudes. This is a common trend in many intertidal to subtidal organisms (Ekman, 1953).

In our study, $X$. washingtona was not found on panels exposed at the three depths shallower than 200 meters. This, however, cannot imply an upper limit to the bathymetric distribution off Oregon since it is based on a set of single, short term samples and does not reflect year round settling possibilities. The absence of $\underline{X}$. washingtona and also of Bankia setacea from these panels exposed at depths above 200 meters will be discussed in detail later.

Bankia setacea, the teredinid borer, was present only in the panels recovered from the 200 -meter site. No specimens of this species were found on panels at the two deeper sites (500 and 1000 meters) or the three shallower sites (50, 100, and 150 meters). Bankia setacea is one of the major surface-water wood-boring molluscs along the northeastern Pacific coast from the Gulf of California northward to Adak, Alaska. This is documented in several papers (e.g., Hill and Kofoid, 1927; Fraser, 1923; Miller, 1951; and Quayle, 1956). These studies were by and large concerned with shallow water areas, especially with borer attack related to commercially important marine structures like piling. Depth dis tributions commonly reported for $\underline{B}$. setacea in these papers range from lower intertidal to 25 fathoms (46 meters) (e.g., Fraser, 1923) or 50 fathoms (91 meters) (Quayle, 1960). 

Turner (1966a), in a detailed discussion of the occurrence of members of the Teredinidae in deep water, stated that of all the teredinid-infested wood samples recovered from great depths, little conclusive evidence had been obtained to show that these organisms had entered the wood at such depths, although they appeared to be able to survive. However, Turner (1966a) did not include $\underline{B}$ setacea among those species that have been previously recorded from depths greater than 50 meters.

In a series of recent studies by Muraoka (1964, 1965, 1966a, 1966b, 1967), test materials exposed off southern California at depths of 2340 to 6800 feet (714 to 2074 meters) showed no attack by teredinid borers, but, as has been mentioned, strong attack by xylophagan borers. Bankia setacea, however, was common in the surface waters adjacent to his test sites (Graham and Miller, 1959). In studies carried out by DePalma (1963) in waters off Fort Lauderdale, Florida, Bankia carinata, a typical surface water teredinid in that area, settled and penetrated wooden test panels at a depth as great as 165 meters (Dr. R. D. Turner, personal communication). In this same study DePalma (1963) found an overlap in the bathymetric ranges between teredinid borers and the pholad borers of the genus Xylophaga. Turner (1966b), commenting on this overlap, noted that species of the deep-water oriented Xylophaga were common in boards exposed near the bottom at a 

depth of 90 meters. At shallower inshore stations, test panels near the bottom had fewer xylophagan specimens. The numbers observed decreased with decreasing exposure depth until, on the bottom boards at depths less than 30 meters, noxylophagan borers were found. The bathymetry versus degree-of-attack response observed in the teredinid borers during DePalma's (1963) sampling program was just the opposite; more teredinids were found on test panels exposed in shallow waters, and less on panels exposed at greater depths.

The data on $\underline{B}$. setacea reported in my study off Oregon, is probably the first known record for positive infestation of wood by a teredinid borer at a depth as great as 200 meters, (Dr. R. D. Turner, personal communication). An overlap between the teredinid and the xylophagan borer populations at a depth of 200 meters is also seen in my data. The conclusion that the teredinid borers are essentially a shallow-water population in these waters, in contrast to the species of Xylophaga which have a deeper bathymetric distribution, is supported by the absence of teredinid specimens from the sample materials exposed at the 500- and 1000-meter test sites.

Both the teredinid and the xylophagan borers are noticeably absent from the three sample sites at depths shallower than 200 meters. For the xylophagan borer, one may postulate that these depths were above the bathymetric range of the species. However, 
Fraser (1923), Bartsch (1921), and Miller (1951), all reported specimens of $X$. washingtona from depths well above 200 meters, which makes this line of reasoning somewhat untenable.

A second line of reasoning evolves a round the seasonal time difference between the samples taken at the 200-meter depth and the samples taken at the three shallower exposure sites. Sample panels were exposed at the 200-meter site during November-December 1966 and during January-February-March 1967, while the sample panels exposed at the shallower depths were installed and recovered during May 1967. The May sample period may have been out of phase with the breeding and the settling time of the xylophagan borer population, but to my knowledge there have been no life cycle studies on $X$. washingtona, so this must remain pure speculation.

Bankia setacea, as was previously mentioned, is the common boring mollusc in the adjacent surface waters. The absence of this species on test materials exposed at depths shallower than 200 meters, but its presence at the 200-meter depth, is indeed puzzling. Two areas of interest, the breeding cycle of $\underline{B}$. setacea and the oceanic circulation of the surrounding water, especially considering coastal upwelling, may be postulated as possible causes for the failure of $B$. setacea to settle on sample panels at the 50-, $100_{-}$, and $150-$ meter depths.

Kofoid and Miller (1927), in a study in San Francisco Bay, 

found breeding of $B$. setacea to begin in February, peak in April or May and cease by midsummer. Miller (1951) considered temperature to be the dominant factor controlling this breeding cycle, with spawning in San Francisco Bay triggered by water temperatures of 8 to $9 \mathrm{C}$ in February and terminated by summer water temperatures of 15 to $18 \mathrm{C}$.

At Friday Harbor, Washington, Johns on and Miller (1935) found the months of October, November, and December to be the peak spawning period, with a cessation of spawning in January or February and a spring flourish in April or May which continued sporadically throughout the summer. They regarded 8 to $9.5 \mathrm{C}$ to be the optimum water temperature range for spawning of $\underline{B}$. setacea, with 7 to $12 \mathrm{C}$ being the outside margin.

Neave (1943), in contrast to the conclusions of Miller and Johnson, found spawning specimens of $\underline{B}$. setacea throughout the year in British Columbia waters, with no correlation between peak spawning periods and water temperatures.

Although the literature appears to be somewhat contradictory as to the actual spawning pattern of this species, some trends can be seen. From the work of Johnson and Miller (1935), the breeding seasons of $\underline{B}$. setacea at Friday Harbor, Washington, has been plotted against water temperatures (W. H. O.I., 1952) in Figure 17. In the same manner, figures obtained on spawning in San Francisco 



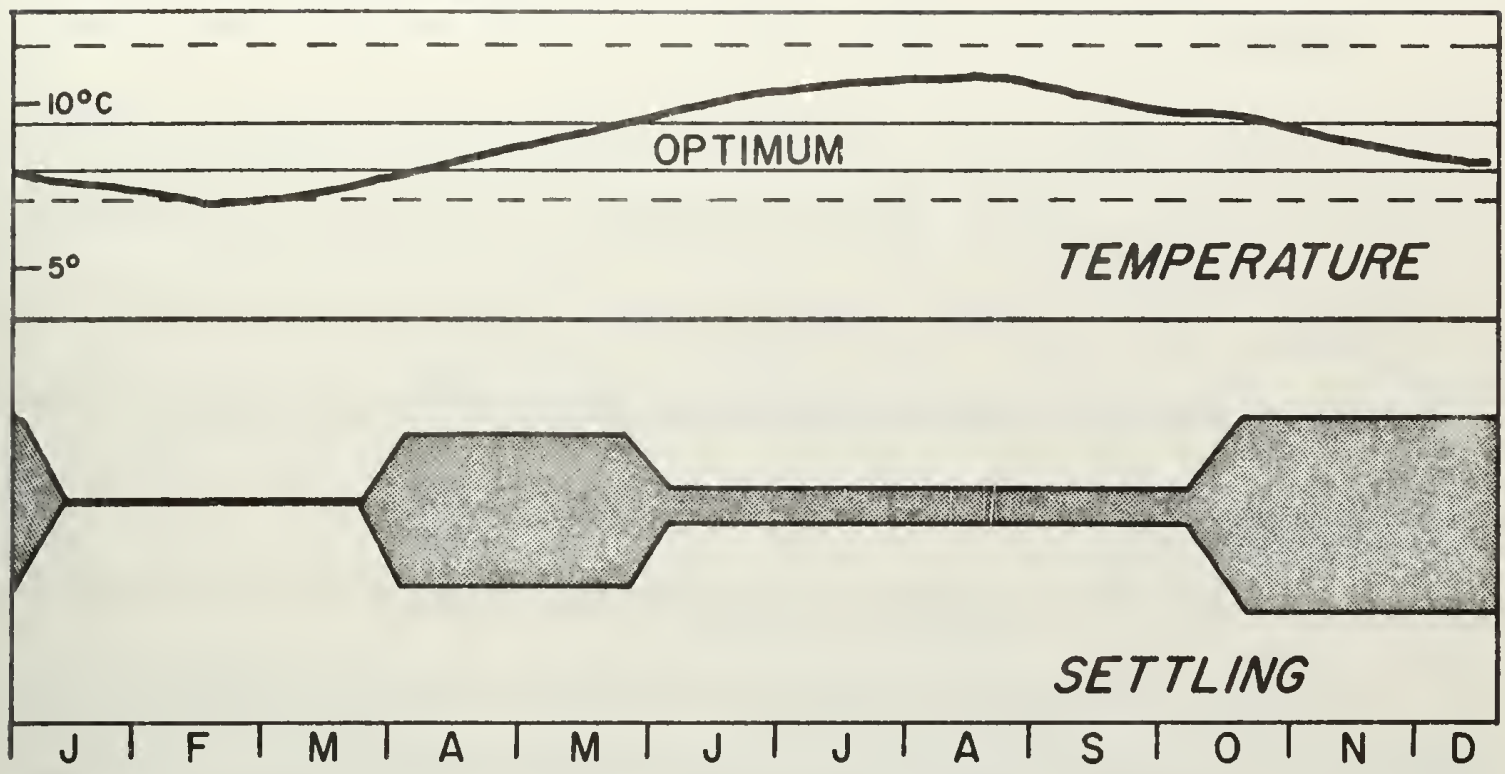

Figure 17. Settling of Bankia setacea in relation to water temperature. Optimum reproductive temperature range, and outside limits shown, after Miller, 1951.

\section{SAN FRANCISCO BAY}

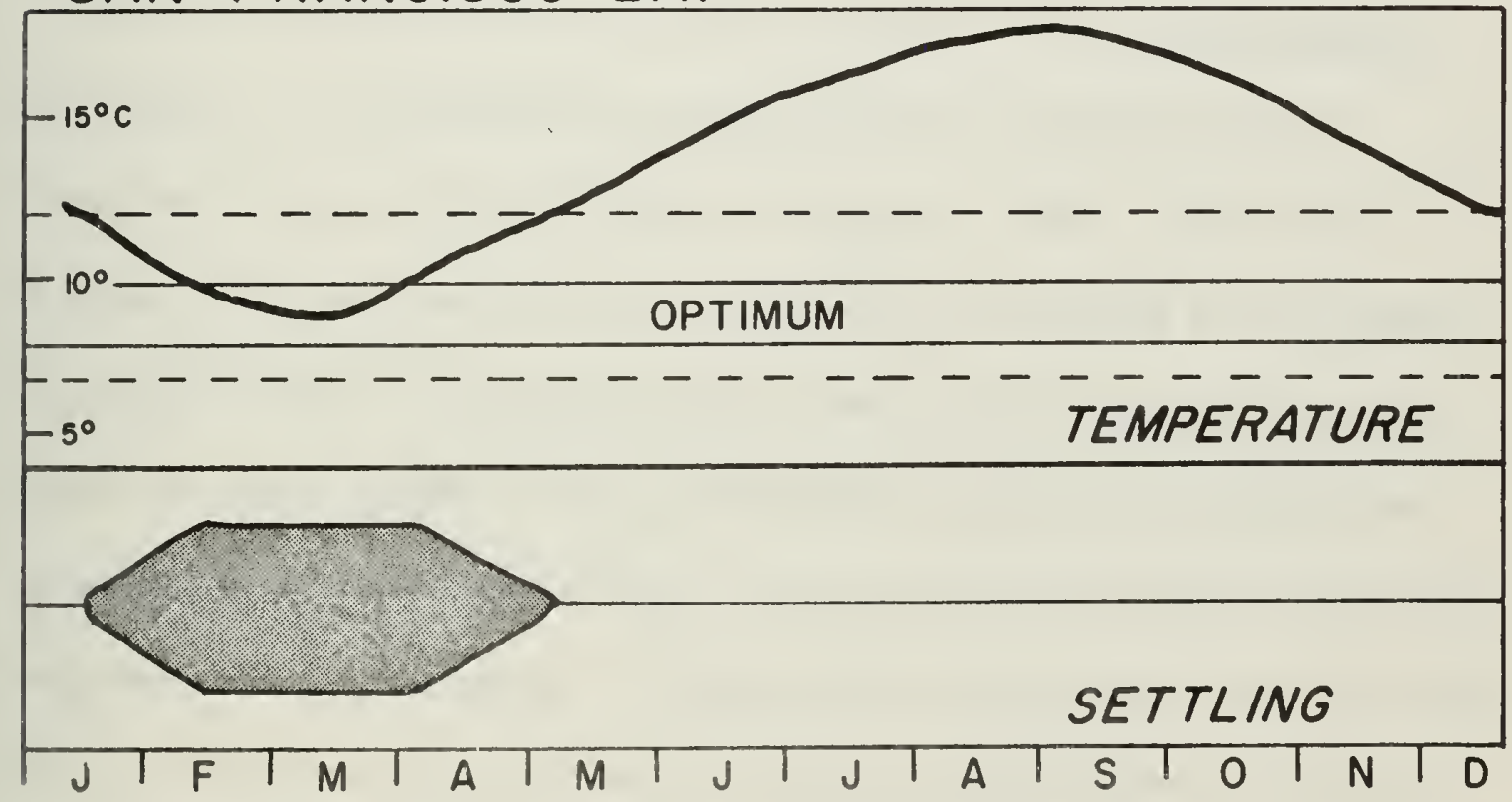

Figure 18. Settling of Bankia setacea in relation to water temperature. Optimum reproductive temperature range, and outside limits shown, after Miller, 1951. 
Bay, California, by Kofoid and Miller (1927) have been plotted against water temperatures in Figure 18. If one calls 8 to $9.5 \mathrm{C}$ an optimal temperature [solid line] for $\underline{B}$. setacea, with 7 to $12 \mathrm{C}$ as outside limits [ dashed line] (following Miller, 1951), a logical and workable concept can be presented in which seasonal fluctuation in surface water temperature in the controlling mechanism which triggers and terminates spawning in $\underline{B}$. setacea. We must also allow for possible ecotypic variation in optimum temperature response between populations as widely separated as San Francisco Bay, California, and Friday Harbor, Washington.

Using the concept mentioned above, a speculative model may be built to understand the possible breeding pattern of $\underline{B}$. setacea off Oregon. If one plots the monthly surface temperatures off Newport, Oregon, for 1967 (Barstow et al., 1968a, 1968b) and applies the temperature limits suggested for spawning in $\underline{B}$. setacea by Miller (1951), a late fall through winter period of peak spawning appears logical (Figure 19). The months of April, May, June, and also September through October seem to be times of logical spawning minimums. In this light, our May sample period, when test materials were exposed at the three shallow depths, may well have coincided with a period of minimum spawning activity by $\underline{B}$. setacea in these waters. On the other hand, the period between November and March, when sample materials were exposed at the 200 -meter site, 



\section{NEWPORT, OREGON}

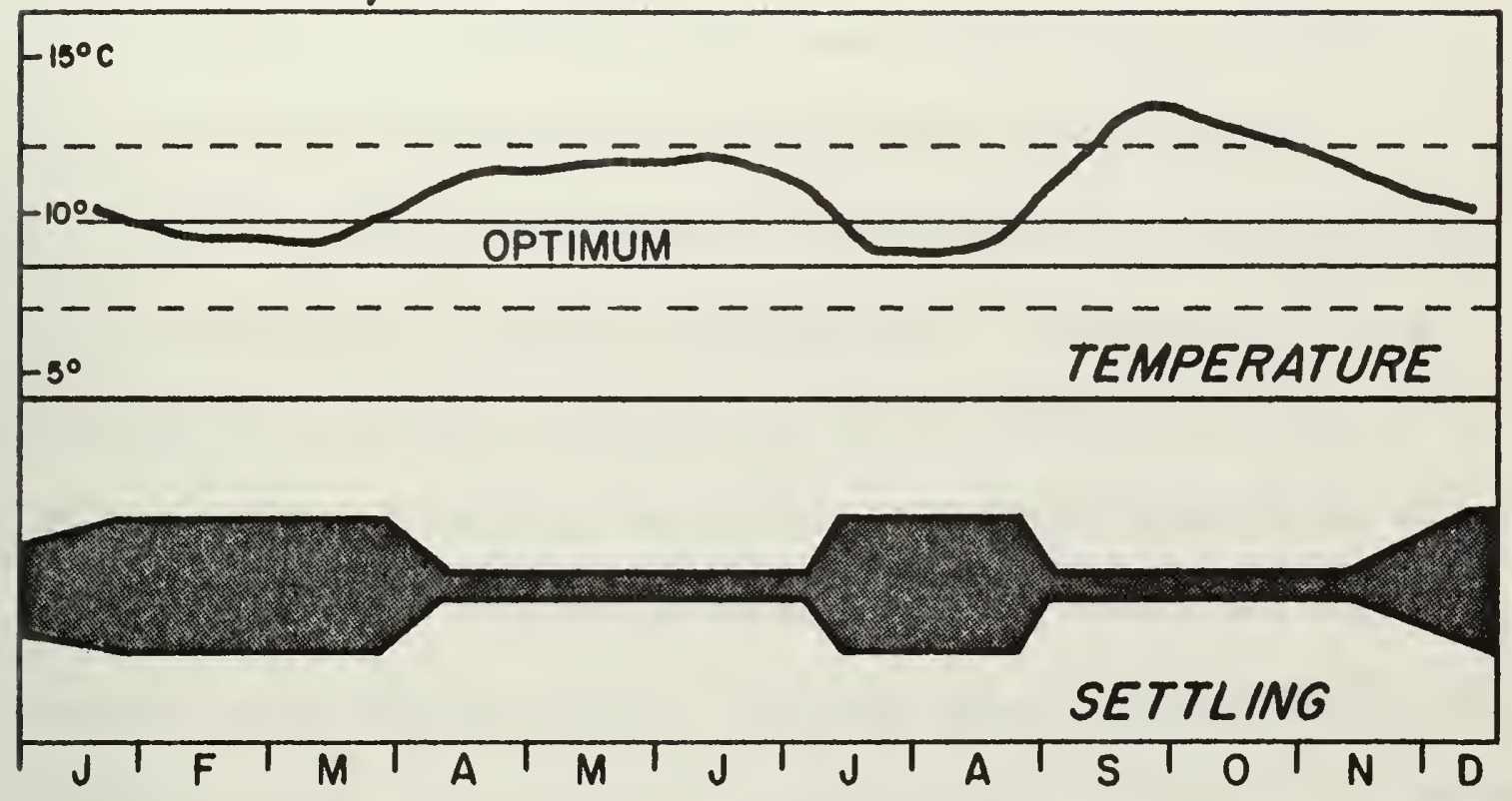

Figure 19. Model of proposed settlement of Bankia setacea in relation to temperatures observed off Newport, Oregon, and within the reproductive limits of Miller, 1951. 
could have fallen during a peak of breeding and settling activity in this species. This reasoning must of course remain speculative, since no actual proof derived from local shallow water sampling can be given to substantitate the breeding behavior of $\underline{B}$. setacea.

A second possible reason for the absence of the teredinid borer at the three inshore stations is the presence of strong seasonal upwelling which usually commences in this area during the month of May or June. Average wind speed and direction data, taken near the sampling site, show the presence of a fairly continuous northerly wind (average direction $343^{\circ} \mathrm{T}$., average speed 12 knots) during the first few weeks of the May-June sampling period. Such wind patterns have been shown to produce significant coastal upwelling in the se waters. Associated with such an upwelling phenomenon is the transport of surface water offshore (Smith, Pattullo and Lane, 1966). Quayle (1953), in a discussion of the planktotropic la rva of $\underline{B}$. setacea, states that duration of the free-swimming period of the larva is about four weeks. The effect of offshore transport of $\underline{B}$. setacea larva during periods of well-developed coastal upwelling may be to carry the larva out to, or perhaps beyond, the test sites in question before they mature and begin to settle out of the water column.

It must be re-emphasized, however, that these discussions on breeding cycles and local circulation a re only speculative in nature. More study is certainly needed at these shallow inshore sites, 

especially a long term series of test exposures which cover a full yearly period, before meaningful conclusions can be drawn. Other factors, such as disturbance of the sample arrays or the short duration of exposure (28 days), could be major or contributing factors in the negative results observed at these three inshore sites. 

ATTACK BY THE PHOLAD BORER XYLOPHAGA

Xylophaga washingtona was the overwhelmingly dominant borer observed in this study. Many interesting trends, such as variation of surface attack per unit a rea with both length and depth of exposure, were seen on the sample boards. In order to present these trends in a logical manner, each wood type will be discussed in turn.

\section{Attack on Pine Sample Panels}

Pine test panels have been quite commonly used in studies of marine borer populations, hence will be our starting point and the focus of discussion. Borer attack on other types of wood panels will then be related to the trends observed on pine.

Variation of Surface Attack with Length of Exposure

The number of xylophagan borers penetrating the surface of pine increased with increasing length of exposure. This was true for all sites where borers were present. Figure 20 clearly demonstrates this trend on a series of pine test panels exposed for 38,50 , and 72 days at 200 meters. Note that in the panel exposed 72 days (Figure 20d), parts of the surface are entirely destroyed. This panel is spongy to the touch. It has an average of 255 xylophagan borer 


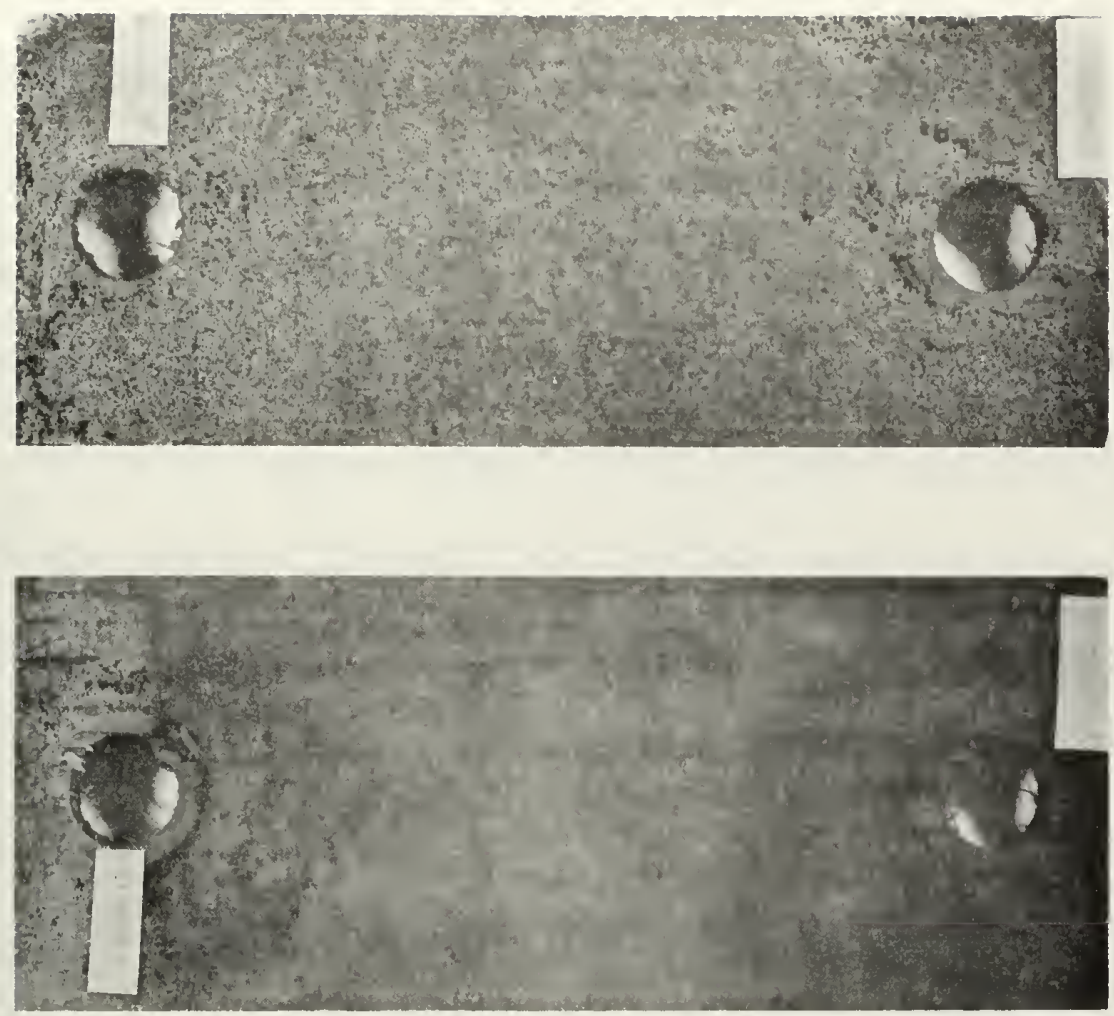

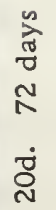

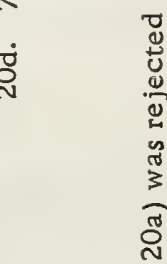

iั

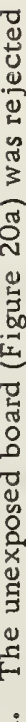

๕̊

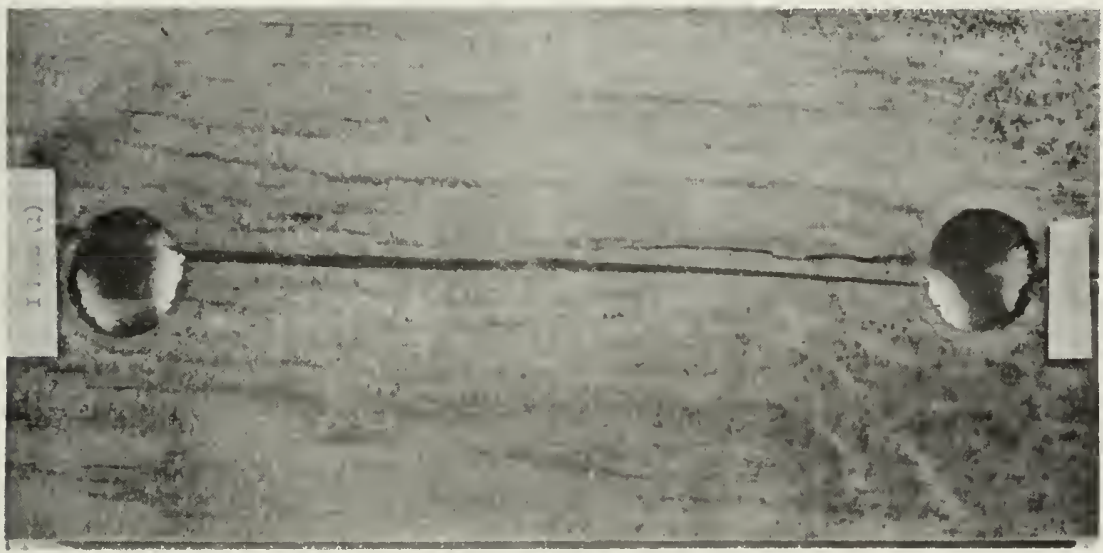

(

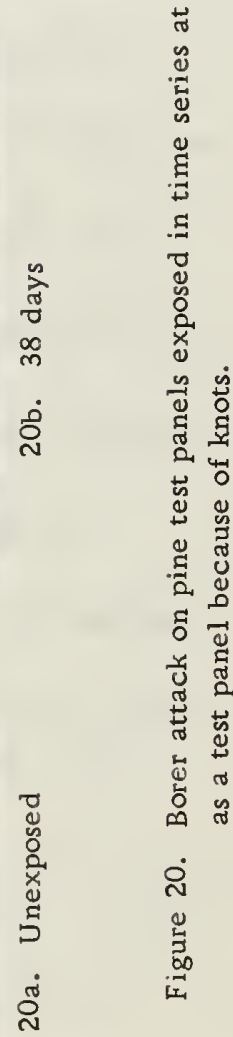


penetrations per square centimeter of surface area. Figures 21, 22, and 23 compare the results obtained with varying the exposure interval at three different depths. Note that increasing exposure time correlates nicely in all cases with increasing attack on the pine.

At the 200-meter depth, the curve generated by the data from these pine panels (Figure 21) is sigmoid, which suggests slow initial settling followed by a rapid increase in attack. This level of attack then tapers off to a plateau, as structural destruction of the substrate board becomes very high.

By way of discussion of these data, one cannot say that the increase in numbers with time was surprising. What is significant is the rate at which the larvae settled. Muraoka (1964), reporting $\underline{X}$. washingtona attack on pine panels exposed at 5640 feet (1880 meters) found an average of only 25 borers per in ${ }^{2}\left(4\right.$ per $\left.\mathrm{cm}^{2}\right)$ after four months exposure, while pine panels exposed in my study for 60 days at 1000 meters averaged 105 borers per $\mathrm{cm}^{2}$. The environment sampled off Oregon was almost identical with that sampled by Muraoka. His panels were exposed, however, some 6 to 12 inches (15 to $31 \mathrm{~cm}$ ) above the sediment. Panels exposed in my study were in contact with the sediment along at least one margin.

My data from 200 and 500 meters, are to the best of my knowledge, the first test-panel borer samples from this depth range. They fill gaps in our knowledge of xylophagan borers at these depths. 



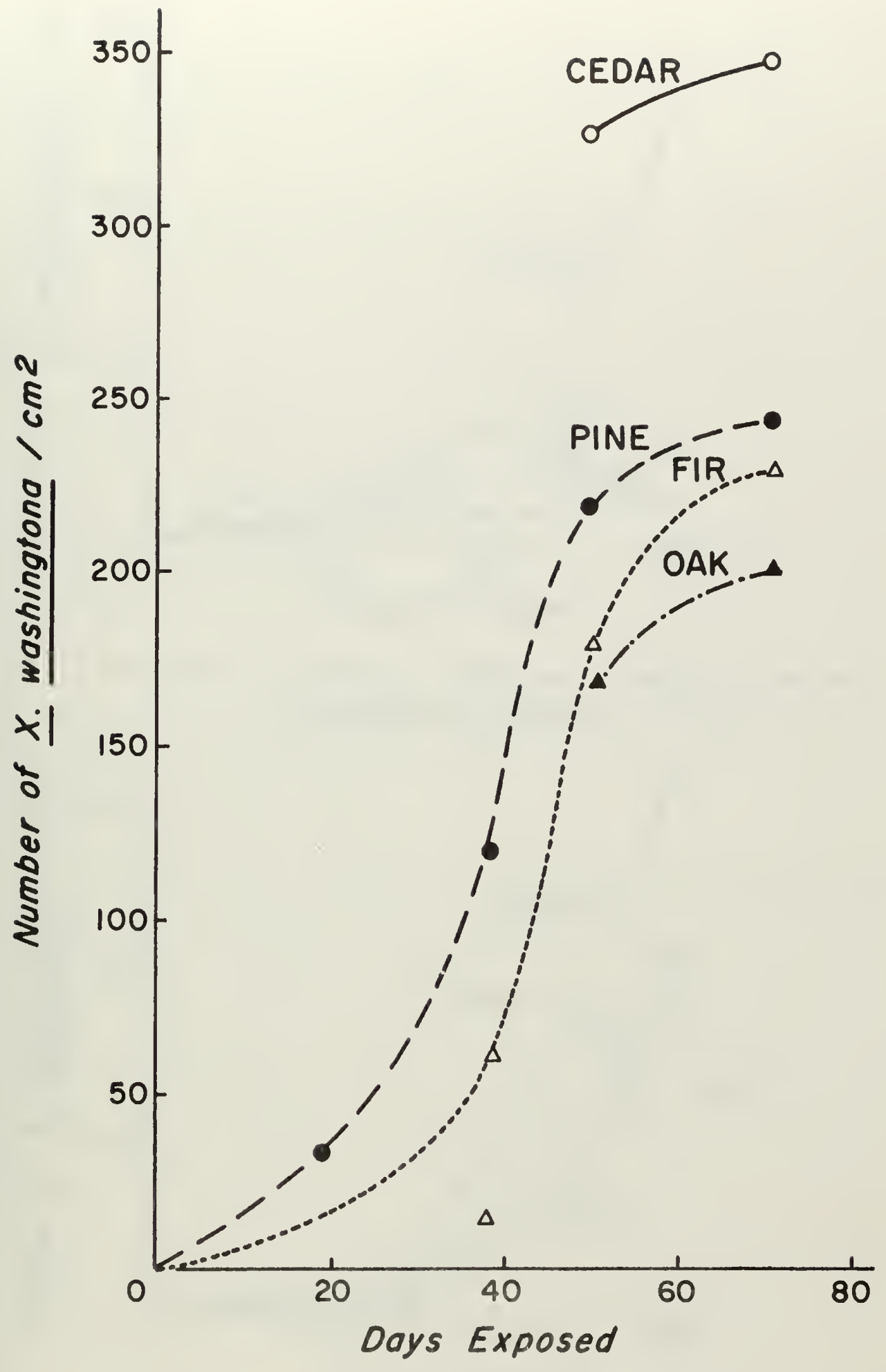

Figure 21. Temporal variation in surface attack of Xylophaga washingtona at $200 \mathrm{~m}$. 



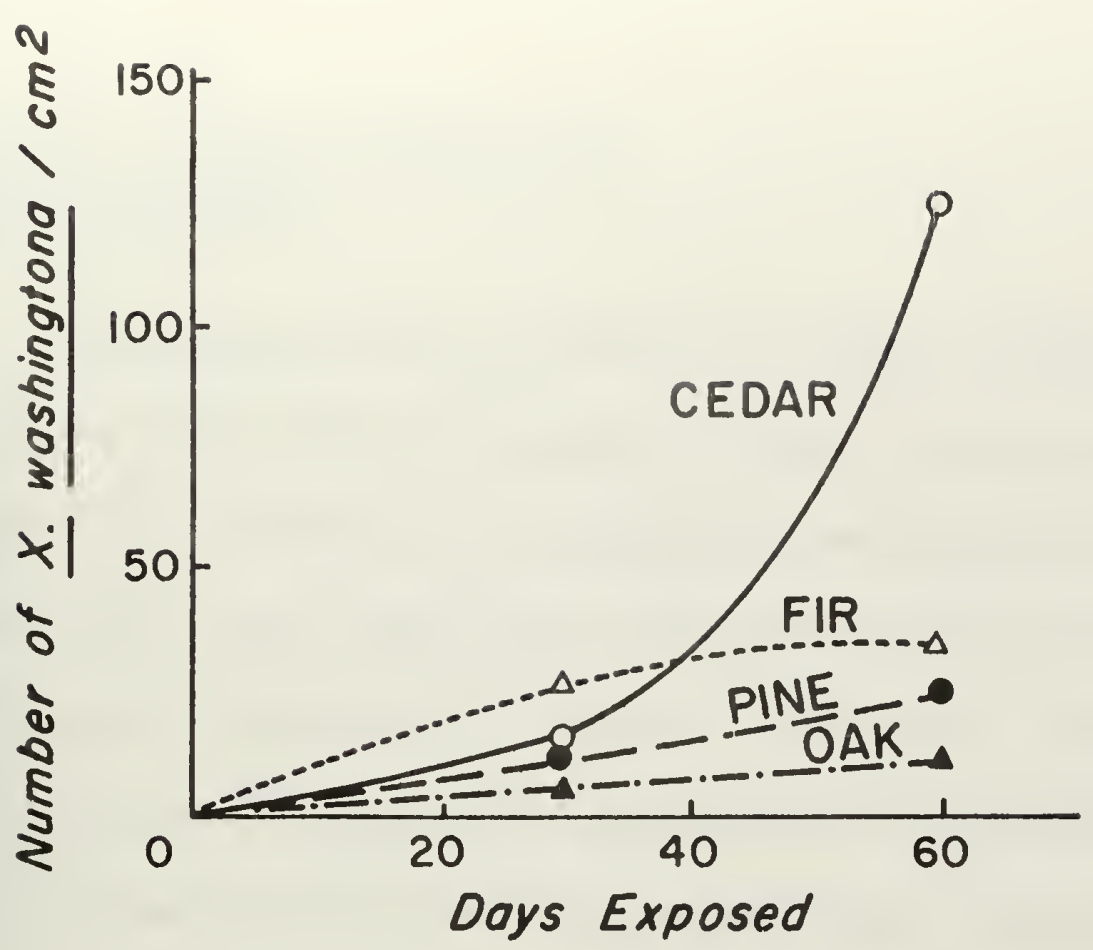

Figure 22. Temporal variation in surface attack of Xylophaga washingtona at $500 \mathrm{~m}$.

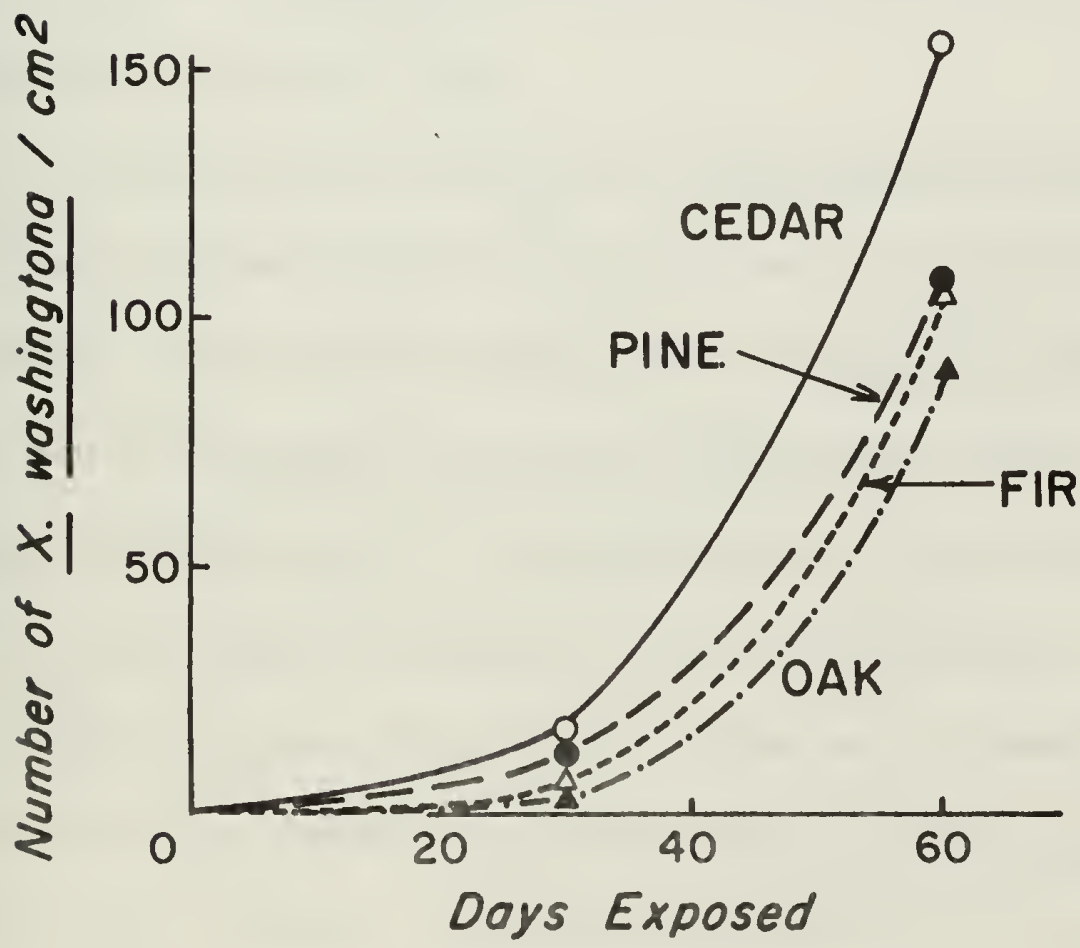

Figure 23. Temporal variation in surface attack of Xylophaga washingtona at $1000 \mathrm{~m}$. 

Variation of Surface Attack with

Depth of Exposure

Considering a time of exposure of roughly 30 days, the attack on pine sample panels decreased in intensity with increasing depth (Figure 24). At 200 meters xylophagan borer penetrations numbered 119 per $\mathrm{cm}^{2}$, while at 500 meters penetration density had dropped to 12 per $\mathrm{cm}^{2}$. Attack was very light at 1000 meters, being only four borers per $\mathrm{cm}^{2}$. Specimens recovered from 200 meters were in a more advanced stage of development than those recovered from deeper sites. The latter had not penetrated far into the panels and still showed the characteristic golden-brown protodissoconch shell mentioned by Turner (1956).

For 60-day tests, the trend of decreasing numbers with increasing depth still holds true for the 200 -meter site when it is compared to the two deeper stations (Figure 25), but apparent difficulty arises with direct comparison between the 500-and the 1000-meter locations. At 500 meters the average number of borer penetrations per $\mathrm{cm}^{2}$ on pine panels is much lower than at 1000 meters.

These results are perplexing. The rates of attack were studied in light of all available environmental data including temperature, salinity, $\mathrm{pH}$, nutrient, and sediment gradients, but no tenable hypothesis could be found which would account for the observed 


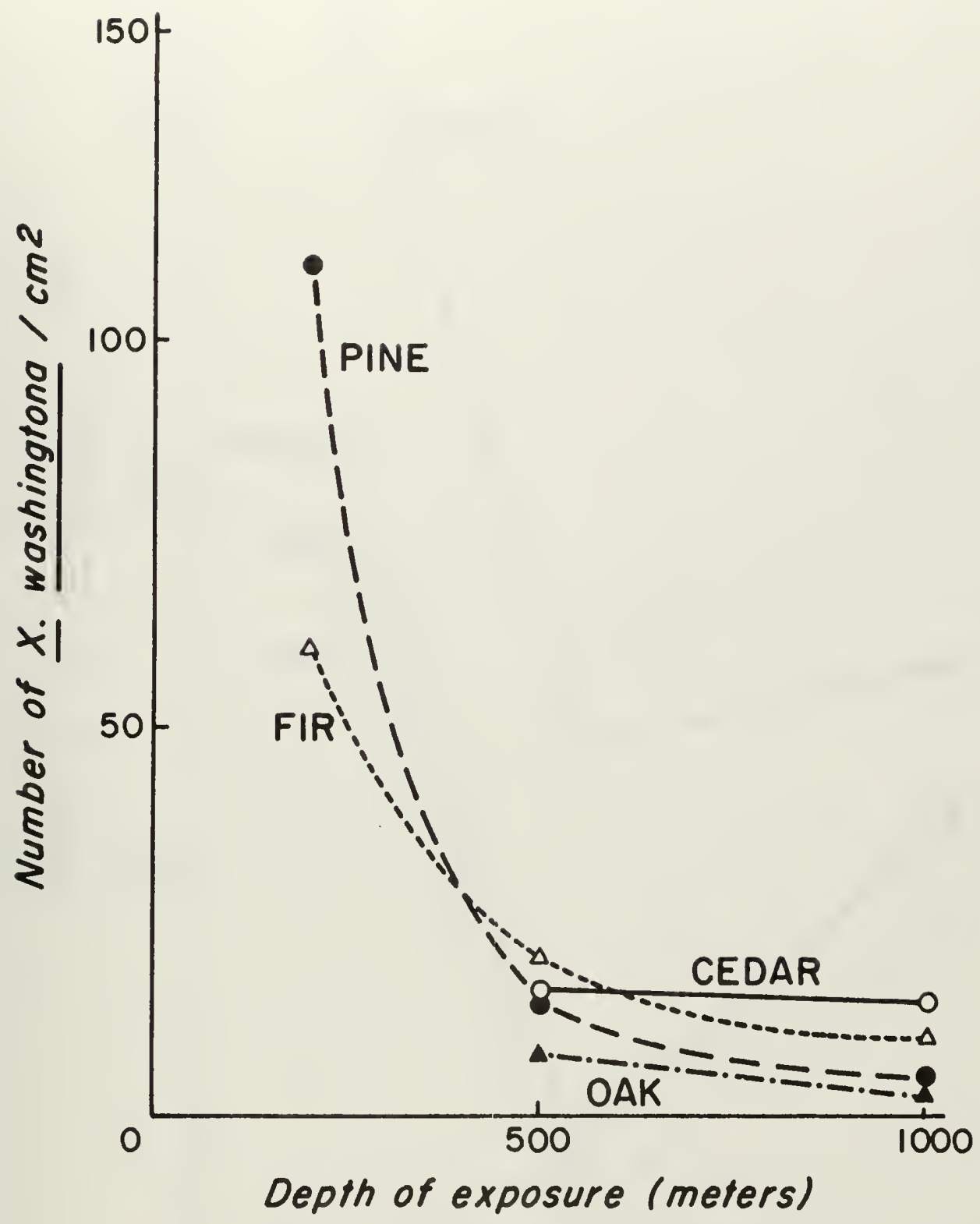

Figure 24. Variation in Xylophaga washingtona surface attack with depth of exposure at 30 days. 



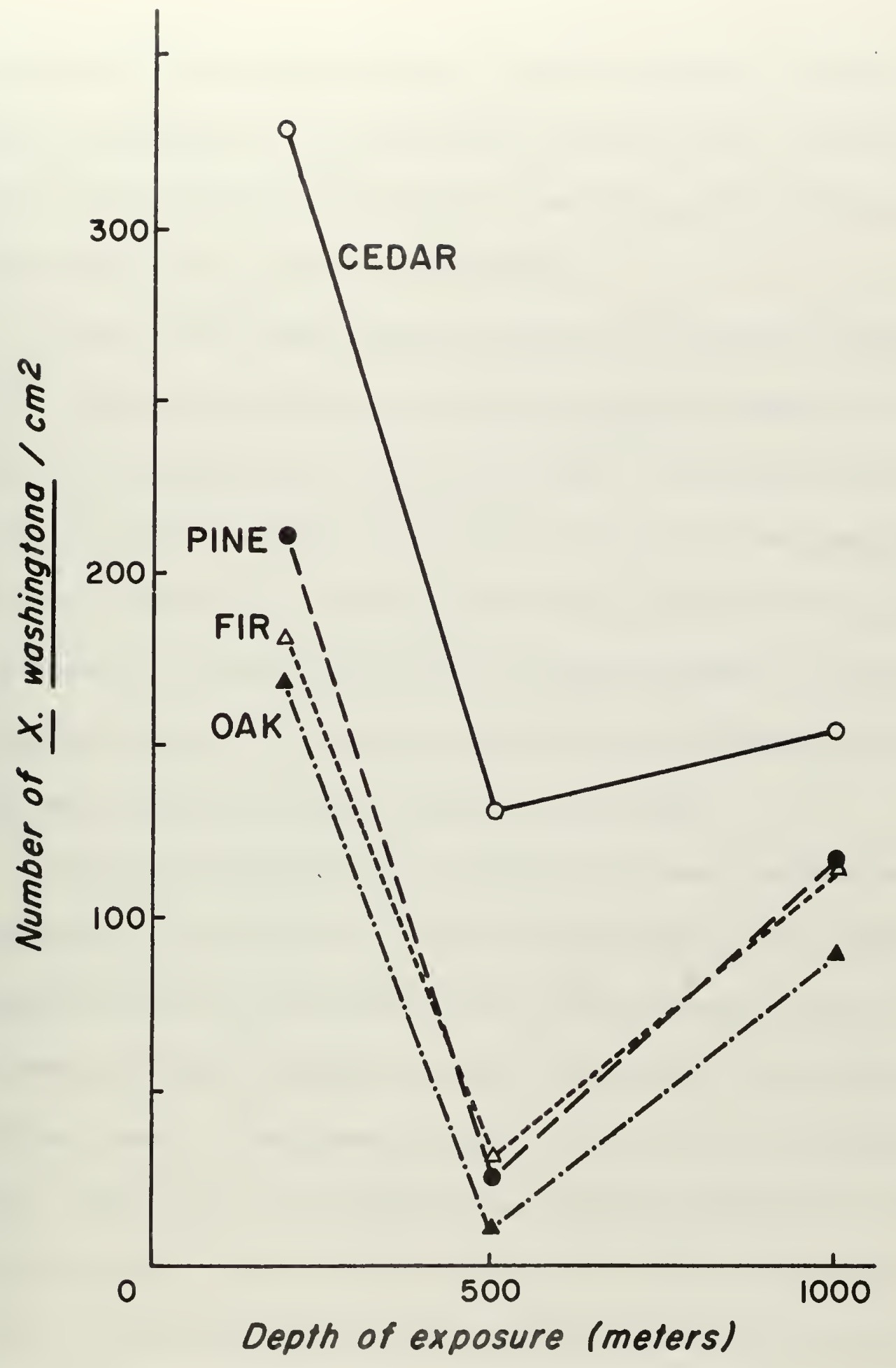



distribution with depth at 60 days. Since this study is, in fact, an initial investigation on borers in these Oregon waters, we do not really know if the 500-meter data are low values, the 1000-meter data, high values, or if both are correct.

From a six month exposure at 2340 feet (714 meters) Muraoka (1965) reported concentrations of X. washingtona in pine on the order of 25 to 200 borers per in ${ }^{2}$ ( 4 to 32 per $\mathrm{cm}^{2}$ ). Muraoka's study was made off southern California in water of comparable temperature. His data would seem to indicate that for an exposure of 60 days at 1000 meters, the data reported in my study seem high. As has been mentioned however, his sample panels were located farther above the sediment interface than those exposed in my study.

Although comparison with available environmental data has not provided any explanation, Dr. Kilho Park (personal communication) suggested that during the sample interval (May through July 1967) seasonal upwelling may have caused an upward shift in the oxygen minimum zone; its maximum normally occurs at about 800 meters (Park, 1967). The borer activity observed in the 500-meter sample might then have been associated with an area of low oxygen concentration. Stefansson and Richards (1964) reported oxygen distribution off the Columbia River, for the month of July, in which upward bending of oxygen isopleths was quite apparent. This all must remain speculation, for supporting hydrographic data were not available and 

furthermore, the effect of low oxygen concentration on the xylophagan borers is unknown.

The high number of borers present on the panels exposed at the 1000-meter depth shows an interesting parallel with data on nektonic and benthic population distributions in these waters. Pearcy (1964) reported higher catches of mesopelagic fish in the water column 40 to 45 miles ( 74 to 83 kilometers) offshore (over depths of about 1000 meters), than at sites closer inshore or farther off shore. Carey and Alspach (1966) presented data showing peaks in the number of benthic fauna at a depth of 1250 meters on the continental slope off Newport, Oregon. While data on phytoplankton productivity is not yet available for the overlying water in this area, it is possible to speculate that this location represents a biological "front" or ecotone, providing organisms with the benefits of both the neritic area to the east and the open oceanic province bordering on the west.

Dr. Roderick Mesecar (personal communication) noted the presence of an anomalous "hot spot" in the surface sediment at this 1000-meter location. One wonders what effect this might have on the borer population.

Finally, it must be stated that we know almost nothing about the life cycle of $X$. washingtona, the location of a reservoir population, or the survival needs of the larval stages. Possible differences in the relative availability of the borers at the different sites could 

well account for the observed distribution.

There is as yet no logical explanation for the observed variation of borer attack on pine with depth. Additional testing is needed, especially with replicate panel exposures north and south along equal depth contours to see if these trends persist along the coast, or a re repeatable at later times.

Distribution of Surface Attack with Increasing Distance from the Sediment

One of the most consistent trends observed during this study was the decrease in the number of borer surface penetrations per unit area with increasing distance above the seawater-sediment interface. Where xylophagan borers were present, this trend was strongly developed on pine sample panels at all depths and exposure times.

Figures 26 and 27 illustrate this trend on pine panels exposed for 30 days at 500 and 1000 meters. Figure 28 is a photograph of the panel exposed at 1000 meters. These panels were oriented with the grain perpendicular to the sediment surface. The darkly discolored area on the lower margin of the panels was caused by the sediment. Those sections of the panels which were buried during exposure showed no borer attack.

Pine panels exposed for 60 days at 500 meters (Figures 29 and 30) and at 1000 meters (Figures 31 and 32), also exhibited this same 



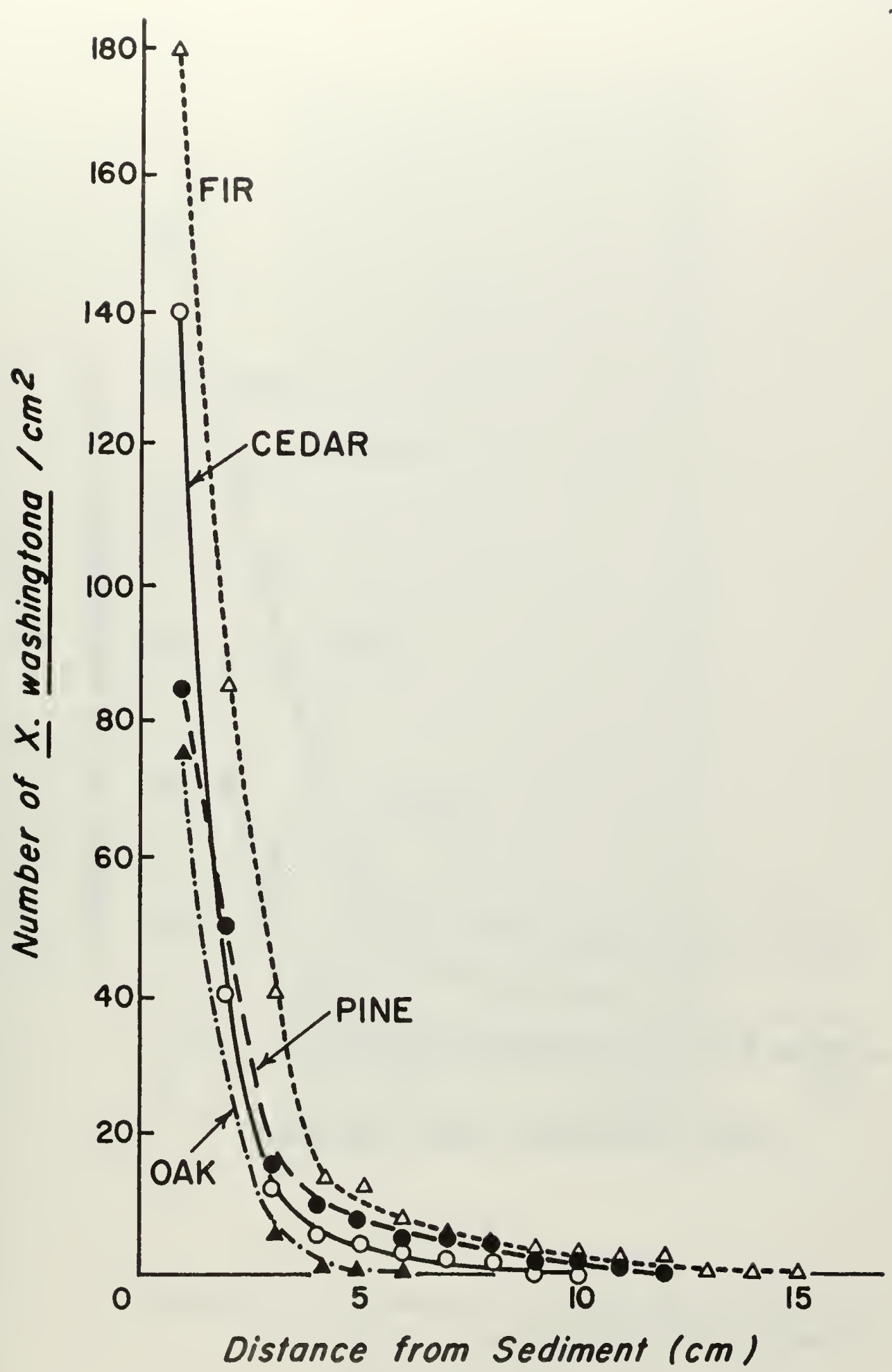

Figure 26. Relationship of Xylophaga washingtona attack to distance from the sediment; panels exposed 30 days at $500 \mathrm{~m}$. 



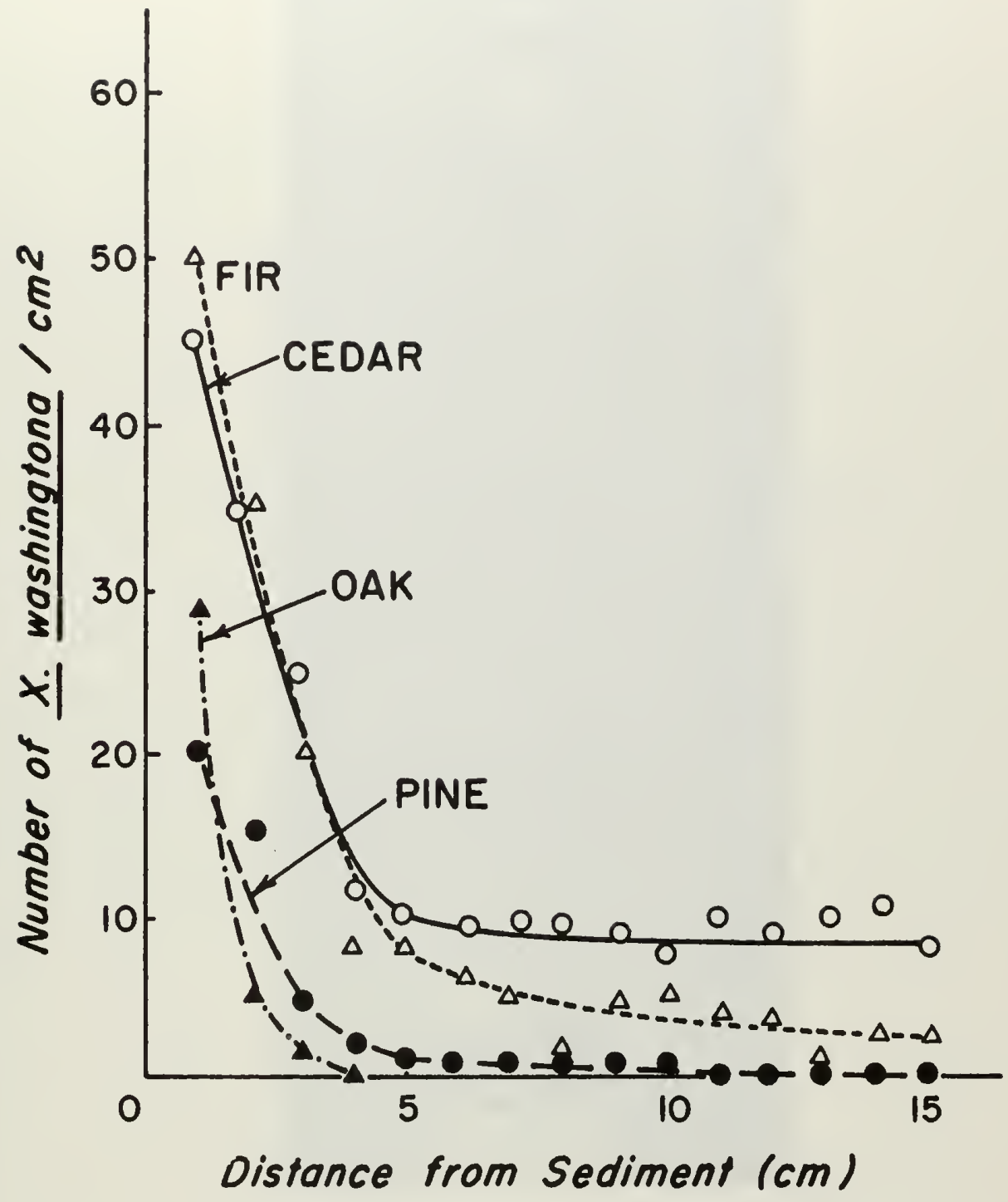

Figure 27. Relationship of Xylophaga washingtona panels exposed 30 days at $1000 \mathrm{~m}$. 



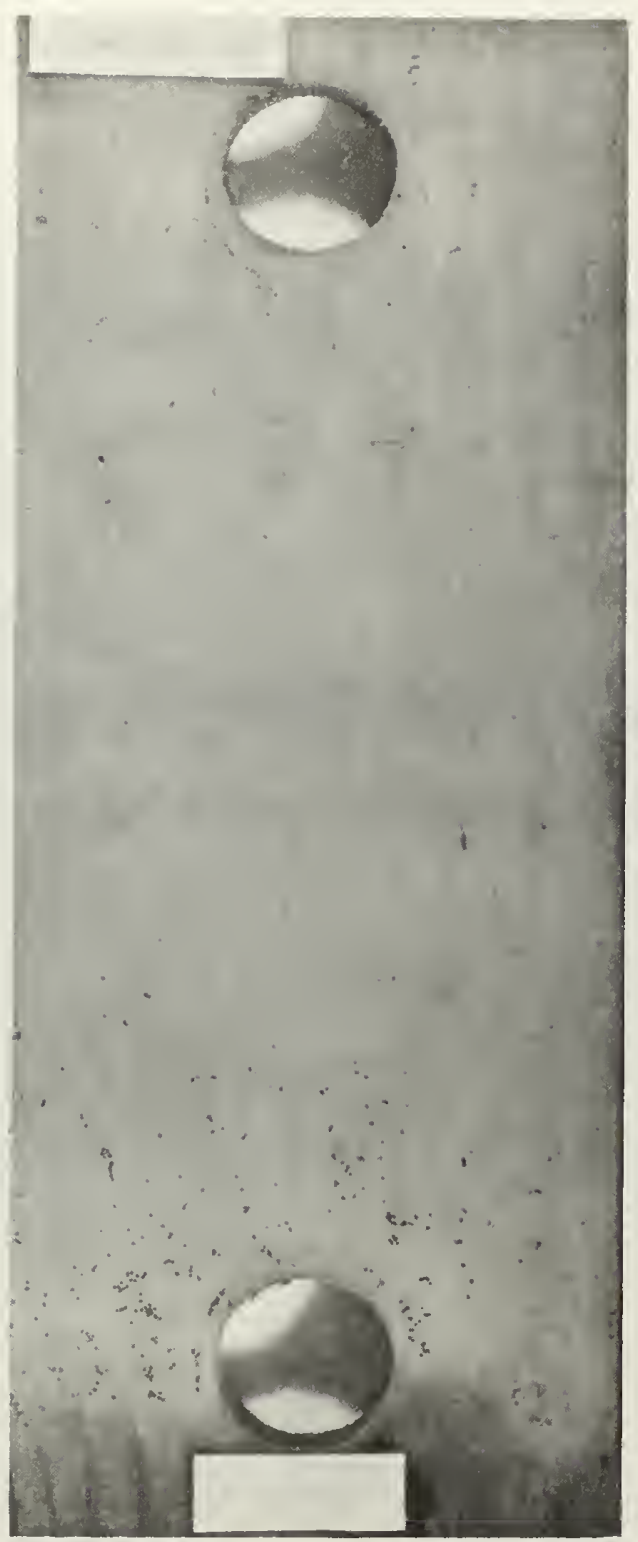

Figure 28. Pine panel exposed 30 days at 1000 meters (.66X). 



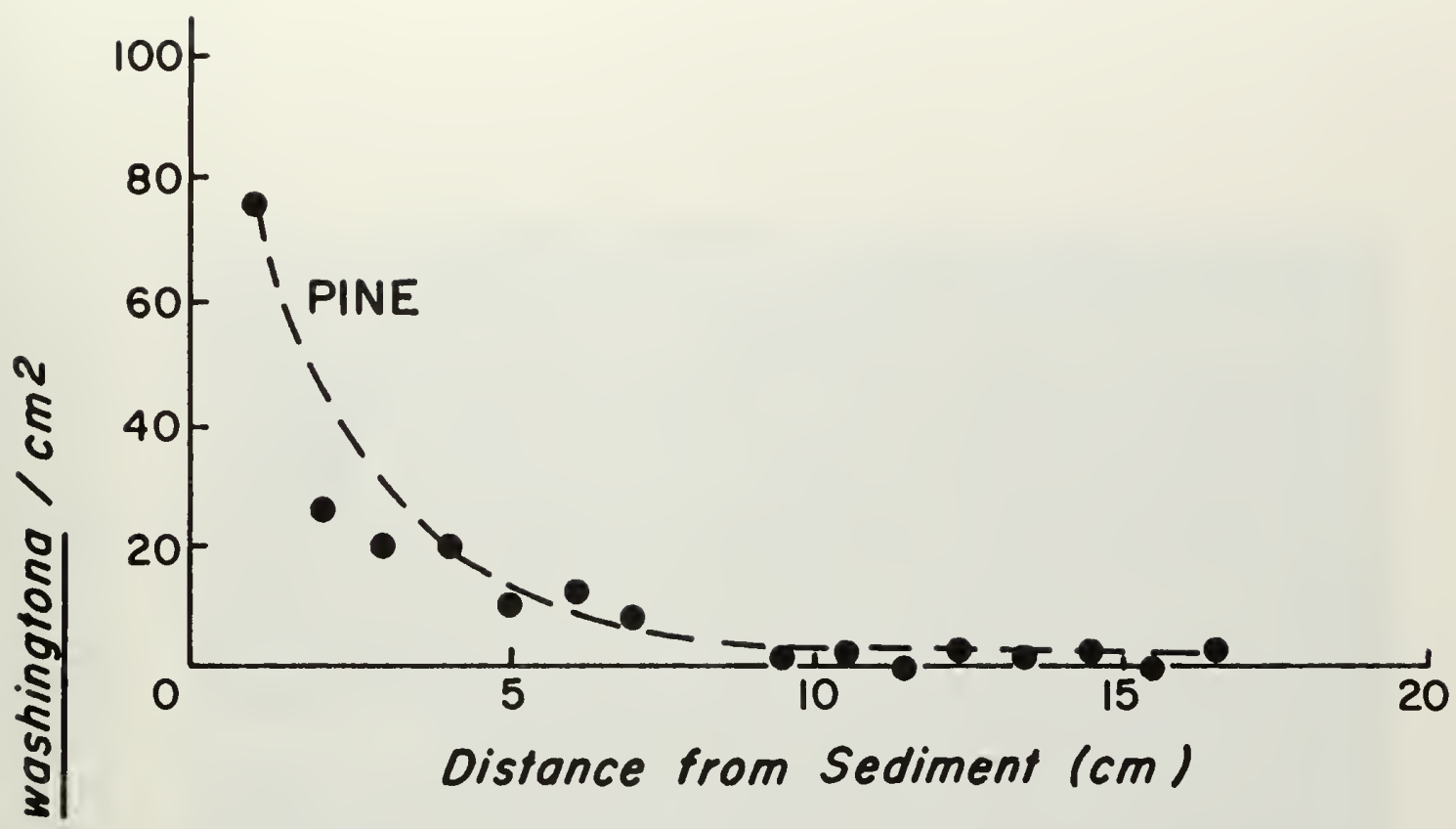

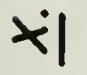

-1
$\vdots$
$\vdots$
8
8

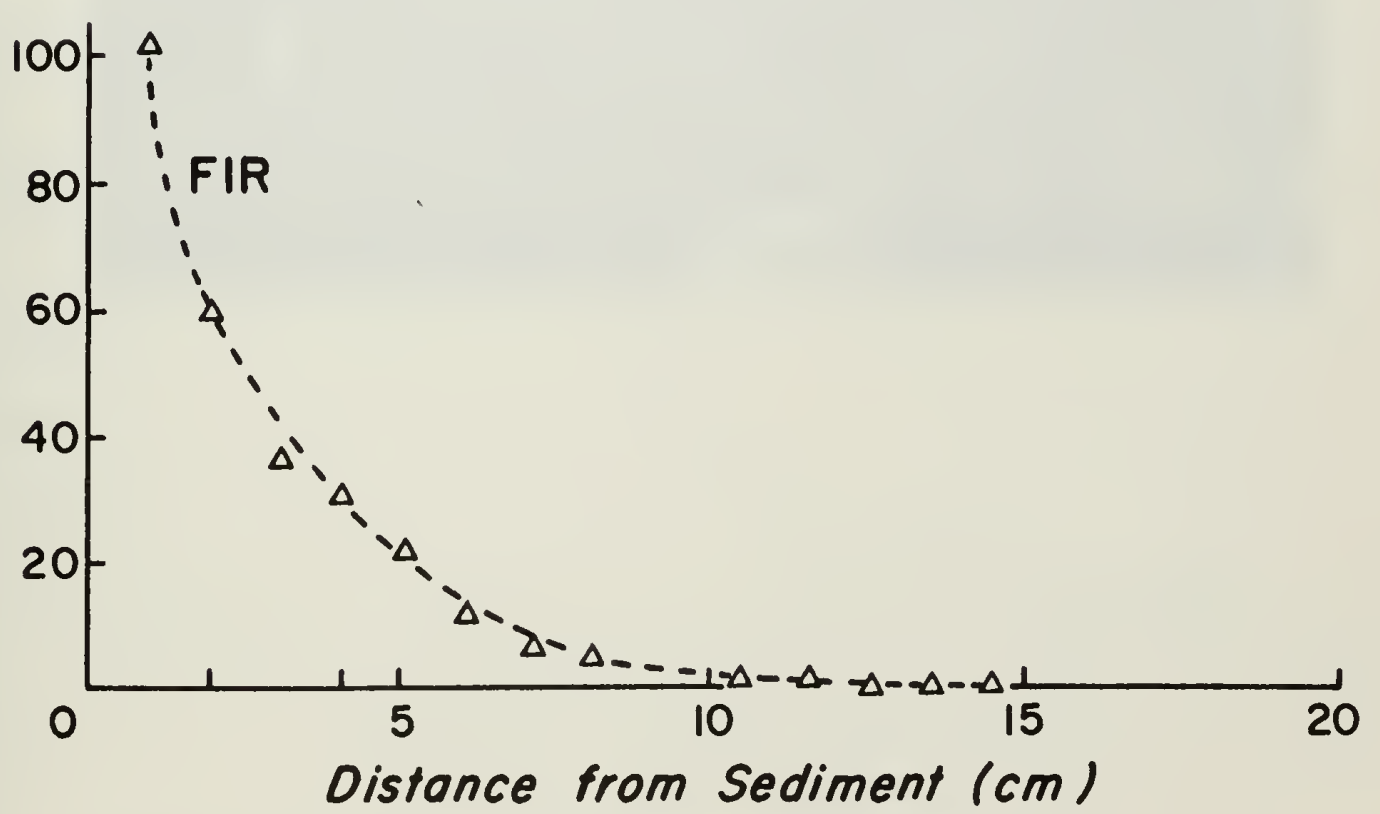

Figure 29. Relationship of Xylophaga washingtona attack to distance from the sediment; panels exposed 60 days at $500 \mathrm{~m}$. 


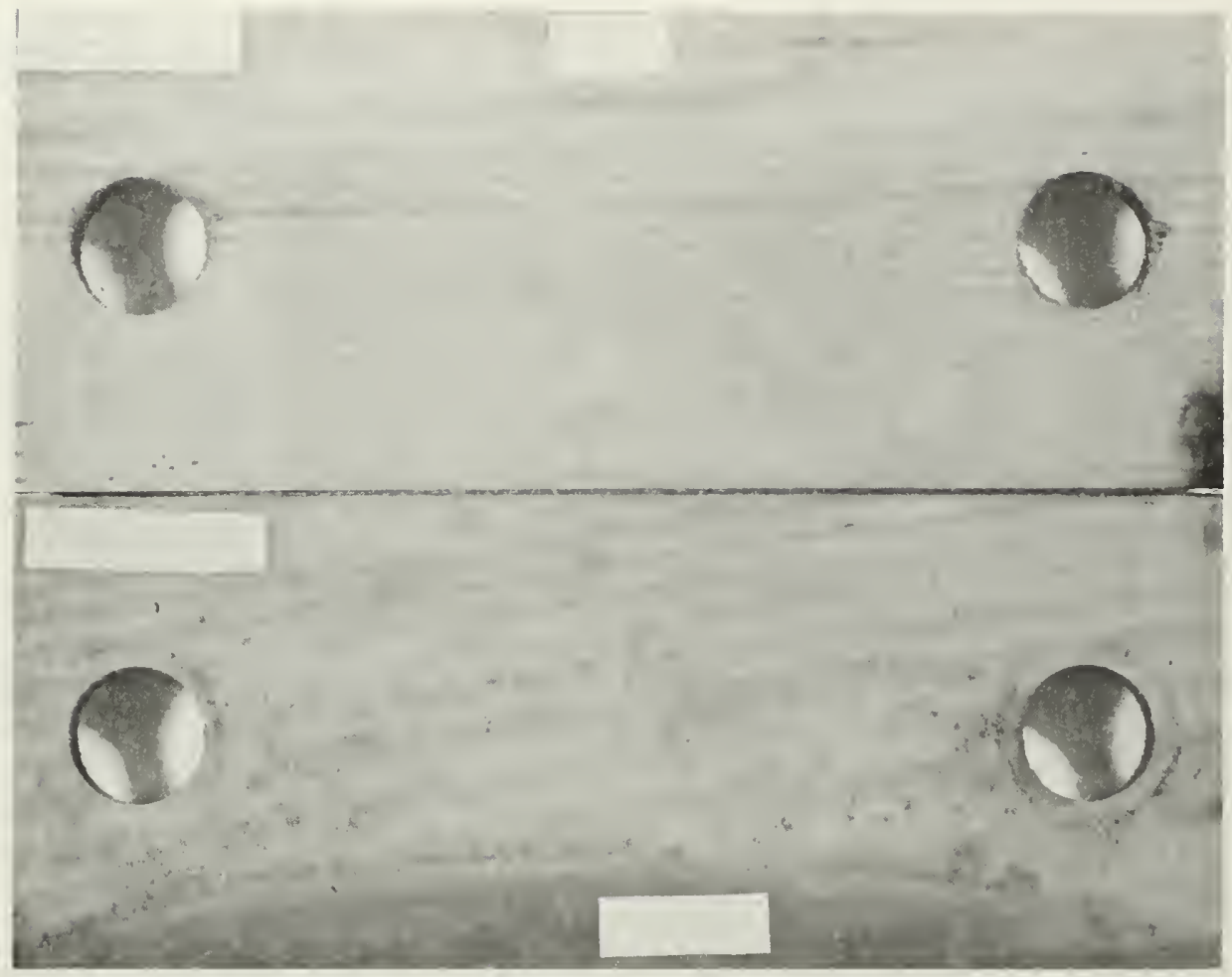

Figure 30. Pine panels exposed 60 days at $500 \mathrm{~m}$. (1/2X). 



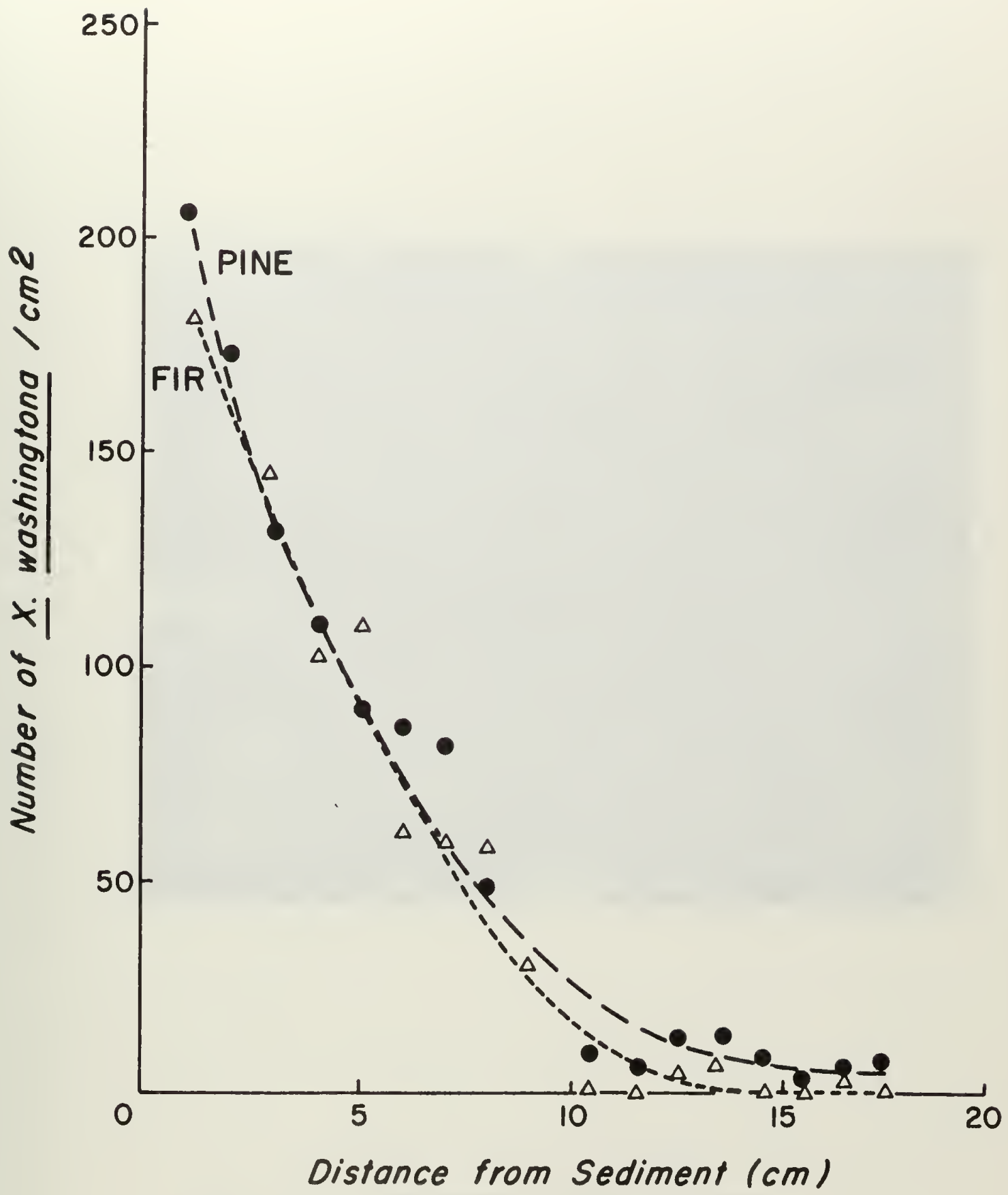

Figure 31. Relationship of Xylophaga washingtona attack to distance from the sediment; panels exposed 60 days at $1000 \mathrm{~m}$. 



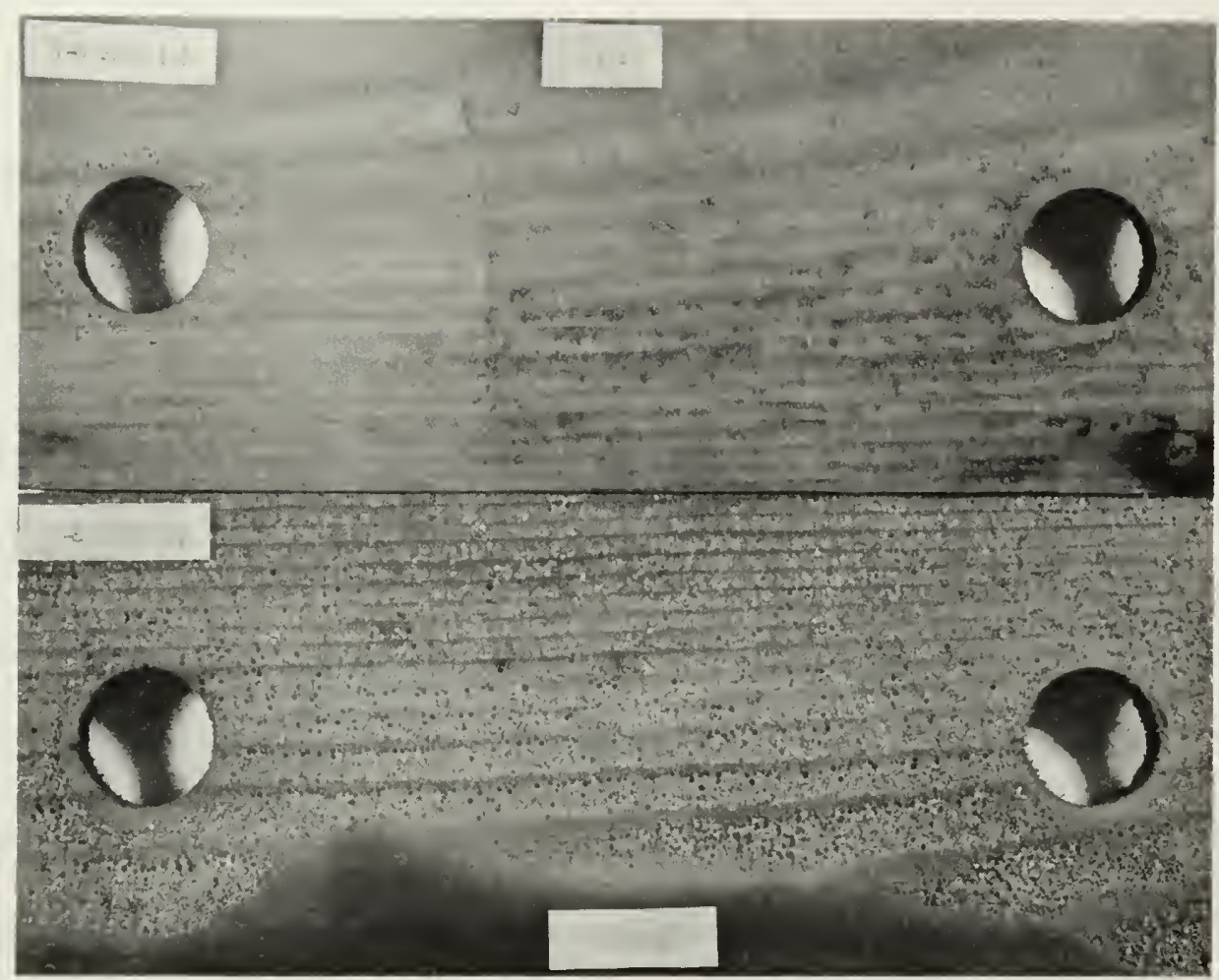

Figure 32. Pine panels exposed 60 days at $1000 \mathrm{~m}$. (1/2X) 

pattern. Note in the photographs that these panels were lying with the grain running parallel to the sediment, and that again a definite sediment discoloration mark can be seen, below which no borer penetrations were observed.

The drop in borer penetrations with increasing distance from the sediment usually occurs within the first six centimeters upward from the interface.

Sometimes an accident or an unexpected event in a sampling program can provide unanticipated information. One sample (Sample III), exposed 72 days at 200 meters, proved a bit puzzling upon first examination. Pine panels from one end of the sample array exhibited a uniform borer attack gradient away from the sediment line on the lower panel. 'This gradient continued smoothly across the upper panel (Figure 33). The lower panel had a very clear cut sediment stain. A duplicate pair of pine panels from the opposite end of the sample rack showed a strange gradient of borer attack. The lower panel had a low density of attack and did not match up with the gradient on the adjacent upper panel (Figure 34). The lower panel in this case was entirely stained by sediment, but borers in the panel were in excellent condition, showing no signs of deterioration from being sediment covered. To explain what had happened in this instance, the entire sample panel array was diagrammed as shown in Figure 35, and the position of the sediment line on every 

83 
Figure 33. Uniform gradient of Xylophaga washingtona attack across adjacent pine panels exposed 72 days at $200 \mathrm{~m}$. Position I in Figure 35.

Figure 34. Split gradient of Xylophaga washingtona attack across adjacent pine panels exposed 72 days at $200 \mathrm{~m}$. Position II in Figure 35. 

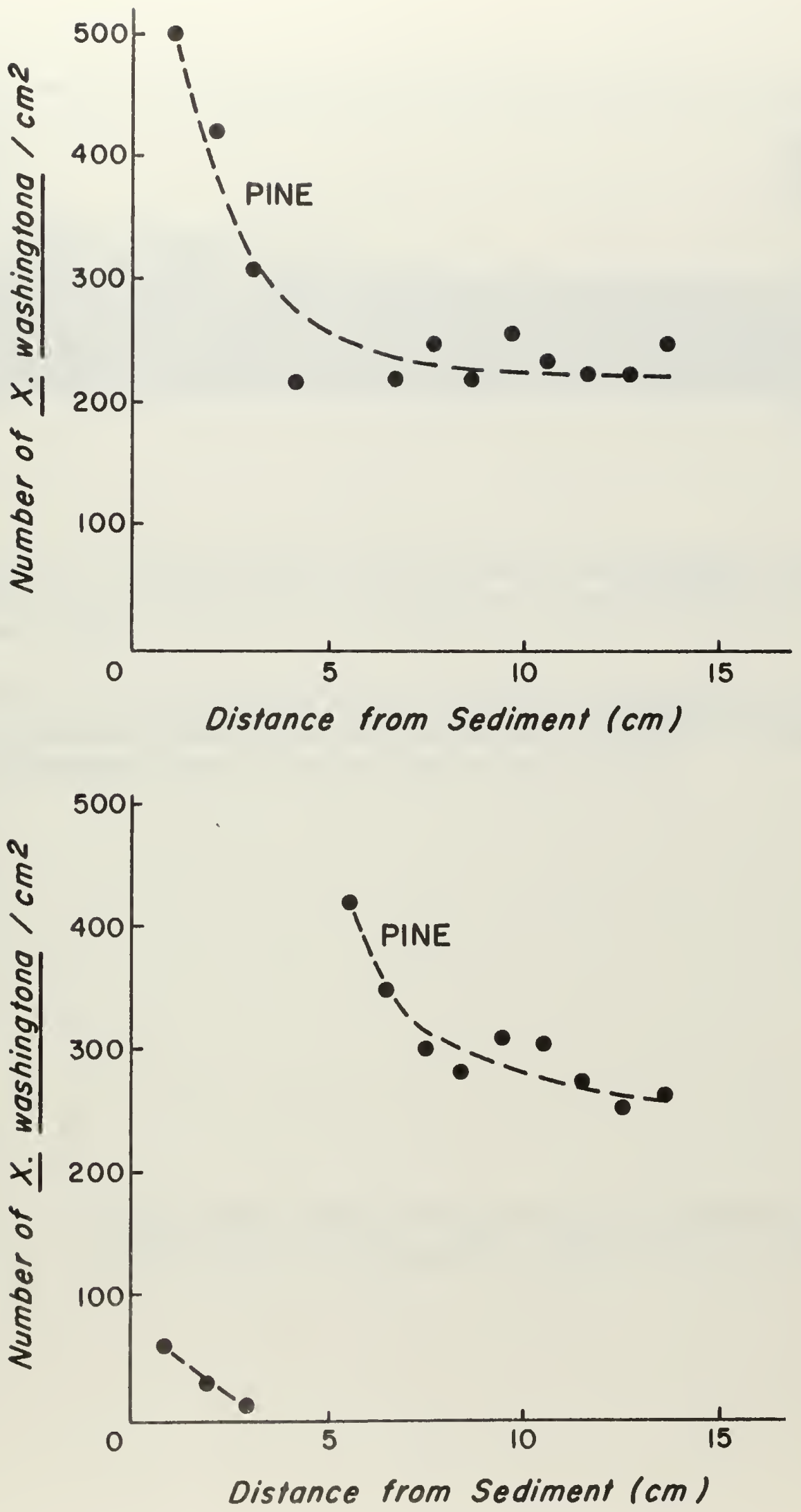


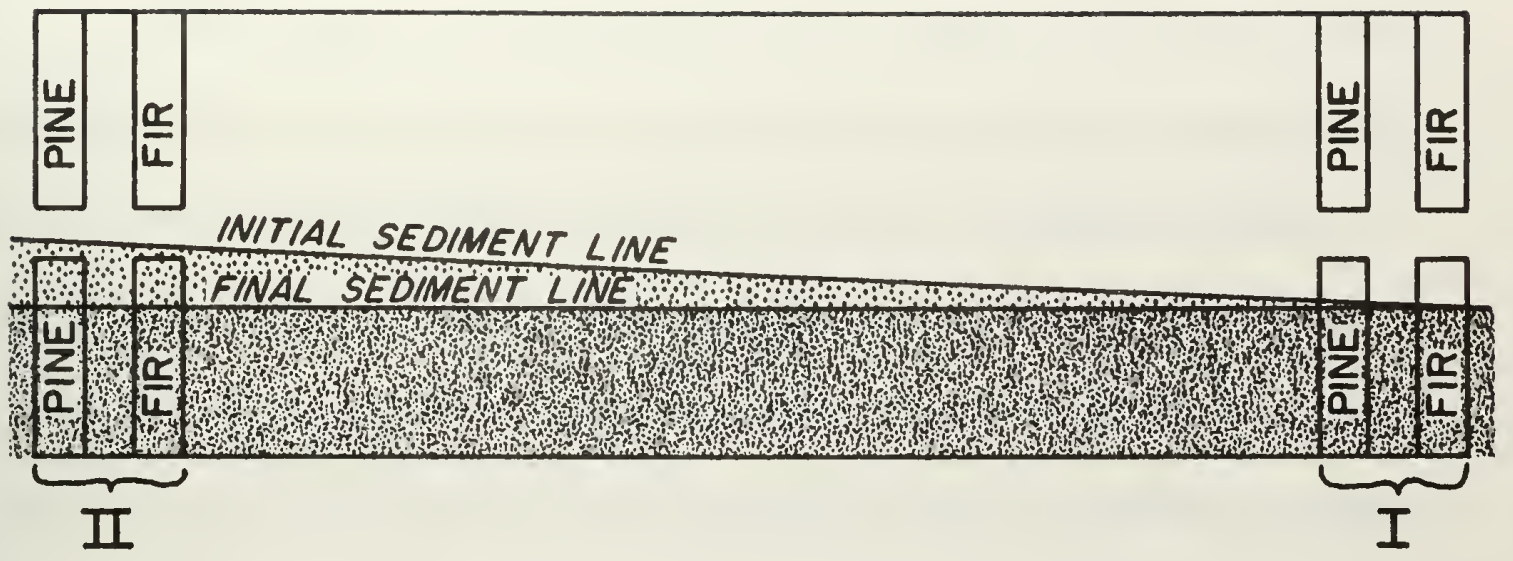

I. Panels in this area show an even gradient of Xylophaga attack proceeding upwards from a single clear sediment line on the lower panel.

II. Panels in this area show a split gradient of Xylophaga attack due to a theorized shift in position at the end of 50 days. Sediment discoloration occurs over the entire lower panel.

Figure 35. Sample panel position diagrammed in relationship to sediment data for Sample III, exposed 72 days at $200 \mathrm{~m}$. 
panel was plotted.

It seems highly likely that when the sample array was originally installed, the lower panels on one end of the array were completely buried and thus protected from borer attack. An initial sediment line (Figure 35) was formed at this time. When the 50-day array, which was attached on the other end of the ground line, was recovered, the buried end of the 72 -day sample array was lifted up slightly and settled back into a second position upon reinstallation of the ground line and mooring system. In this second position, the upper margins of the lower panels on the left hand end of the array then were exposed to borer attack for the remaining 22 days before the array was recovered.

The average number of surface penetrations per unit area on the supposed 22-day exposure can be plotted against the curve derived with values obtained from known exposure intervals (Figure 21), and appear to fit quite well, giving credibility to our hypothesis.

The dramatic decrease in number of borers with increasing distance from the sediment is not new information. Muraoka (1964, 1966a, 1966b, 1967) and DePalma (1962) both observed it. Muraoka (1966b) found that boards placed 25 feet ( 7.5 meters) above the bottom in deep water were usually completely free from borer attack even after exposure intervals greater than one year.

Turner (1966b) postulated that currents above the bottom 

prevented settlement of borer larva in the experiments listed above. She also stated, however, that our lack of knowledge of the development, behavior, and length of the free-swimming state in the borer larva prevent any definite conclusions. One must also add to this that little is known about the near-bottom current structure in deep water.

From the data off Oregon it can be hypothesized that the initial xylophagan attack begins very close to the sea-sediment interface and progresses upward with increasing time of exposure. This can be demonstrated by comparison of the photographs of panels exposed for 30 and 60 days at 1000 meters (Figures 28 and 32).

We know little about environmental gradients very near the sea-sediment interface at depth. Thermoprobe measurements, taken by Mesecar (1968b) provided an interesting look at temperature gradients across the sea-sediment interface. These temperature measurements were made very near the sites where sample arrays were placed during my study. Mesecar's thermal profiles from depths of 515 and 1370 meters are shown in Figure 36. The temperature of the water appears to increase markedly in the few centimeters nearing the sediment interface. This increase correlates with the observed distribution of X. washingtona on the sample panels. Again, however, our lack of knowledge of the basic biology of the larval form prevents drawing meaningful conclusions with respect 



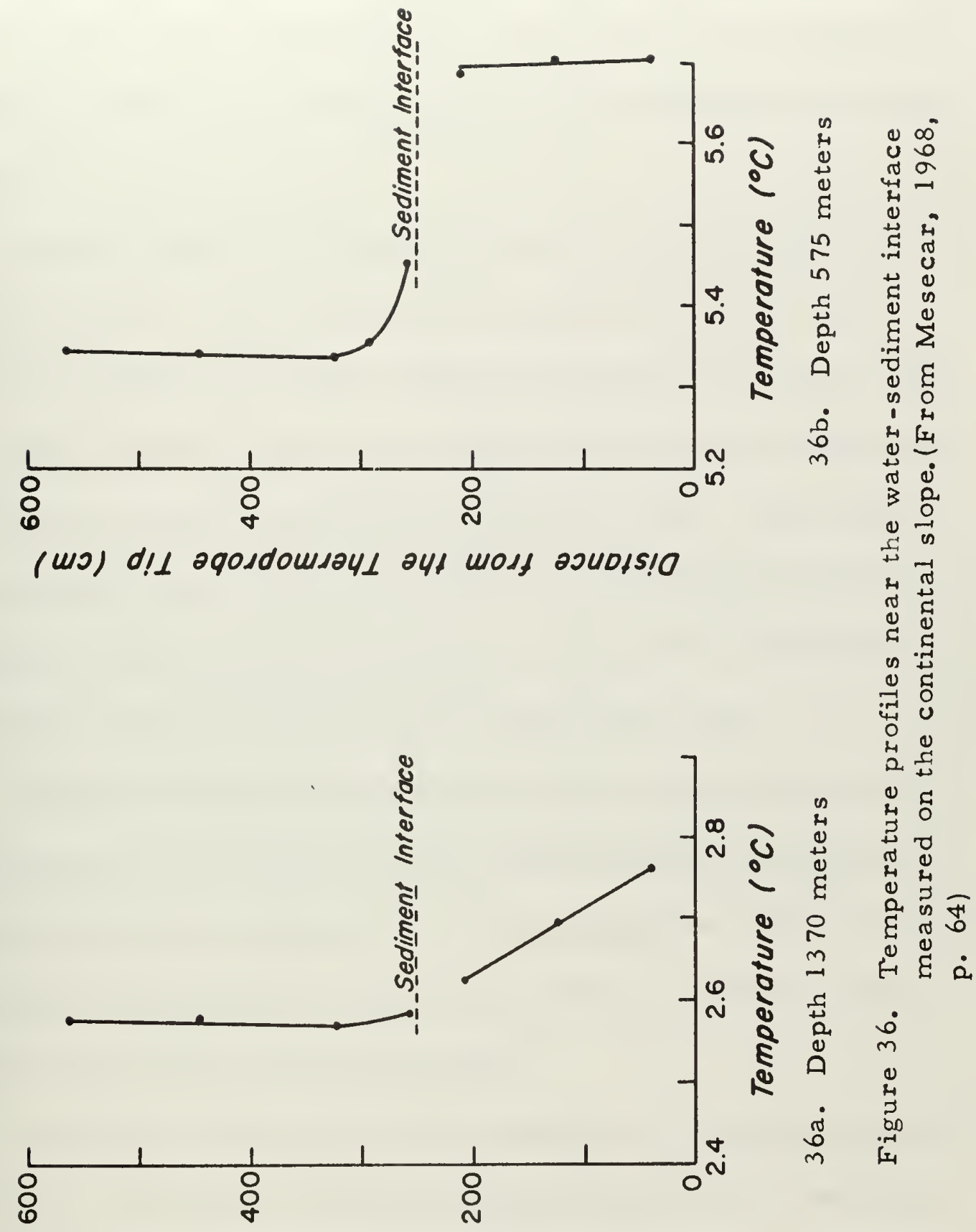

(wo) d!l agosdomsayl aपt most asubls!O 

to this temperature gradient. At least it provides added insight into some of the environmental factors working near the sea-sediment interface which might give rise to the observed distribution of the borers.

Larval behavior may influence borer distribution across the sample panels. Many borer larvae have been thought to exhibit substrate preference during settling; one general hypothesis being that they could somewhat delay metamorphosis until a suitable substrate was encountered (Isham and Tierney, 1953). Lane (1961), observing settling behavior of "teredo," reported that the tiny bivalve larva explored the wood surface with its foot, probing and exploring until an optimal spot for settling was found.

The xylophagan borers observed in my study also appeared to be able to discriminate or have variable degrees of success in various substrates (Figure 32 ). Heavy penetration of the less dense spring wood compared to light attack on the more dense summer wood is quite clear on the pine panels.

Muraoka (1965) observed the tendency of $\underline{X}$. washingtona larva to be more numerous in highly protected areas and in cracks and crevices in the sample panels. He felt that protection of the larvae from currents was the probable reason for this type of distribution. Panels recovered in my study off Oregon also demonstrated this tendency towards intense micro-distributions in sheltered habitats 

on the sample panels. In the majority of photographs of sample panels it can be clearly seen that settling is intense in a ring about the holes drilled in the boards. This area was a highly sheltered crevice caused by the abutment of the acrylic spacers against the sample panels.

Degree of Borer Penetration

So far we have been discussing the intensity of attack on the surface of pine panels by $X$. washingtona. Now, let's focus our attention on the depth of borer penetration as revealed in sectioned panels.

In a pine panel exposed for 72 days at 200 meters, for example, the average maximum depth of borer penetration was $8.6 \mathrm{~mm}$. A sample panel only $19 \mathrm{~mm}$ thick, attacked from both sides, is nearly destroyed by this level of penetration (Figure $37 d$ ).

The average depth of maximum borer penetration in pine sample panels increased with increasing time of exposure at 200 meters (Figure 38).

The degree of penetration in pine decreases with increasing depth of exposure (Figures 39 and 40). This could be a factor of lower temperatures with greater depth effecting boring rates, or possible increases in the density of the wood substrate brought on by compression at higher pressures. 


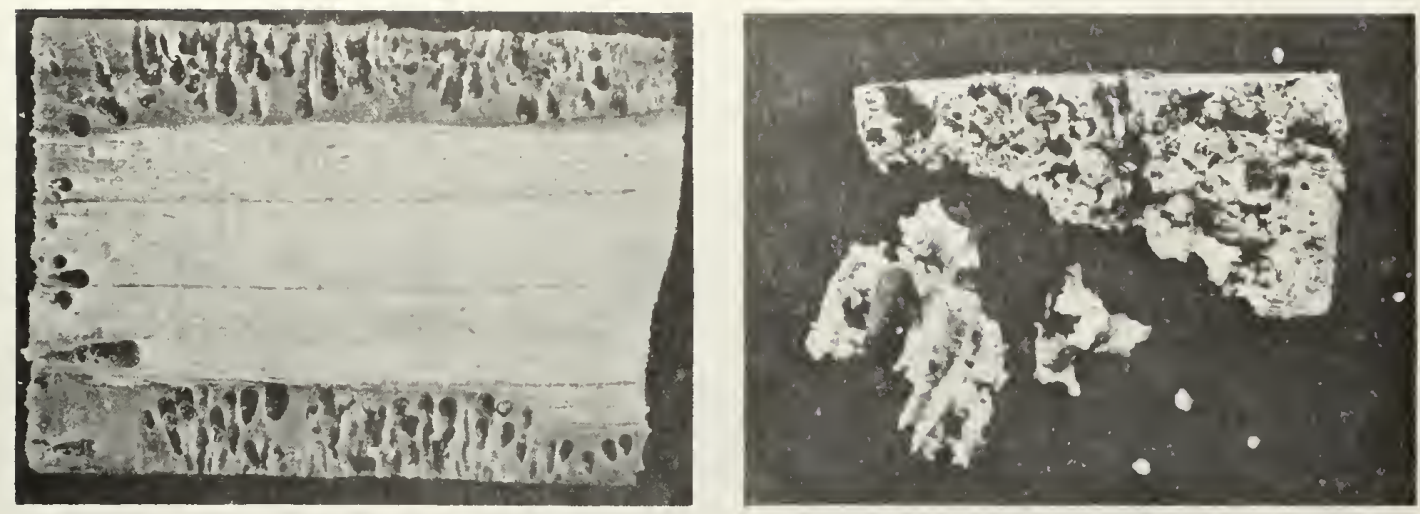

37a. Cedar: 50 days

37b. Cedar: 72 days
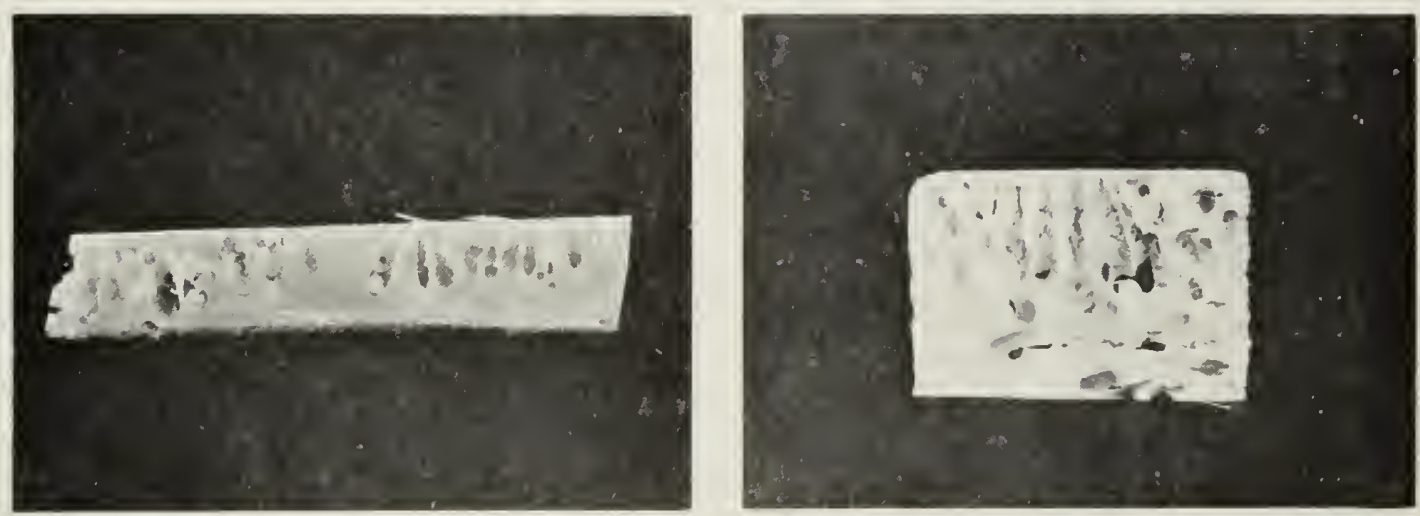

37c. Pine: 50 days

37d. Pine: 72 days

photos by Stander

Figure 37. Comparative sections of pine and cedar panels exposed 50 days (on left) and 72 days (on right) at $200 \mathrm{~m}$; all magnifications equal ( $2.4 \mathrm{X})$. 


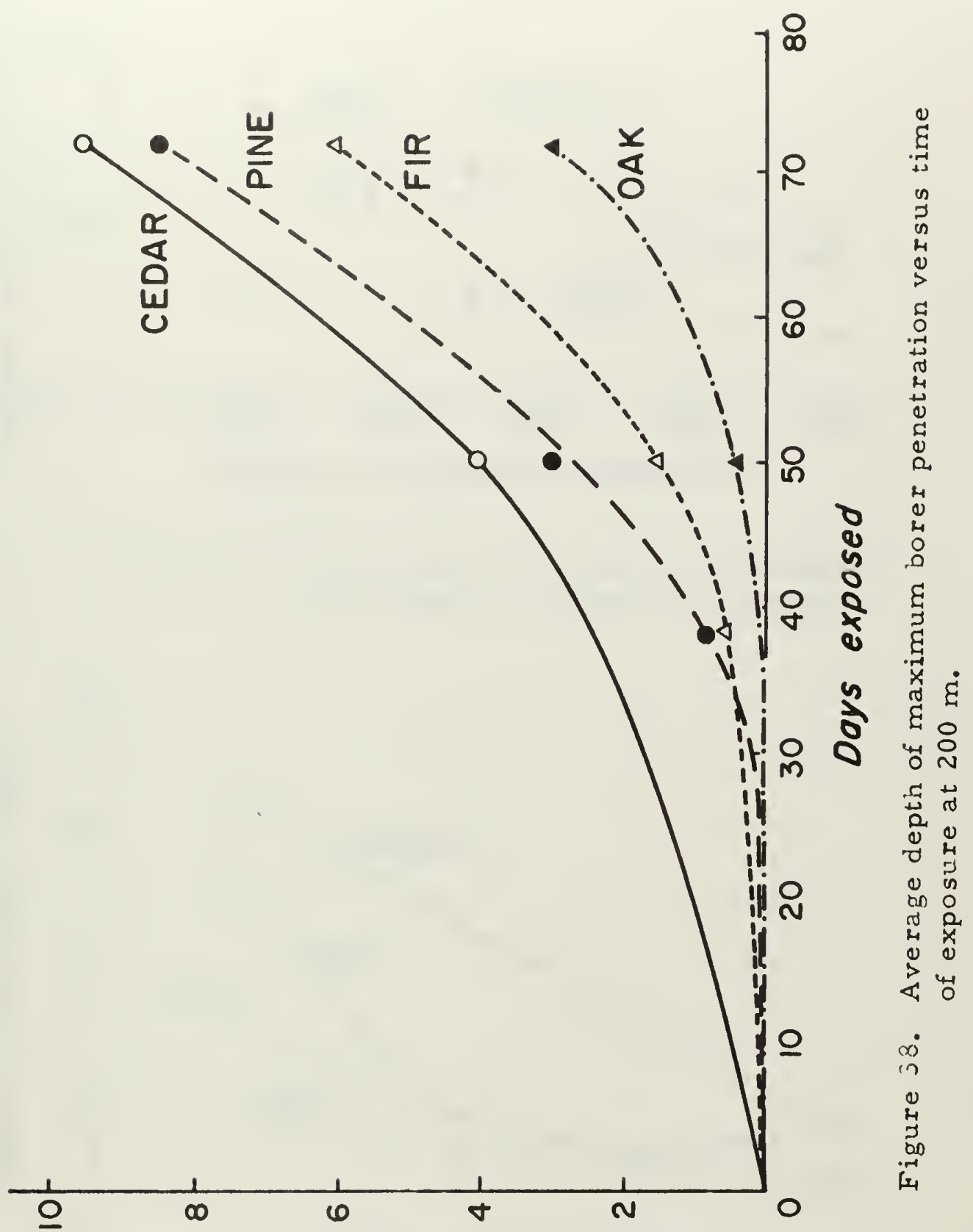

(ww) v0!1011202d 12109 wnw!xow to 41d2p 260121t 


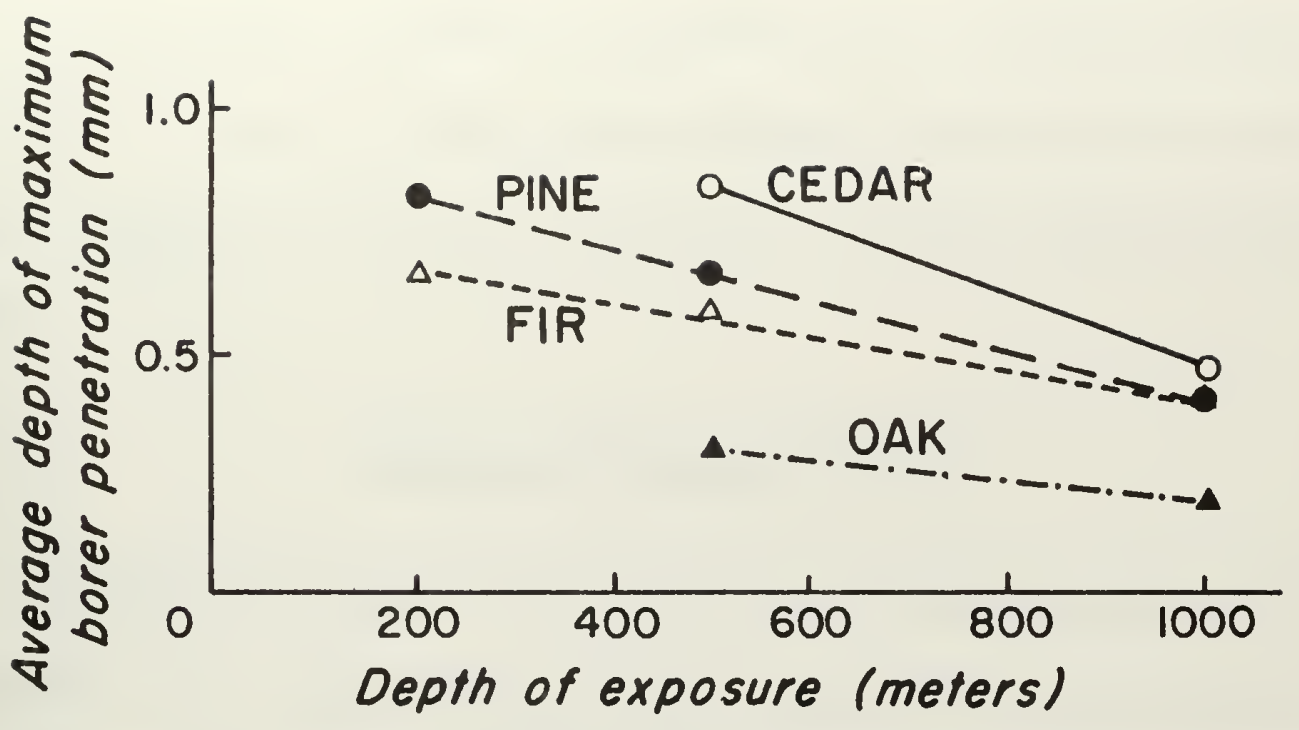

Figure 39. Average depth of maximum penetration versus depth of exposure for 30 days.

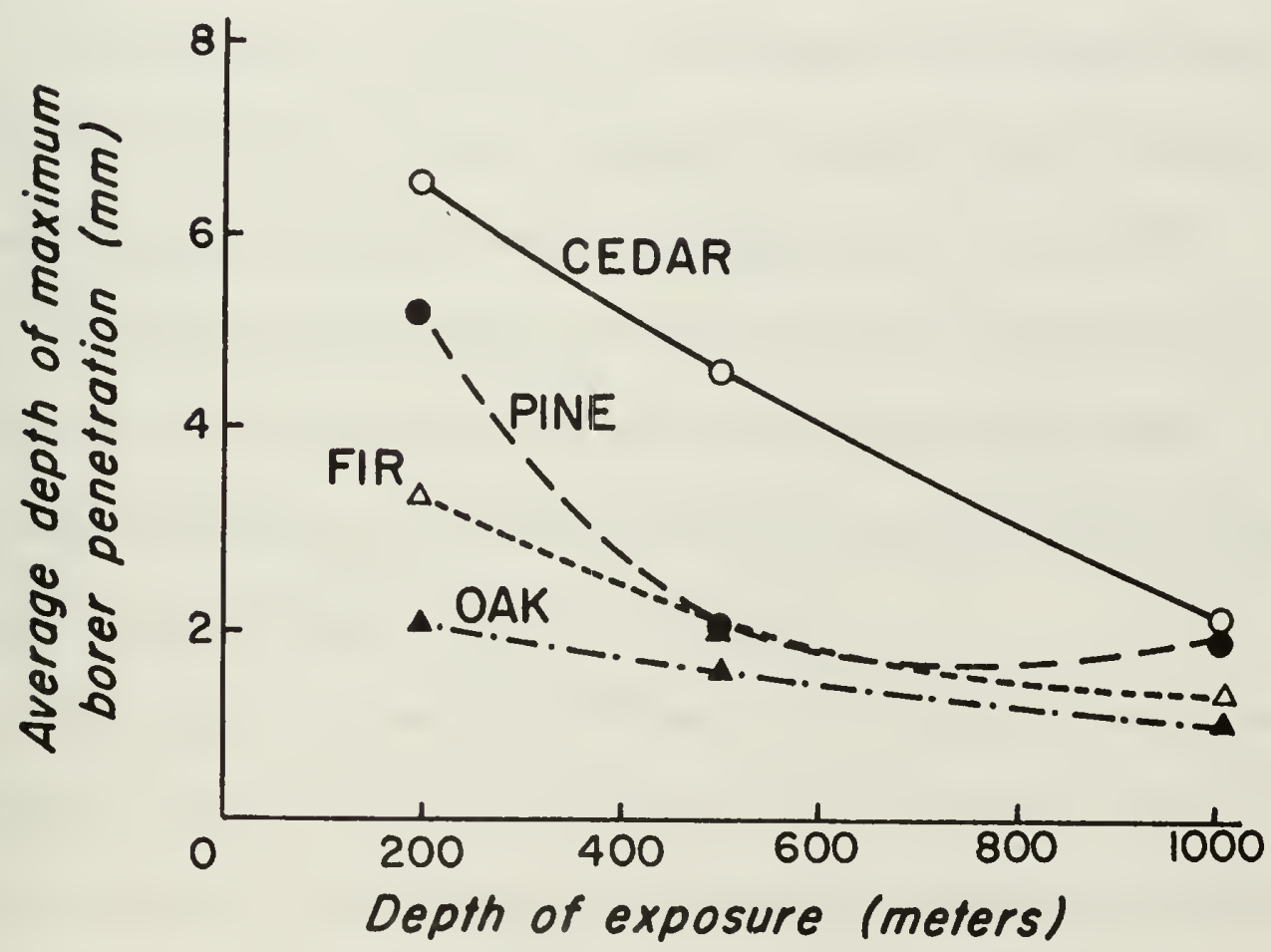

Figure 40. Average depth of maximum penetration versus depth of exposure for 60 days. 

A discussion of density of substrates; i.e., of the wood panel, as a factor in depth of borer penetration will be discussed in detail later, following presentation of data on wood types of different densities.

\section{Attack on Fir Sample Panels}

Douglas-fir timber, one of the key raw materials on which the industrial base of the Pacific Northwest operates, is of ten used in wood pilings and other submerged structures along the Pacific coast; hence, it was a prime material for test exposure to borer attack.

As with pine, the number of xylophagan borers penetrating the surface of fir sample panels increased with the length of exposure. This trend was seen in all samples (Figures 21, 22, and 23).

At the 200-meter depth, fir panels were attacked less than pine. This was true for all exposure intervals at that depth. At the two deeper stations, fir panels had levels of surface attack slightly higher or nearly equal to that seen on pine.

In Sample I, exposed at 200 meters for 38 days, the fir panels averaged as low as 10 penetrations per $\mathrm{cm}^{2}$ of surface area, and no sediment line could be found on the panels. Detailed inspection of the pine panels exposed in this array revealed a noticeable sediment line, and a well defined gradient of borer attack upwards from this line (Figure 4l). In this sample array, panels of pine were 



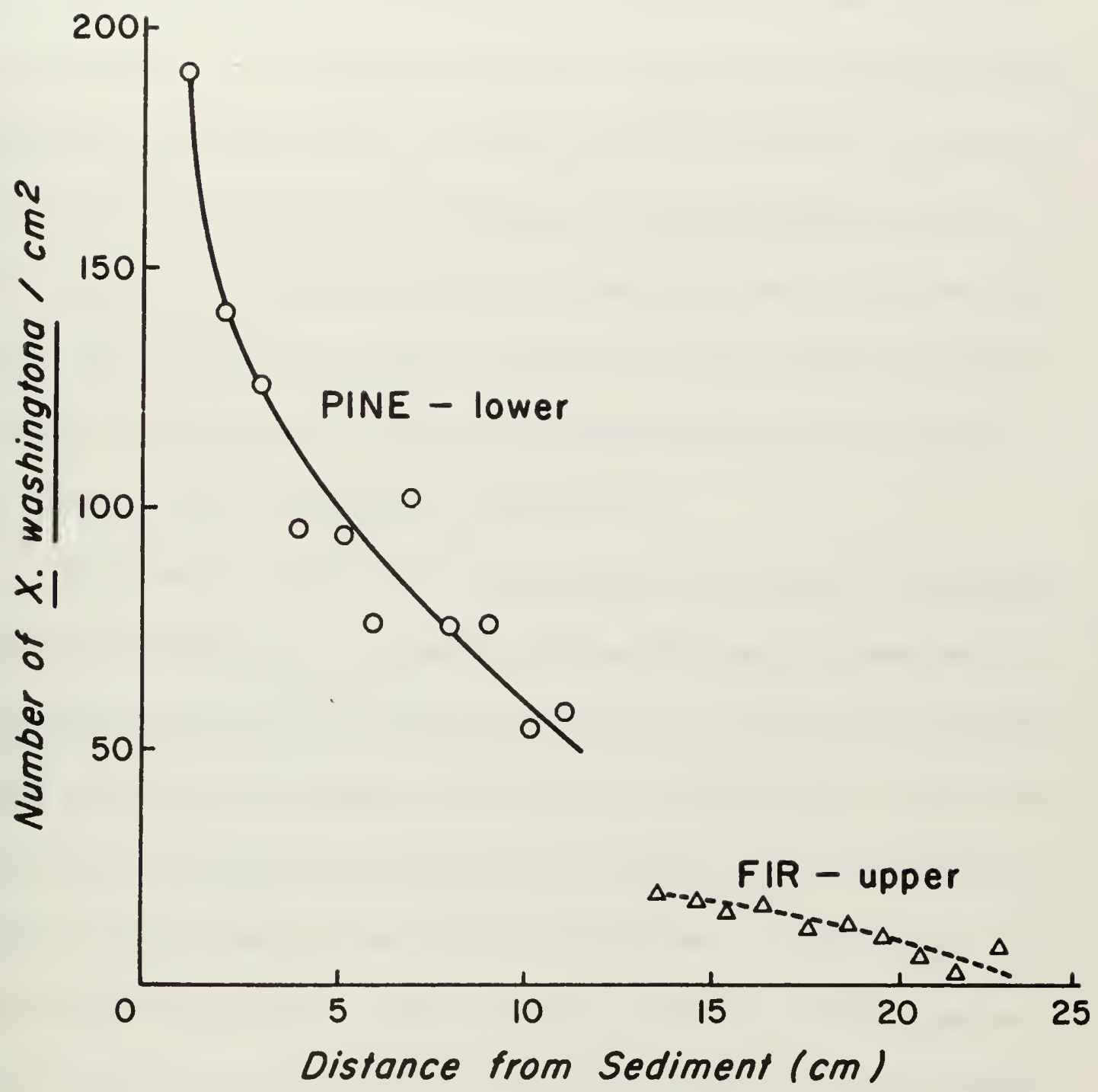

Figure 41. Xylophaga washingtona gradient across pine and fir panels exposed 38 days at $200 \mathrm{~m}$. 

placed side by side with fir so that one half of the array was fir and the other pine. Further study of the panels led to the conclusion that fir was in a position above pine during exposure and thus well separated from the sea-sediment interface. Based on the gradients found in pine and discussed above, one may speculate that the fir samples at this site could well have exhibited surface penetration values in the range of 60 to 75 per $\mathrm{cm}^{2}$ had they been in contact with the sediment. This estimated value is based on an extrapolation of the dif ferences obtained between pine and fir panels exposed at this site for 50 and 72 days respectively (Figure 21).

The trend in variation of surface attack with depth of exposure seen on fir sample panels closely followed the pattern observed on pine (Figures 24 and 25). Thirty-day exposures showed decreased attack with increased depth. At 60 days, the 1000-meter-station fir panels showed higher numbers than those exposed at the 500-meter depth, but both deeper sites showed lower levels of attack than we re recorded at 200 meters. This unexpected result at 500 meters occurred in pine as well, and was discussed in detail previously (page 69).

Fir panels exhibited decreasing borer attack with increasing distance from the sea-sediment interface (Figures 26, 27, 29, and 31), which closely followed data observed on pine panels. The trend seemed well developed at all stations and exposure intervals. 

Let us recall the discussion of sample array III (page 82) in which borer distribution across pine sample panels showed signs that the sample array had been disturbed in the middle of the exposure period. The fir panels (Figures 42 and 43) from this array exhibited corresponding patterns (Figures 33 and 34); these results give strength to my previous suggestion of disturbance of this array.

The average depth of maximum borer penetration observed in fir panels at 200 meters (Figure 38) followed the same trend with time seen in pine panels. The maximum penetration in fir, however, was always less than in pine.

Borer penetration decreased with increasing depth of exposure in fir panels (Figures 39 and 40). The trend again followed that described for pine with the average depth of maximum penetration being either less than or nearly equal to that seen in pine.

The specific gravity of Douglas-fir falls within the range of 0.45 to 0.48 according to the Wood Handbook (U.S. D. A., 1955) while that of pine, being in the range 0.36 to 0.40 , is somewhat less. Substrate density has a definite effect on wood-boring molluscs (Muraoka, 1966a) and often causes stenomorphic variation in shells and muscles (Dr. R. D. Turner, personal communication). Therefore, the less dense pine is attacked somewhat more severely than the fir. 

Figure 42. Uniform gradient of Xylophaga washingtona attack across adjacent fir panels exposed 72 days at $200 \mathrm{~m}$. Position I in Figure 35.

Figure 43. Split gradient of Xylophaga washingtona attack across adjacent fir panels exposed 72 days at $200 \mathrm{~m}$. Position II in Figure 35. 

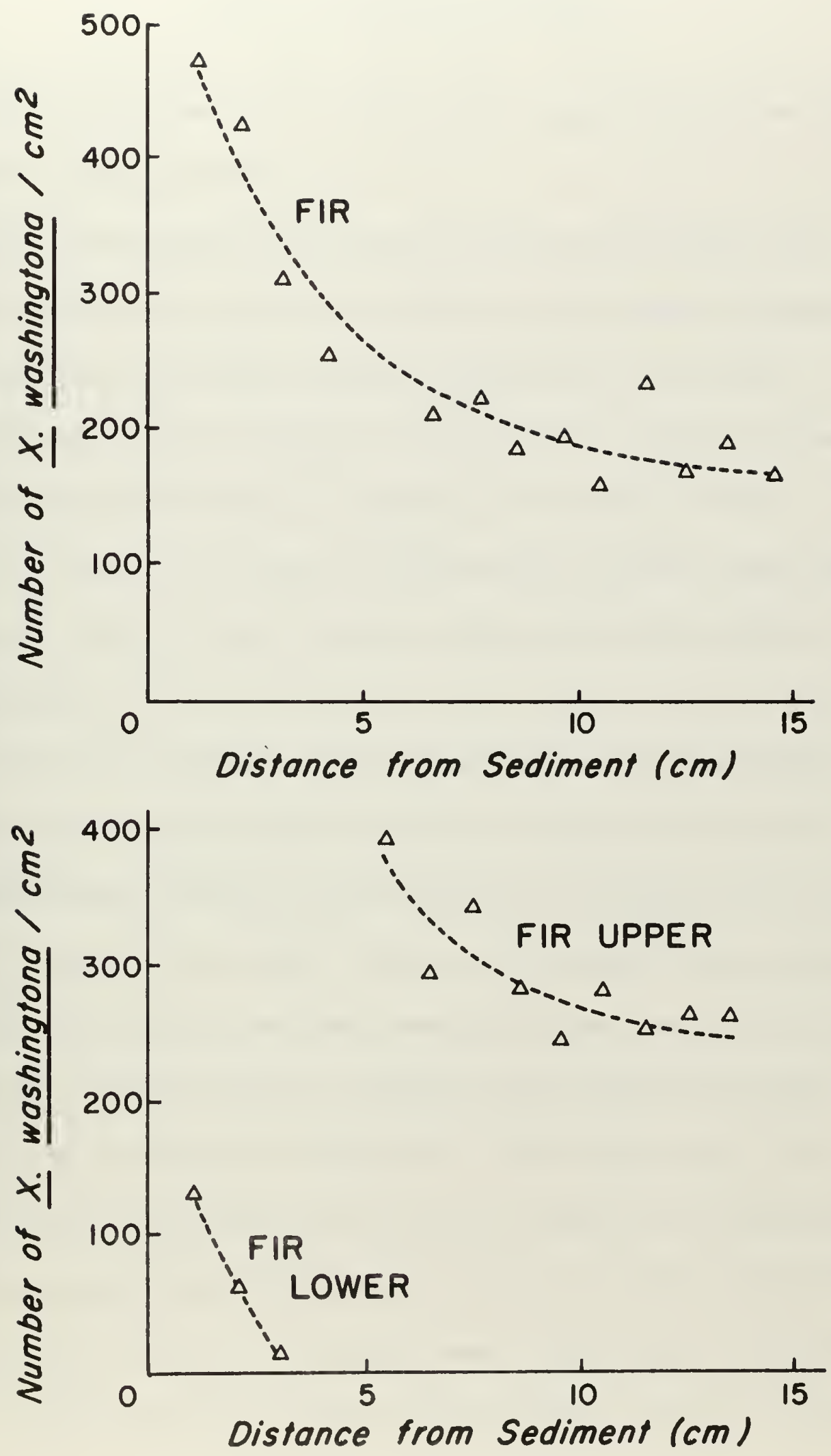



\section{Attack on Oak Sample Panels}

Oak, the densest of the woods tested, appeared to be the most resistant to borer attack.

The same general trend seen on fir and pine panels, of increased degree of surface attack with increasing length of exposure, was exhibited on the oak test panels (Figures 21, 22, and 23).

Compared to pine and fir, oak panels were everywhere less heavily attacked by borers, no matter what the time interval. In Sample I, exposed for 38 days at 200 meters, only pine and fir panels were used, hence the lack of data for other woods here except by extrapolation.

At 30 days elapsed exposure, oak panels at the two deeper stations show the same trend of decreased surface attack with increasing depth of exposure seen on pine and fir (Figure 24). The degree of attack is very light, however, averaging seven penetrations per $\mathrm{cm}^{2}$ at 500 meters and three penetrations per $\mathrm{cm}^{2}$ at 1000 meters. At 60 days elapsed exposure, oak panels again exhibit the same trends seen on pine and fir (Figure 25). Both deeper sites show lower levels of attack than occurred at 200 meters, but 500 meters shows less attack than 1000 meters. In all cases the magnitude of borer attack was less on oak panels than on either pine or fir boards.

A rapid decrease in numbers of borers per unit area over the 

first several centimeters upward from the sea-sediment interface occurred on oak panels (Figures 26 and 27). This same pattern appeared on pine and fir. The attack on oak exposed 30 days at 500 and 1000 meters was usually low and decreased rapidly to zero within six centimeters of the sea-sediment interface. The xylophagan borers recovered were immature and had not yet bored far into the oak.

For oak exposed 60 days at 1000 meters, the degree of attack increased with time, but the same trend of distribution across the panel surface was present (Figure 44 ).

Figure 38 shows how the depth of maximum borer penetration proceeded in oak test boards with increasing time of exposure at 200 meters. The pattern seen closely followed that recorded from the pine and fir sample panels; the major difference was that the average depth of maximum penetration in oak was always less. The characteristic increase in maximum penetration with increasing time, seen in pine and fir, was also observed in oak (Figure 39 and 40). These two figures also illustrate a slight decrease in average depth of maximum penetration with increasing depth of exposure. This was also seen in pine and fir.

Let me once again allude to substrate density as a possible critical factor in the differences in borer attack between wood types which we have observed, but defer detailed discussion until later. 



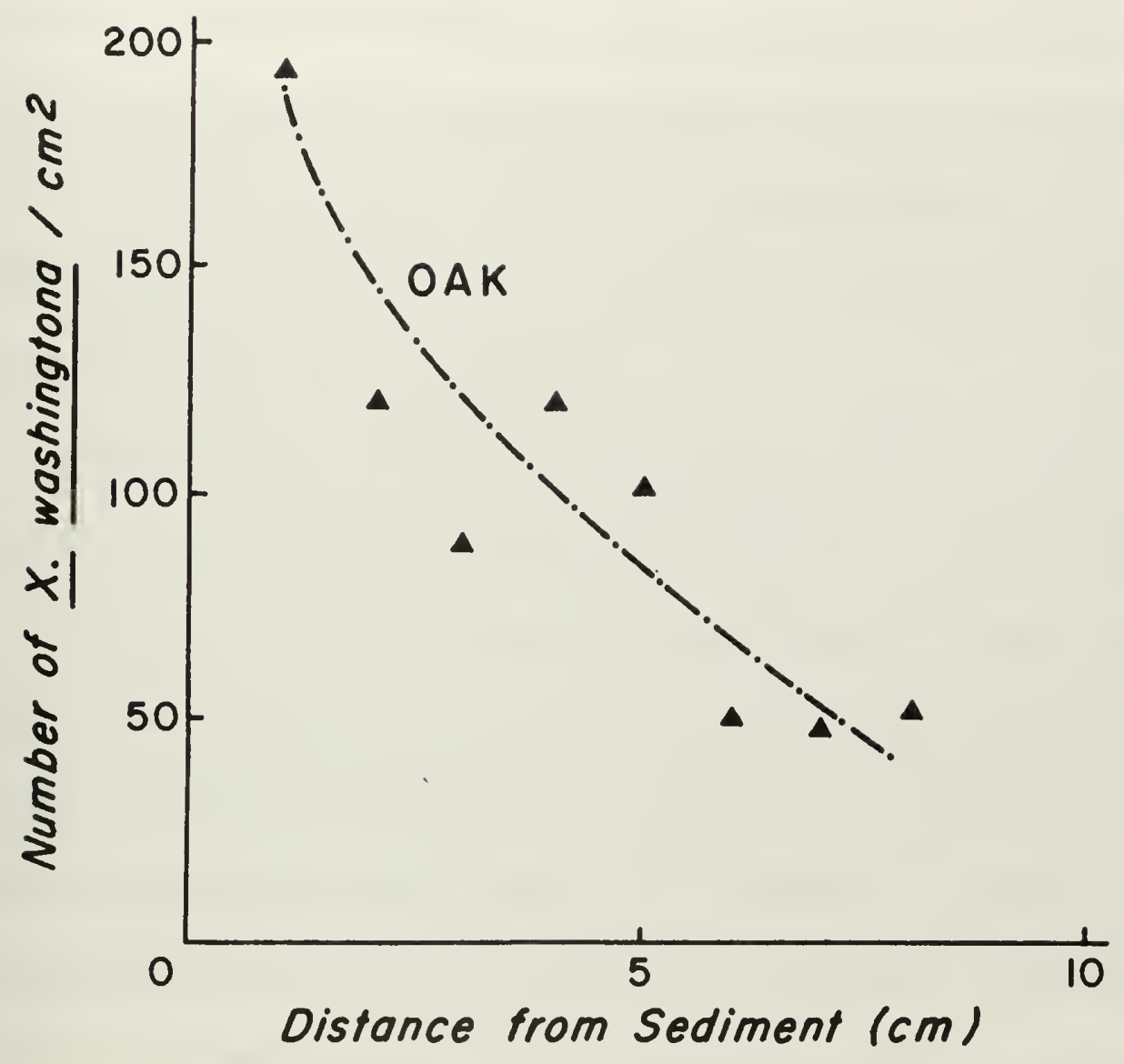

Figure 44. Xylophaga washingtona gradient on oak panels exposed 60 days at $1000 \mathrm{~m}$. 



\section{Attack on Cedar Sample Panels}

In this series of tests, cedar panels were observed to be the least resistant of all wood types to xylophagan borer attack. The extreme deterioration incurred on a cedar panel by a 72-day exposure at the 200-meter site can be observed in Figure 45. A crosssection taken from the same panel is shown on Figure $37 \mathrm{~b}$. This board is almost totally destroyed.

Figures 21, 22, and 23 illustrate the increase in surface penetrations per $\mathrm{cm}^{2}$ on cedar with time. In nearly all cases, attack on the cedar is much more intense than that which occurred on pine, oak, or fir. The intensity of attack at the 200-meter site for 50 to 72 days, as expressed by increasing surface penetrations, shows little increase with time. This may be linked to the lack of available undisturbed wood surface for additional settlement. The average surface penetration density of 332 borers per $\mathrm{cm}^{2}$ on the 50 -day exposure is only slightly below the 348 borers per $\mathrm{cm}^{2}$ observed on the 72 -day sample at 200 meters. These densities of borers saturate the available surface area. Damage still occurs within the panel, however.

In general, cedar followed the trends of decreasing intensity of attack with increasing depth of exposure seen on the pine, fir, and oak panels. The deviation from this general trend seen at the 60 -day 



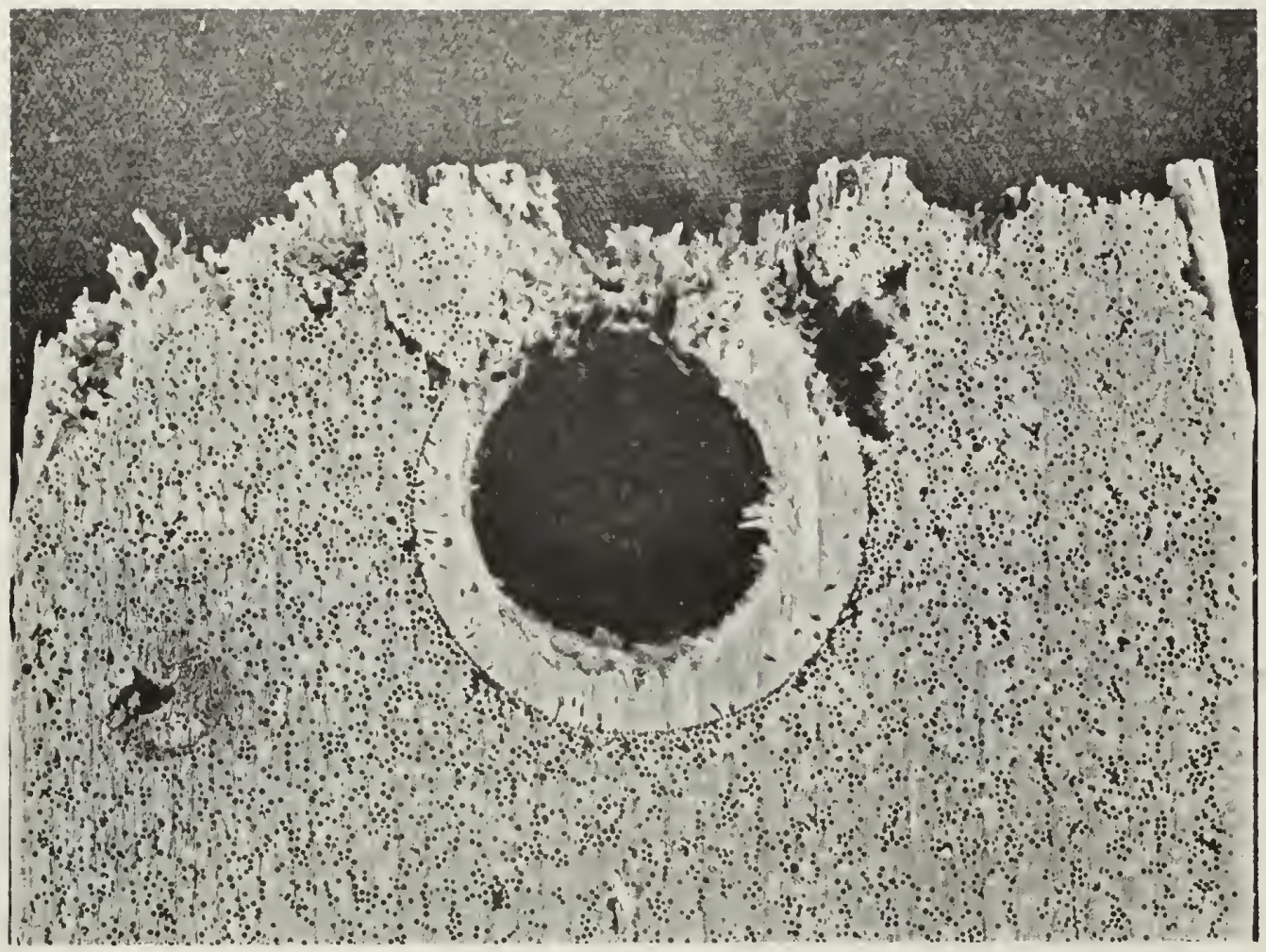

photo by Stander

Figure 45. Margin of a cedar test panel exposed 72 days at $200 \mathrm{~m}$; section of this panel shown in Figure $36 \mathrm{~b}(1.3 \mathrm{X})$. 

exposures at 500 and 1000 meters are also comparable to that seen in the other types of test boards.

In nearly all cases, intensity of attack on cedar was higher than that recorded from the other three wood types. This is especially noticeable at the 60-day level of exposure at all three deep stations (Figure 25).

Again, as was seen on pine, fir, and oak, the number of surface penetrations per $\mathrm{cm}^{2}$ decreased as distance from the sea-sediment interface increased. This trend on the 60-day-exposure cedar (Figures 46, 47, and 48) was characterized by a less marked decrease within the first several centimeters above the bottom than is seen on other panels. This was possibly the result of the higher levels of attack on the cedar. Nevertheless, the basic decreasing trend is still apparent.

The manner in which maximum burrow penetration changes with increasing time of exposure at 200 meters on the cedar panels is illustrated in Figure 38. As in pine, fir, and oak, maximum penetration depth increases with time. For cedar, however, at an exposure level of 72 days and a depth of 200 meters, boring from both sides of the panel had completely riddled the test board. As burrows from both sides of the panel met in the center, no significant wood was left for additional borer activity. Maximum burrow depth was then recorded as one half the panel thickness $\left(9 \frac{1}{2} \mathrm{~mm}\right)$ or 



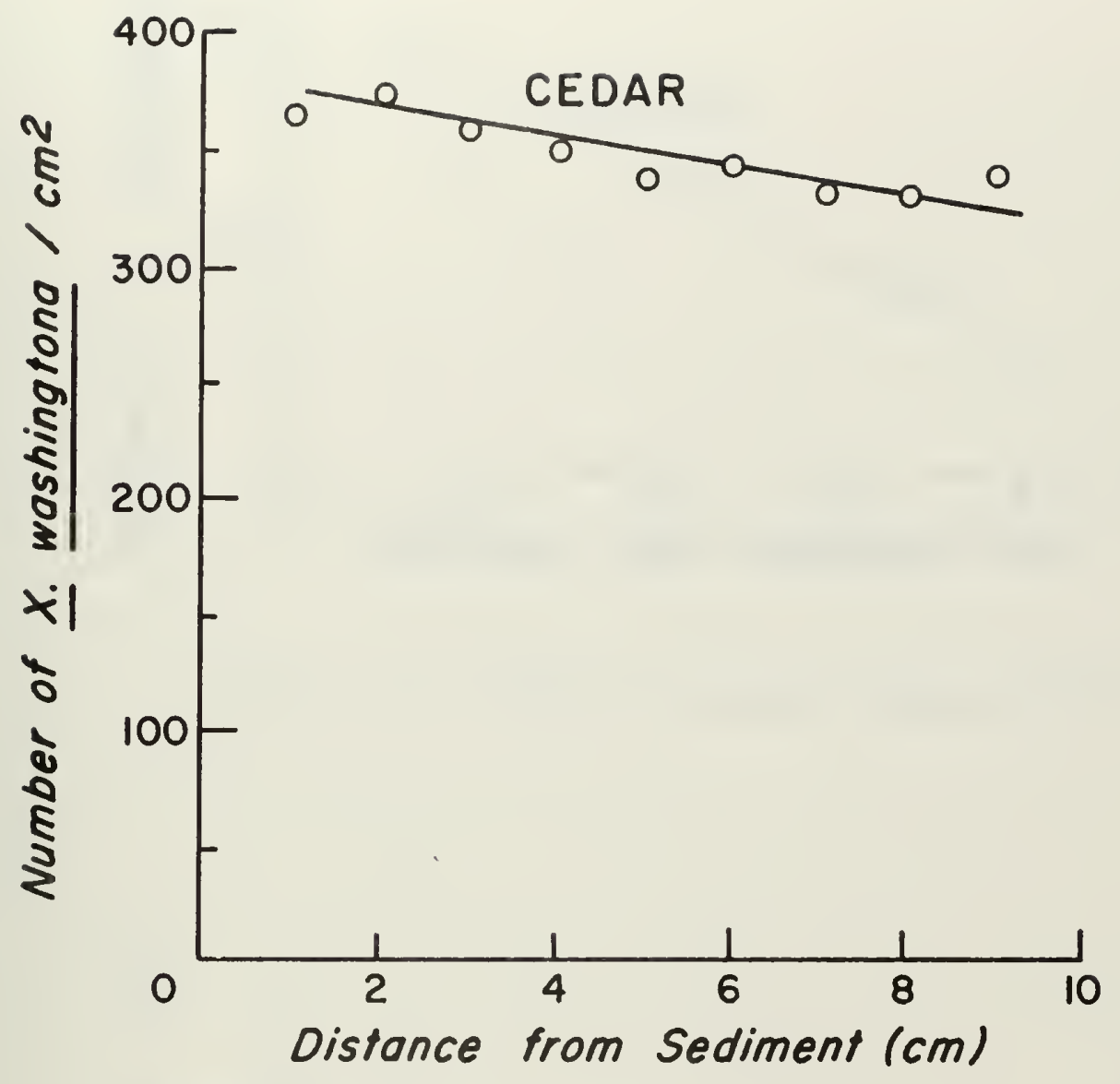

Figure 46. Gradient on cedar 72 days at $200 \mathrm{~m}$. 



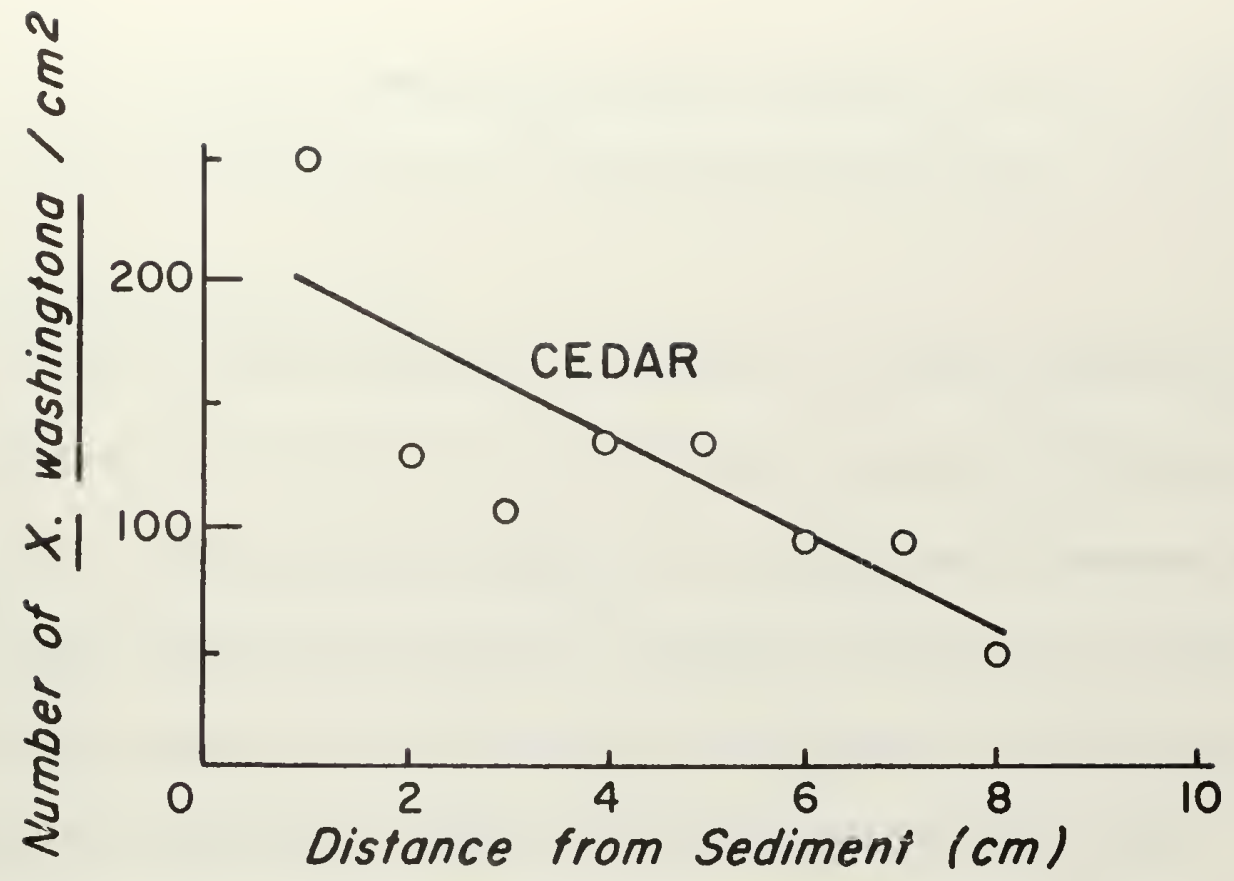

Figure 47. Gradient on cedar 60 days at $500 \mathrm{~m}$.

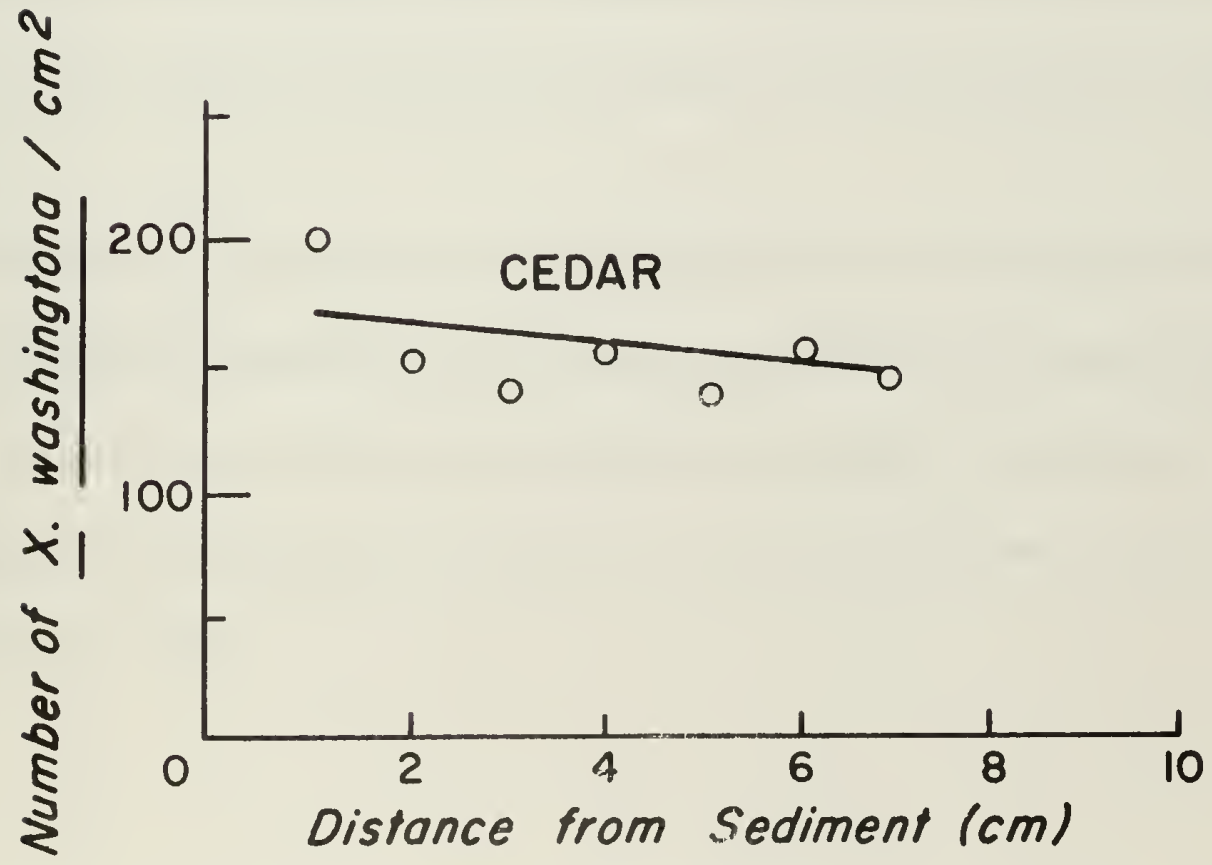

Figure 48. Gradient on cedar 60 days at $1000 \mathrm{~m}$. 

greater, the true value being impossible to measure. These cedar panels were in the final phase of degradation by xylophagan marine borers.

There was little difference in numbers of surface penetrations per unit area between the 50 - and the 72-day samples at 200 meters. Comparison of parts a and b, Figure 37, photographs of sections of cedar panels exposed for these time intervals, illustrate the point that has been made; i.e., the depth of penetration markedly increases with time of exposure. While the surface attack may not be greatly different between these two panels, the borers have still been busy inside.

Variation of the depth of maximum penetration in ceda $\mathrm{r}$ decreased with increasing depth of exposure (Figures 39 and 40). This trend in cedar agreed well with data observed from pine, fir, and oak.

In all cases, depth of maximum penetration measured in the cedar exceeded the value for all other wood types on the same sample array, regardless of the exposure interval or depth. Cedar also has the lowest specific gravity (range 0.31 to 0.37 ) of all the woods tested (U. S. D. A., 1955 ). 



\section{Integration and Summary of Wood Destruction \\ Caused by the Pholad Borer Xylophaga}

Variation of Surface Attack

with Exposure Time

The life cycles of xylophagan borers are almost wholly unstudied. For Xylophaga washingtona the length of time after settling required before reproduction begins, remains obscure. Seasonal aspects of spawning are also unknown. This overall poverty of information regarding the biology of the species makes data interpretation quite difficult and often impossible.

A general increase in the amount of surface attack with increasing time of exposure was observed for all wood types. This was observed regardless of the depth of exposure. After 60 days of exposure, the size of borers on any panel varied from newly settled protodissoconch stages to larger stages with well established burrows. Size classes could not be established by inspection of the surface of the wood, nor by observations of sections. Extracting individual borers from the wood for size class analysis and histological study of the soft parts proved impractical within the time limits of this study; thus, life cycle information is beyond the scope of this thesis. The data obtained did not indicate if the range in sizes was due to continued settling from a source external to test array, or if larger forms present on the panels were in fact reproducing. This 
latter idea, while seemingly the least tenable, cannot be ruled out, for Kofoid (1921) reported that in $\underline{B}$. setacea sexual maturity was reached within one month after settling. The fact remains, however, that surface attack by borers did progress with time on all woods tested.

\section{Variation of Surface Attack with Exposure Depth}

The reservoir population of $\underline{X}$. washingtona has not been lo* cated. It is probably associated with waterlogged driftwood which lies on the ocean floor. The manner or stage in which larvae are dispersed from adult population areas, where ever they may be, has not been determined.

Environmental gradients in the area of the sea-sediment interface prove to be a two-edged sword. Not only are they generally unstudied at depths greater than 200 meters, but when such data are available our knowledge of the biology of the xylophagan borers is so slight that correlations cannot be meaningful.

In this study, all woods exhibited a general decrease in borer attack with increasing depth of exposure at a 30-day exposure interval. At an exposure level of 60 days, while this concept held true when comparing the 200-meter site with deeper stations, the 1000 meter depth had higher levels of surface attack than were seen at 500 meters. As was previously discussed, no single environmental 
factor seemed to be correlated with this distribution pattern. Perhaps the answer lies less with the environment and more with the biology of the xylophagan borers. For instance, the proximity of a test site to a reservoir of borer population would increase the availability of borers for settlement on test panels exposed there. This all must remain speculative until further studies on the biology of the borer population and the environment are conducted.

Distribution of Attack with Increasing Distance From the Sea-Sediment Interface

Muraoka (1965, 1966a, 1966b) and DePalma (1962) both reported that in deep water, xylophagan borer attack decreased with increasing distance upward from the water-sediment interface. Turner (1966b) postulated that this was a response to near-bottom currents which prevented settling. In fact, as little as we know about bottom currents and other environmental gradients notwithstanding, our knowledge of their effect on the borer species is even more negligible. Actual settling behavior has never been observed in $\underline{X}$. washingtona. Perhaps the la rvae are initially distributed and settle near the mud-line and new settlers crawl upwards, in the manner observed in "teredo" by Lane (1961), when the wood near the water-sediment interface is already heavily infested. There may also be some thigmotropism exhibited by the larval forms during 

settling; they may respond to zones which provide a crevice or corner in which to settle. Muraoka (1966b) reported settling and attack by $\underline{X}$ washingtona to be most intense in such zones. One must realize that this is speculation designed to offer somewhat logical alternatives to causal factors already proposed in the literature.

In all woods tested in my study, the trend of decreasing borer attack with increasing distance from the sediment interface was consistent at all depths and exposure intervals. On all panels a strong decreasing gradient of attack appeared within the first 6 to 20 centimeters above the sediment line. Although we cannot at this time determine the causes of this gradient, its appearance on the 30-day exposures, and its progression upward on the 60 -day panels seem to indicate that xylophagan attack does, in fact, originate within the first few centimeters of the sea-sediment interface and move upwards.

Density of Substrate versus Average Depth of Maximum Borer Penetration

Throughout the preceding sections on the various wood types, density has been alluded to as a major factor causing the differences in borer attack. Let us now pursue this topic in greater detail.

In general, we assume that all panels in an array at a given exposure site were exposed to the same environmental conditions. 

Differences in attack among woods exposed in single arrays must then have been somehow related to the differences in the substrates themselves. Two major characteristics then become important, the wood chemistry, and the wood density (as expressed through'specific gravities). If chemistry was of prime importance, one might expect cedar to be fairly resistant to borer attack, for it is listed as a highly deterioration-resistant wood by the U.S. D. A. Wood Handbook (1955); however, this is not the case, as it was observed in this study to suffer the highest levels of damage by xylophagan marine borers. In fact, Mr. R. D. Graham of the Forest Research Laboratory stated (personal communication) that for native wood species from the Pacific Northwest such as these, extractants do not seem to play a role in either preventing or encouraging deterioration in the marine environment. Wood density, on the other hand, has been mentioned by $\mathrm{Dr}$. R. D. Turner (personal communication) as a major factor effecting levels of xylophagan borer attack in different wood types. She also commented that differences in substrate density can lead to stenomorphic alteration of shell characteristics and to variation in the degree of "chimney" formation (the formation of a burrow lining comprised of a cone of compacted fecal pellets). Soft woods showed the highest borer penetration and largest degree of chimney formation.

An interesting graph results (Figure 49) when specific gravities 


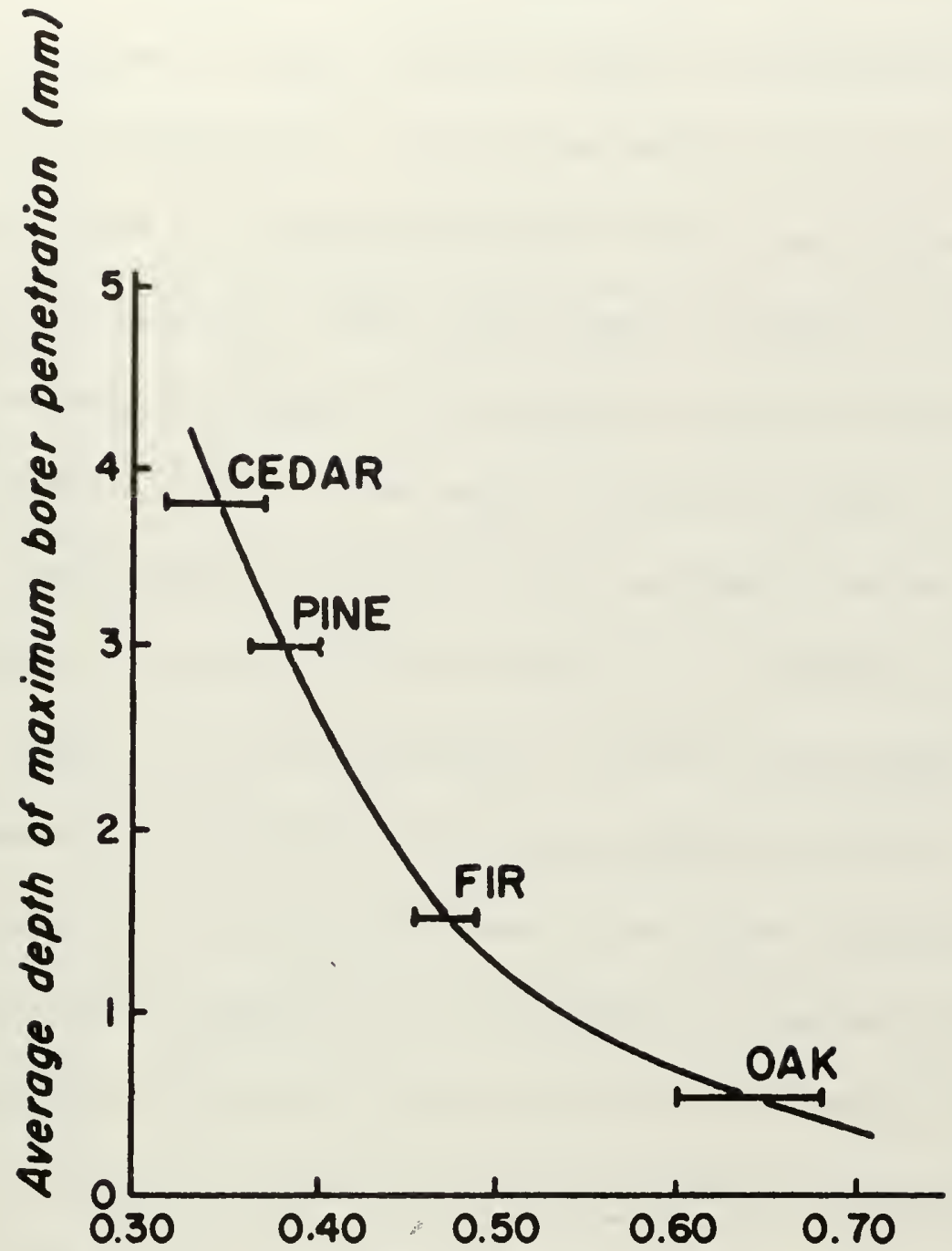

Specific gravity ronges of the wood types

Figure 49. Comparison of wood density with average maximum depth of penetration on wood exposed 50 days at $200 \mathrm{~m}$. Range of wood density from U.S. D.A. (1955) 


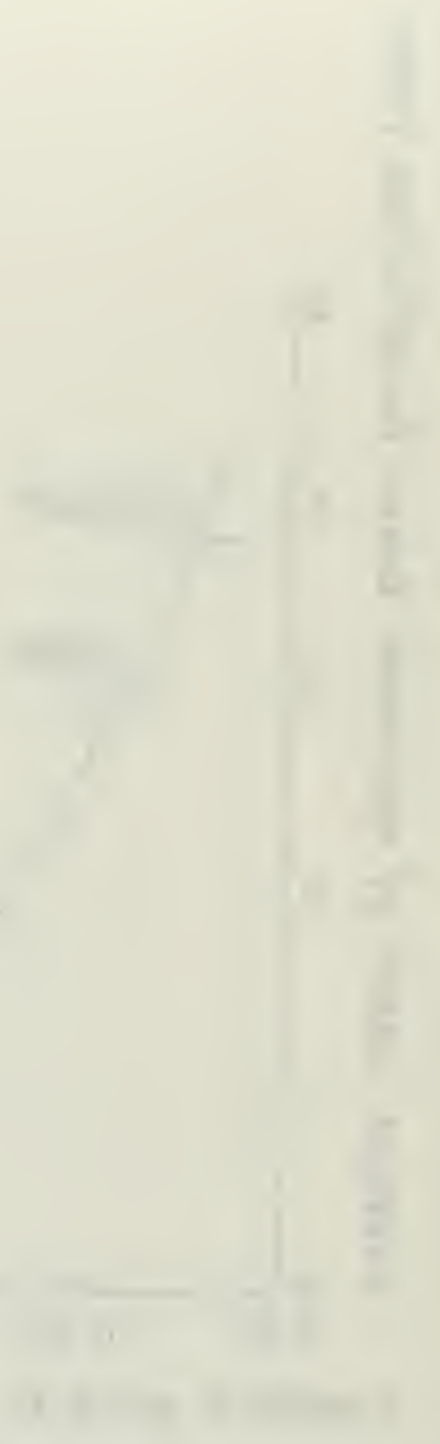


of the four woods used in my study (pine, fir, oak, and cedar) are plotted against average maximum depths of penetration for the 50-day exposure at 200 meters. As can be readily observed, increasing density leads to a decreasing depth of borer penetration over an equal time interval. The average depth of maximum borer penetration reflects the density relationships among these four woods, both with respect to time and to depth of exposure (Figures 38, 39, and 40). Cedar panels were at all times and depths subject to the deepest penetrations, followed in turn by pine, fir, and finally oak.

Figures 39 and 40 illustrate a trend of decreasing depth of maximum penetration with increasing depth of exposure. Lower temperatures at depth might cause lower rates of growth and boring activity in the organisms. This should be reflected in shorter burrow lengths. However, increased pressure at depth compresses the wood, in turn increasing the substrate density, thus boring might be more difficult (Dr. Andrew G. Carey, Jr., personal communication). Both theories seem plausible, perhaps even in an interacting manner with other yet unrecognized factors. Conclusions, however, must await further testing. 
ATTACK BY THE TEREDINID BORER, BANKIA

\section{Location and Intensity}

The teredinid Bankia setacea was found only at the 200-meter exposure site. All three sample arrays exposed at this depth were attacked. The intensity of $\underline{B}$. setacea settling and destruction, measured in borer penetrations per $\mathrm{cm}^{2}$ of surface area, was very low, however, when compared to concentrations of xylophagan borers on the same sample panels. For example, at the 38-day exposure interval, pine averaged less than 1 teredinid borer per $\mathrm{cm}^{2}$, compared with over 100 xylophagan borers per $\mathrm{cm}^{2}$.

As with the xylophagan borers, the number of $\underline{B}$. setacea present on a panel appeared to increase with increasing length of exposure. This can be illustrated by comparing the 38-day exposure mentioned above with the 50-day sample at the same site (Figure 50), which exhibited 7 teredinid borers per $\mathrm{cm}^{2}$ in contrast to over 200 xylophagan borers per $\mathrm{cm}^{2}$.

The characteristic used to count Bankia setacea in this study was the presence of a distinctive siphon-pallet burrow closure. The siphon-pallet is calcareous in nature and remains at the wood surface. This is usually quite easy to observe, but on the panels exposed for 72 days, the high degree of surface destruction by 



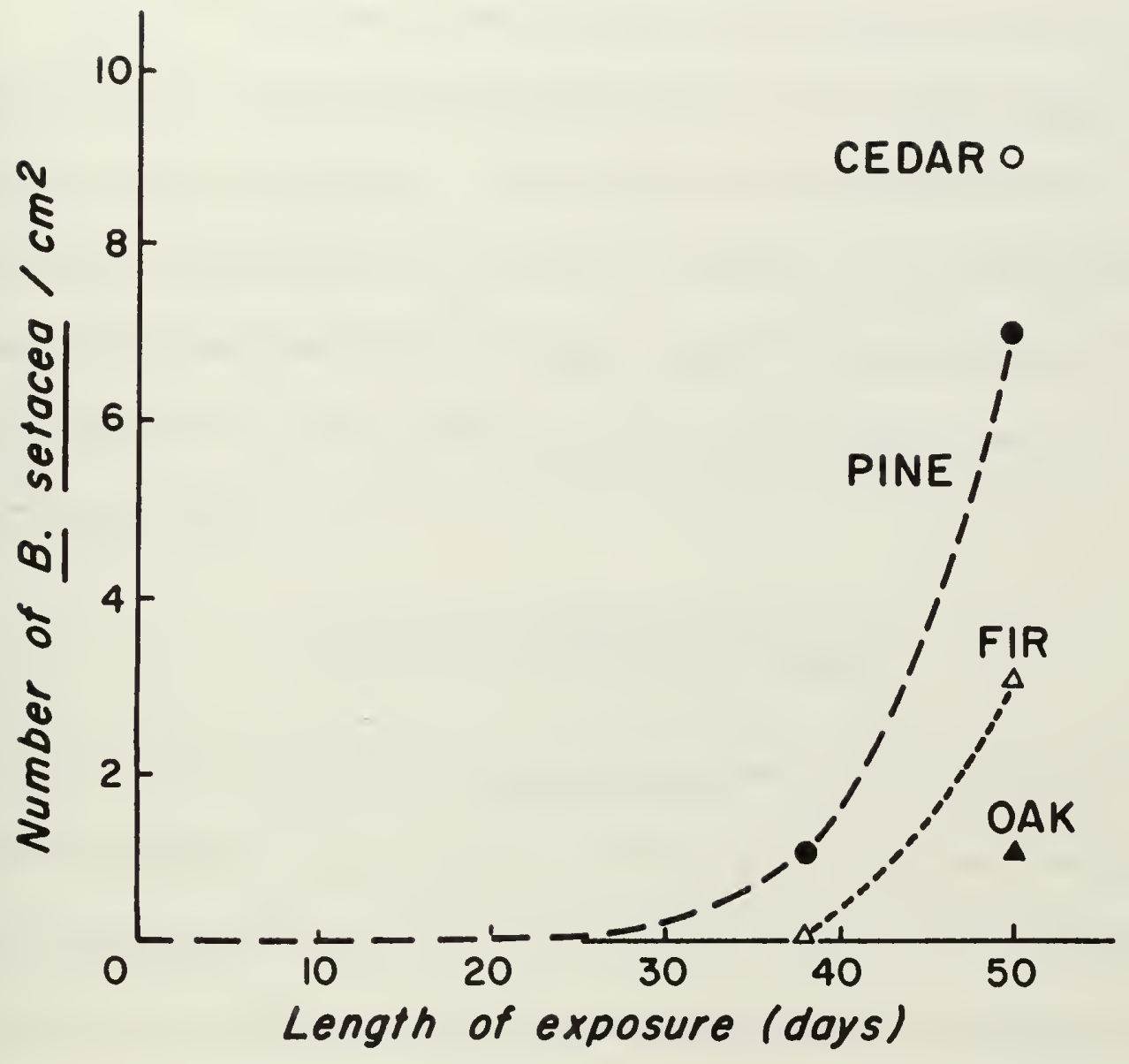

Figure 50. Temporal variation of Bankia setacea surface attack at $200 \mathrm{~m}$. 

X. washingtona broke down much of the surface area of the wood and obliterated many teredinid burrows. Accurate evaluation of teredinid attack on the se panels was impossible.

Figure 50 illustrates that the same relationship between intensity of surface attack and wood type appears true for $\underline{B}$. setacea as well as for $\underline{X}$. washingtona. Although counts could not be made accurately, this trend was also seen on boards in the 72 -day exposure. Cedar suffered the most intense attack followed in turn by lesser attacks on correspondingly more dense woods, pine, fir, and oak, in that order.

\section{Orientation of Maximum Attack}

In contrast with the $X$. washingtona attack, observed to be heaviest along the lower margin of sample panels and decreasing with increasing distance from the sediment, the pattern is the opposite with the teredinids. Highest concentrations of $\underline{B}$. setacea were found on the upward-facing (toward the sea surface) horizontal margins. The attack downward, along the vertical faces of the sample panels, rapidly dwindled to nothing. These data, when correlated with the fact that $\underline{B}$. setacea is a common surface-water inshore borer, are not surprising. It might be speculated that the $\underline{B}$. setacea larvae are dropping from the surface waters above, and reaching a suitable substrate, settle. 



\section{Competition}

The observed teredinid attack was quite low. Kofoid and Miller (1927) report, however, that Bankia setacea does not typically attack in large numbers common in other teredinid species like Teredo navalis. Johnson and Miller (1935) regarded low settlement rates as normal for $\mathrm{B}$. setacea. They reported that severe damage was caused by this species because of the large size (up to one meter in length) which may be attained by a mature specimen. In our samples, however, the animals were all quite small. The burrows of B. setacea appeared to be about the same length as the $\underline{X}$. washingtona excavations. However, after 72 -days exposure, many teredinid burrows were destroyed by the xylophagan attack. In many other cases, the teredinid borer, after entering the wood and turning to burrow with the grain as is its habit, had run into a mass of xylophagan borers which blocked further burrow expansion. It appears that at this 200 -meter site the $X$. washingtona have a competitive edge over the local teredinid species, $\underline{B}$. setacea. 
EXPERIMENTAL ERRORS AND PROBLEMS TO BE SOLVED IN FUTURE RESEARCH

\section{Experimental Error Encountered}

This section is designed to amplify the problems discussed under Materials and Methods and to cite specific instances in this research where these problems prevented the drawing of firm conclusions.

(1) To obtain measurements of borer attack at several different exposure sites which can be meaningfully compared, it is essential that sample arrays be exposed in a uniform manner at each site. The methods of installation used in this study did not provide adequate control of the final orientation of the sample array with respect to the sea-sediment interface. In Sample I, for example, it is concluded that the entire row of fir panels was not in contact with the sediment, while the row of pine panels was. Under these conditions the two sets of panels did not receive identical treatment and comparisons of borer attack became difficult. The problem is apparent when comparing the 30- and the 60-day exposures at 500 or 1000 meters; panels were oriented with grain perpendicular to the sediment in one case and in the other case, with grain parallel to it. Possibly the use of large square sample panels, in back to back pairs with grains running in perpendicular directions, would provide 

equal data no matter which side of the array was in contact with the bottom.

(2) A second error, introduced by sea-going operations, is possible disturbance of the array during sampling. The time-series method in which one long term array remained in place while the short-term array was removed from the other end of the ground line, while inexpensive, promoted a chance of disturbing the long term array--as I suggest occurred in Sample III.

At all the shallow sites, inside the 200-meter bottom contour, disturbance of the mooring systems or sample arrays by local fishermen is a strong possibility.

(3) More replication of both test materials within arrays and additional arrays at each depth studied is needed to provide some measure of the precision of the estimates of borer attack.

Duplicate sample panels were exposed on each array, but in most cases, due to the orientation of the sample panels with respect to the sediment, each received a different treatment. Only in Sample I, where $15 \mathrm{fir}$ and 15 adjacent pine panels were exposed at $200 \mathrm{me-}$ ters for 38 days, did we achieve any replication in which precision can be measured. The fir panels were exposed farther from the sediment than the pine, but within wood type the treatment can be assumed to be equal. Examining the estimate of the mean number of borers per $\mathrm{cm}^{2}$ on the surface of the boards one finds that pine 

had an average of 116 penetrations per $\mathrm{cm}^{2}$ with an estimated standard error of \pm 2 . Fir, on the other hand, averaged only 11 penetrations per $\mathrm{cm}^{2}$ of surface area with an estimated standard error of \pm 1 .

If this level of precision holds true for the other averages estimated in this study, the general conclusions made are then fairly well backed up, with the exception of the 30-day samples in deep water. In those samples, the extremely low densities of organisms probably were not estimated with nearly the same precision as in Sample I. The differences among wood types must then be looked upon carefully and with an eye to additional testing procedures that will test statistically the conclusions I am drawing in this thesis.

(4) The methods employed in this study for taking a limited sample with respect to seasons were dictated, in part, by funding and in part by time-sharing of research ship services. The limits that this imposes on data interpretation have been obvious throughout the results and discussion section. A sampling program continuous through all seasons is sorely needed. Samples along similar bottom contours, both north and south of positions treated in this study, seem essential if we are to understand if patterns of borer distribution with depth observed in this study are real.

(5) The lack of on-site environmental data, taken in the area of the sea-sediment interface, is very frustrating. In general, gradients very near the sea floor in deep water have not been studied. In fact, 

methods and materials for such measurements have just recently been conceived and employed at sea (Carey and Paul, unpublished; Mesecar, 1968b). It is a near-impossibility for the individual researcher to undertake complete measurement of on-site chemical, circulatory, and geologic conditions. Well-coordinated interdisciplinary studies of specific ocean areas are suggested as the best means of solving this type of problem.

\section{Future Research Needed}

This work has suggested several areas of future study which seem highly desirable for the investigation of deep-water marine borers off the coast of Oregon. The first major concern is our lack of knowledge about the biology of the xylophagan borers encountered. The location of the borer reservoir population is obscure. What really are the sources of the larval borers that settle on the exposed test panels? Past benthic dredging and trawling off Oregon collected little wood from the ocean floor (Dr. James E. McCauley, personal communication). Additional bottom trawling and photography will give clues as to the amounts of wood present on the bottom near the sample sites.

The length and the nature of the larval stage of the xylophagan borers need investigation. In what form is the larva released by the adult borer? How long, and at what location, can the larval forms 

survive until new wood becomes available for settling? What are the reproductive habits of the adult borer? How long does it take to mature after settling? When does reproduction occur?

Much of this may be answered by a long-term series of testpanel exposures with monthly collection and histological study of borer reproductive tissue. Sampling for near-bottom larval forms with a device such as the epibenthic bottom skimmer (Frolander and Pratt, 1962) may be required to comprehend larval distribution.

Another major unknown is the effect of environmental factors on the borers. Laboratory studies with living xylophagans involving current, temperature, pressure, and oxygen remain to be undertaken. This work then needs to be related to field studies at many varied locations.

A time-series exposure encompassing a full year or more is highly desirable for answering questions of seasonal distribution, reproductive behavior, and intensity of attack. The inshore sites, where results were negative, need to be carefully re-examined for periods much longer than 28 days and in all seasons.

Test-panel arrays might also be exposed in vertical strings to sample boring and fouling attack from the sea surface to the bottom. This seems feasible using a mooring system with a subsurface float similar to that used by Collins, Creech, and Pattullo (1966).

The maximum depth of the $X$. washingtona population off Oregon 

is still an unknown. Testing in water deeper than 1000 meters is needed.

All these studies require time, money, and a research vessel. They also involve refinement of sample arrays and the development of mooring systems with long term reliability. 



\section{CONCLUSIONS}

1. A reliable, relatively inexpensive system for mooring and recovering test materials at depth in an open ocean environment has been developed.

2. Practical methods have been devised to launch and recover such a system at sea, including a backup recovery scheme should the surface float be lost.

3. Two marine wood-boring molluscs, Xylophaga washingtona and Bankia setacea, were found to be active destructive agents on wood panels exposed in this study.

4. No other boring or fouling organisms were observed on test panels exposed during this study.

5. Xylophaga washingtona was found to be the major destructive agent in this study. Bankia setacea was found in relatively low numbers.

6. The xylophagan borer was found to be present and quite actively boring at depths of 200, 500, and 1000 meters. The teredinid borer, B. setacea, was found only at the 200 -meter test site.

7. The geographic ranges of $\underline{X}$. washingtona and $\underline{B}$. setacea were confirmed by this study. To my knowledge the specimens of B. setacea taken at 200 meters are the deepest record of known settlement and attack by a member of the family 

Teredinidae.

8. In both species of wood borers the degree of attack, expressed in surface penetrations per unit area, increased with time over sampling periods up to 72 days.

9. A sample interval as short as 30 days was adequate to pick up the initial stages of borer attack, especially for $\mathrm{X}$. washingtona.

10. The maximum surface attack per unit a rea possible is limited by the size of the borers which are settling, and the amount of surface area available on the test panel.

11. Wood panels exposed for 72 days at 200 meters were virtually destroyed by borer attack. In this light, longer term exposures would require panels much thicker than those used in this study $(3 / 4$ inch $)$.

12. In general, the amount of attack by $\underline{X}$. washingtona was much greater at 200 meters than at deeper sites. This was true for all exposures of equal time.

13. Attack by the pholad borer $X$. washingtona was initiated on that area of the test boards nearest the sediment surface and appeared to spread upward with time.

14. Xylophaga washingtona attack was most dense on those a reas of the panel in proximity to the sea-sediment interface. The degree of attack rapidly decreased with increasing distance above the sediment. No borer attack was observed on areas 

of the boards beneath the sediment surface.

15. Xylophagan borers exhibited a preferential settling on less dense spring wood over more dense summer wood.

16. Xylophagan borers also exhibited preferential settling in cracks and crevices and in other sheltered areas such as connection points between supporting rods and the test panels.

17. The initial settlement of $\underline{B}$. setacea began along the uppermost horizontal margin of test panels and spread downward.

18. At the 200-meter site, where both species of borers were present, $X$. washingtona appeared to be much more vigorously established than $\underline{B}$. setacea. By 72 days many of the teredinid burrows were being destroyed by the intense $X$. washingtona attack.

19. The amount of damage brought about by the xylophagan borer appears directly related to the density of the wood exposed. Materials of lowest density, like cedar, had highest levels of penetration and surface attack. Conversely, denser materials, for example oak, showed lower levels of penetration and surface attack.

20. The average depth of maximum xylophagan borer penetration into the wood increased with increasing length of exposure at all water depths sampled.

21. For equal lengths of exposure, the average depth of maximum 

burrow penetration decreased with increasing water depth of test-panel exposure.

22. Additional study of deep-water boring molluscs in the following areas is strongly recommended:

a. A time-series study, sampled monthly, over a period of at least one year should be undertaken at one or more depths.

b. The area between 200 meters and the shoreline should be resampled in hopes of clarifying the apparent discontinuity of $\underline{B}$. setacea distribution and the upper limits of $\underline{X}$. washingtona distribution.

c. Histological studies of specimens gathered monthly over a year period should be undertaken in an attempt to describe the reproductive cycle of the xylophagan borers.

d. Additional testing along the continental slope both at different depths and north and south of the stations sampled in this study should be undertaken.

e. Attempts at obtaining true replication at each sample site should be made so that the precision of numerical data can be estimated.

f. More on-site environmental data is needed, including information on the natural distribution of wood on the sea floor. 


\section{BIB LIOGRAPHY}

Ansell, A. D. and N. B. Nair. 1967. Shell movements of a wood boring bivalve. Nature 216:595.

Barstow, Dennis et al. 1968a. Hydrographic data from Oregon 1966. (In preparation)

Barstow, Dennis et al. 1968b. Hydrographic data from Oregon 1967. (In preparation)

Bartsch, Paul. 1921. A new classification of the shipworms and descriptions of some new wood boring mollusks. Proceedings of the Biological Society of Washington 34:25-32.

Bartsch, Paul. 1927. The shipworms of the Philippine Islands. Bulletin of the United States National Museum. No. 100, Vol. 2, Part 5, p. 533-562.

Buonanni, Fillipo. 168l. Ricreatione dell' occhio e della mente nell' observation' dell chiooccole [Recreation of the eye and of the mind in thè observation of shells]. Roma, 1681. 384 p. (Cited in: Turner, R. D. 1954. The family Pholididae in the Western Atlantic and the Eastern Pacific. Part I. Johnsonia 3(33):1-64.)

Carey, A. G., Jr. 1968. Assistant Professor, Oregon State University, Dept. of Oceanography. Personal communication. Corvallis.

Carey, A. G., Jr. and M. A. Alspach. 1966. Ecology of the benthic fauna off the Oregon coast. 44 numb. leaves. (Oregon State University. Dept. of Oceanography. Final report on National Science Foundation Grant GB 53l)

Carey, A. G., Jr. and R. R. Paul. 1968. A modification of the Smith-MacIntyre grab for simultaneous collection of sediment and bottom water. (In preparation)

Carruthers, J. N. 1963. History, sand waves and near-bed currents of La Chappele Bank. Nature 197:942-946. 
Clapp, W. F. and Roman Kenk. 1963. Marine borers, an annotated bibliography. Washington, D. C., U. S. Navy, Office of Naval Research. $1136 \mathrm{p}$.

Coe, W. R. 1933. Sexual phases in Teredo. Biological Bulletin 65: $293-303$.

Coe, W. R. 1941. Sexual phases in wood-boring mollusks. Biological Bulletin 81:168-176.

Collins, C. A., H. C. Creech and J. G. Pattullo. 1966. A compilation of observations from moored current meters and the rmographs. Vol. 1. Oregon continental shelf, July 1965 to February 1966. 39 numb. leaves. (Oregon State University. Dept. of Oceanography. Data report no. 23 on National Science Foundation Grant GP 4472, Reference 66-1)

Dall, W. H. 1886. Reports on results of dredging by the United States Coast Survey Steamer BLAKE, Report on the Mollusca. Part I. Bulletin of the Harvard Museum of Comparative Zoology $12(6): 171-318$.

Dall, W. H. 1908. Reports on the dredging operations off the west coast of Central America by the United States Fish Commission Steamer ALBATROSS. Bulletin of the Harvard Museum of Comparative Zoology 43(6):205-487.

DePalma, J. R. 1962. Marine fouling and boring organisms in the Tongue of the Ocean, Bahamas, exposure II. 13 numb. leaves. (U.S. Naval Oceanographic Office. Marine Sciences Department. Informal Manuscript Report no. 0-64-62) (Unpublished)

DePalma, Jr. 1963. Marine boring and fouling organisms off Fort Lauderdale, Florida. 27 numb. leaves. (U.S. Naval Oceanographic Office. Marine Sciences Department. Informal Manuscript Report no. 0-70-62) (Unpublished)

DePalma, J. R. 1966. A study of the marine fouling and boring organisms at Admiralty Inlet, Washington. 14 numb. leaves. (U. S. Naval Oceanographic Office. Oceanographic Surveys Department. Informal Manuscript Report no. 0-6-66) (Unpublished) 

DePalma, J. R. 1968. A study of deep ocean fouling. Paper submitted for presentation at the Second International Congress on Marine Corrosion and Fouling, Athens, Greece, September 20 to 24 , 1968. 8 numb. leaves.

Dubois, Raphä̈l. 1889. Remarques sure las physiologie et l'anatomie du syphon du Pholas dactylus. Comptes Rendus des Séances de la Société de Biologie, Paris 40(30):521-523.

Ekman, Sven. 1953. Zoogeography of the Sea, tr. by E. Palmer. London, Sidgwick and Jackson, 1953. 417 p.

Fraser, C. M. 1923. Marine wood borers in British Columbia waters. Transactions of the Royal Society of Canada 17(5): $21-28$.

Frolander, H. F. and Ivan Pratt. 1962. A bottom skimmer. Limnology and Oceanography 7(l):104-106.

Graham, R. D. 1968. Associate Professor, Forest Research Laboratory, Oregon State University. Personal communication. Corvallis.

Graham, R. D. and D.' J. Miller. 1959. Marine exposure tests of pressure-treated Douglas-fir and southern pine. In: Symposium on treated wood for marine use. Philadelphia. p. 56-69. (American Society for Testing Materials. Special Technical Publication no. 275)

Gray, J. E. 1838. Remarks on the boring of Patella and Pholas. Proceedings of the Zoological Society of $\overline{\text { London }}$ 5:10 $\overline{1}$.

Hill, C. L. and C. A. Kofoid. 1927. Marine borers and their relation to marine construction on the Pacific Coast. Final report of the San Francisco Bay Marine Piling Committee. Berkeley, University of California. $357 \mathrm{p}$.

Isaacs, J. D. et al. 1965. Development and testing of taut-nylon moored instrument stations. Geo-Marine Technology 2(8): $16-19$.

Isham, L. B. and J. Q. Tierney. 1953. Some aspects of the larval development and metamorphosis of Teredo pedicellata. Bulletin of Marine Science of the Gulf and Caribbean 2:574-589. 
Johnson, M. W. and R. C. Miller. 1935. The seasonal settlement of shipworms, barnacles and other wharf-pile organisms at Friday Harbor, Washington. University of Washington Publications in Oceanography $2(1): 1-18$.

Johnston, George. 1850. An introduction to conchology; or elements of the natural history of molluscous animals. London, J. Van Voorst, 1850. 614 p.

Jones, R. E. 1965. Design, placement, and retrieval of submersible test units at deep-ocean test sites. Port Hueneme, California. 91 p. (U. S. Naval Civil Engineering Laboratory. Technical Report no. R-369)

Knudson, Jorgen. 1961. The bathyl and abyssal Xylophaga (Pholadidae, Bivalvia). Galathea Report 5: $163-209$.

Kofoid, C. A. 1921. Biological phase--the marine borers. In: Report on the San Francisco Bay Marine Piling Survey. San Francisco, San Francisco Bay Marine Piling Committee, 1921. p. $23-61$.

Kofoid, C. A. and R. C. Miller. 1927. Biological section. In: Marine borers and their relation to marine construction on the Pacific Coast. Final report of the San Francisco Bay Marine Piling Committee, ed. by C. L. Hill and C. A. Kofoid. University of California. p. 188-344.

Lane, C. E. 1961. The Teredo. Scientific American 204(2):132142.

MacGinitie, G. E. 1935. Ecological aspects of a California marine estuary. The American Midland Naturalist 1 6:629-765.

Maloney, Neil J. 1965. Geology of the continental terrace off the central coast of Oregon. Ph. D. thesis. Corvallis, Oregon State University. 233 numb. leaves.

McCauley, J. E. 1968. Associate Professor, Oregon State University, Dept. of Oceanography. Personal communication. Corvallis.

Menzies, R. J. 1957. The marine borer family Limnoridae (Crustacea: Isopoda). Bulletin of Marine Science of the Gulf and Caribbean 7:101-200. 

Menzies, R. J. 1959. The identification and distribution of the species of Limnoria. In: Marine boring and fouling organisms, ed. by Dixy Lee Ray. Seattle, University of Washington. p. $10-33$.

Mesecar, R. S. 1968a. Instructor, Oregon State University, Dept. of Oceanography. Personal communication. Corvallis.

Mesecar, R. S. 1968b. Oceanic vertical temperature measurements across the water-sediment interface at selected stations west of Oregon. Ph. D. thesis. Corvallis, Oregon State University. 99 numb. leaves.

Miller, R. C. 1926. Ecological relations of marine wood-boring organisms in San Francisco Bay. Ecology 7:24 7-254.

Miller, R. C. 1951. Distribution of wood-boring molluscs on the Pacific Coast of North America in relation to ecological conditions. In: Report of Marine Borer Conference, U. S. Naval Civil Engineering Laboratory, Port Hueneme, California, May 10-12, 1951. Port Hueneme. p. Fl-F3.

Muraoka, J. S. 1964. Deep-ocean biodeterioration of materials Part I. Four months at 5640 feet. Port Hueneme, California. 45 p. (U. S. Naval Civil Engineering Laboratory. Technical Report R -329)

Muraoka, J. S. 1965. Deep-ocean biodeterioration of materials Part II. Six months at 2340 feet. Port Hueneme, California. 53 p. (U. S. Naval Civil Engineering Laboratory. Technical Report R-393)

Muraoka, J. S. 1966a. Deep-ocean biodeterioration of materials Part III. Three years at 5300 feet. Port Hueneme, California. 62 p. (U.S. Naval Civil Engineering Laboratory. Technical Report R-428)

Muraoka, J. S. 1966b. Deep-ocean biodeterioration of materials Part IV. One year at 6800 feet. Port Hueneme, California. 60 p. (U. S. Naval Civil Engineering Laboratory. Technical Report R-4.56)

Muraoka, J. S. 1966c. Deep-ocean biodeterioration of materials Part V. Two years at 5640 feet. Port Hueneme, California. 59 p. (U.S. Naval Civil Engineering Laboratory. Technical Report R-495) 
Muraoka, J. S. 1967. Deep-ocean biodeterioration of materials Part VI. One year at 2370 feet. Port Hueneme, California. 57 p. (U.S. Naval Civil Engineering Laboratory. Technical Report R-525)

Neave, Ferris. 1943. Seasonal settlement of shipworm larva. Progress Report of the Fisheries Research Board of Canada, Pacific 54:12-14.

Park, Kilho. 1967. Nutrient regeneration and preformed nutrients off Oregon. Limnology and Oceanog raphy 12:353-357.

Park, Kilho. 1968. Associate Professor, Oregon State University, Dept. of Oceanography. Personal communication. Corvallis.

Pearcy, W. G. 1964. Some distributional features of mesopelagic fishes off Oregon. Journal of Marine Research 22:83-i 02.

Pomerat, C. M. and C. M. Weiss. 1946. The influence of texture and composition of surface on the attachment of sedentary ma rine organisms. Biological Bulletin 91:57-65.

Purchon, R. D. 1941. On the biology and relationships of the lamellibranch Xylophaga dorsalis (Turton). Journal of the Marine Biological Association of the United Kingdom 25:1-39.

Purchon, R. D. 1955. The structure and function of the British Pholadidae (Rock-boring lamellibranchia). Proceedings of the Zoological Society of London 124:859-911.

Quayle, D. B. 1953. The larva of Bankia setacea Tyron. In: Report of the British Columbia Department of Fisheries for 1951. Victoria. p. 88-91.

Quayle, D. B. 1956. The British Columbia shipworm. In: Report of the British Columbia Department of Fisheries for 1955. Victoria. p. 92-104.

Quayle, D. B. 1960. The intertidal bivalves of British Columbia. Victoria, British Columbia Provincial Museum. 104 p. (Handbook no. 17)

Richards, H. G. 1942. Xylophaga atlantica, new species. The Nautilus 56(2):68. 
Runge, Erwin. 1966. Continental shelf sediments, Columbia River to Cape Blanco. Ph. D. thesis. Corvallis, Oregon State University. 143 numb. leaves.

Sellius, Gottfried. 1733. Historia naturalis teredinis seu xylophagi marini tubul-conchoidis speciatim. Belgici, Trajecti ad Rhenum. 366 p. (Cited in Turner, R. D. 1966. A survey and illustrated catalogue of the Teredinidae (Mollusca:Bivalvia). Cambridge, Mass., Harvard University Museum of Comparative Zoology. 265 p.)

Smith, John. 1894. Pholas crispata Linn. as a borer. Proceedings and Transactions of the Natural History Society, Glasgow 4(1): 37-39.

Smith, R. L., J. G. Pattullo and R. K. Lane. 1966. An investigation of the early stage of upwelling along the Oregon coast. Journal of Geophysical Research 71:1135-1140.

Sowerby, G. B. 1835. Characters and observations on new genera and species of Mollusca and Conchifera collected by Mr. Cuming. Proceedings of the Zoological Society of London 3 : $109-111$.

Steffansson, U. and F. Richards. 1964. Distributions of dissolved oxygen, density, and nutrients of the Washington and Oregon coasts. Deep Sea Research 11:355-380.

Turner, H. J. 1965. Fishbite. Geo-Marine Technology 1(6):20-21.

Turner, R. D. 1954. The family Pholididae in the Western Atlantic and the Eastern Pacific. Part I. Johnsonia 3(33):1-64.

Turner, R. D. 1955. The family Pholadidae in the Western Atlantic and the Eastern Pacific. Part II. Johnsonia 3(34):65-160.

Turner, R. D. 1956. Notes on Xylophaga washingtona Bartsch and on the genus. The Nautilus 70(1):10-12.

Turner, R. D. 1959. The status of systematic work in the Teredinidae. In: Marine boring and fouling organisms, ed. by Dixy Lee Ray. Seattle, University of Washington. $536 \mathrm{p}$. 
Turner, R. D. 1965. Some results of deep water testing. In: Annual report of the American Malacological Union. Philadelphia. p. 9-11.

Turner, R. D. 1966a. A survey and illustrated catalogue of the Teredinidae (Mollusca: Bivalvia). Cambridge, Mass., Harvard University Museum of Comparative Zoology. 265 p.

Turner, R. D. 1966b. Implications of recent research in the Teredinidae. In: Holz und Organismen, ed. by G. Becker and W. Lies. Internationales Symposium, Berlin-Dahlem, 1965. Berlin, Dunker and Humblot. p. 437-446.

Turner, R. D. 1967-1968. Museum of Comparative Zoology, Harvard University. Personal communications. Letters of: 26 October, 1967; 7 November, 1967; 25 January 1968; and 15 February 1968. Cambridge, Mass.

Turton, William. 1819. A conchological dictionary of the British Islands. London. J. Booth. 272 p.

Turton, William. 1822. Conchylia Insularum Brittannicarum: the shells of the British Islands, systematically arranged. London, M. A. Nattali. 279 p.

Tyron, G. W. 1862. Monograph of the family Teredinidae. Proceedings of the Academy of Natural Science of Philadelphia $14: 453-482$.

Tyron, G. W. 1863. Contributions toward a monography of the order Pholadacea with descriptions of new species. Proceedings of the Academy of Natural Science of Philadelphia 15:143-150.

U. S. Department of Agriculture. 1955. Wood handbook. Washington, D.C. 528 p. (Agriculture Handbook no. 72)

Woods Hole Oceanographic Institution. 1952. Marine fouling and its prevention. Annapolis, Maryland, United States Naval Institute. $388 \mathrm{p}$.

Yonge, C. M. 1937. Evolution and adaptation in the digestive system of the metozoa. Biological Reviews 12:87-115. 




$$
11
$$


 \\ DUDLEY KNOX LIBRARY}

